\title{
Soil mechanics in pavement engineering
}

\author{
S. F. BROWN*
}

Application of soil mechanics principles to the design of pavement foundations, the design of complete pavements and to their structural evaluation 'in-service' has lagged some way behind knowledge accumulated through research. Present design methods are generally empirical and often based on use of the California Bearing Ratio test, which was abandoned in California some fifty years ago.

The soil mechanics problem is one of understanding how soils and granular materials respond to repeated loading and applying this knowledge to pavement design with the aid of appropriate theoretical analysis and an understanding of failure mechanisms. Non-linear stress-strain characteristics are a particular feature of the problem and have to be catered for in design and evaluation. Various 'tools' are available to assist the pavement engineer. These include theoretical analysis, laboratory testing apparatus, field testing and full-scale trials with appropriate instrumentation.

The resilient and permanent strain response of clays and granular materials is reviewed in the context of the requirements for design. The essentially empirical UK Highways Agency method of design and its evolution are discussed in the light of current soil mechanics knowledge. By contrast, the development of mechanistically based approaches is outlined, together with suggestions for the implementation of present knowledge in a practical method of design for pavement foundations. Parallels are drawn between road and rail track design and developments relating to the latter are also reviewed. A forward look suggests that further research to improve understanding of the effective stress state below pavements and the application of recent theoretical work on partially saturated soils could form the basis for improved pavement engineering in the future.

KEYWORDS: pavements and roads; design; repeated loading; clays; field instrumentation; deformation; laboratory tests.
L'application des principes de la mécanique des sols à la conception des couches de fondation et de chaussées entières, ainsi qu'à l'évaluation structurale des chaussées en service a un certain retard sur l'état actuel des connaissances. Les méthodes de conception actuelles tendent à être empiriques et reposent souvent sur l'essai de portance californien, que la Californie ellemême n'utilise plus depuis une cinquantaine d'années. Le défi qui se pose à la mécanique des sols est de comprendre la réaction des sols et des matériaux granulaires à des charges répétées et d'appliquer les leçons qu'on en tire à la conception des chaussées en s'appuyant sur une analyse théorique judicieuse et sur la compréhension des mécanismes de rupture. Un aspect particulier de cette question est les caractéristiques de tension-déformation non linéaires, dont il faut tenir compte dans la conception et l'évaluation. L'ingénieur des chaussées dispose à cette fin d'une panoplie d'outils: analyse théorique, essais en laboratoire, essais sur le terrain et essais en vraie grandeur sur chaussées instrumentées. On examine ici les déformations élastiques et permanentes d'argiles et de matériaux granulaires dans le contexte des critères de conception. On analyse aussi la méthode de conception, essentiellement empirique, utilisée par l'administration routière du Royaume-Uni (UK Highways Agency), ainsi que son évolution, à la lumière de ce que l'on sait actuellement sur la mécanique des sols. Par opposition, l'exposé décrit brièvement les méthodes mécanistes qui ont été formulées et préconise l'application des connaissances actuelles dans une méthode pratique de conception des couches de fondation. Il compare la conception des routes et celle des voies ferrées et examine les progrès réalisés dans ce dernier domaine. Pour ce qui est de l'avenir, le génie routier aurait fort à gagner de recherches plus poussées sur les tensions efficaces dans le sous-sol, ainsi que de l'application de récents travaux théoriques sur des sols partiellement saturés.

\footnotetext{
* Professor of Civil Engineering, University of Notting-
} INTRODUCTION

Pavements are civil engineering structures used for the purpose of operating wheeled vehicles safely and economically. There is a very wide range of 
pavement structures depending on the nature of the vehicles to be accommodated, the wheel loads involved and the numbers of such loads to be carried over a given time period. Fig. 1 shows cross-sections for a number of different pavement types ranging from unsurfaced 'gravel' roads commonly found in developing countries, to heavy duty flexible bituminous or rigid concrete pavements used for the motorway systems of industrialized countries. Railway track is included as another specialist type of pavement in which the method of transmitting load to the soil differs from a highway or airport pavement but for which the essential principles of soil mechanics equally apply.

It is clear from the structures in Fig. 1 that the scope of pavement engineering is rather wide. An essential ingredient is soil mechanics since all the structures are in intimate contact with the ground and most combine one or more layers of unbound granular material. In addition, the complete pavement engineer needs to understand the principles of asphalt mechanics, of concrete technology and of stabilization as well as the more complex structural configurations used in railway track. The engineer needs to be concerned with vehicle loading, whether from trucks, aircraft, container terminal traffic or railway rolling stock and with the influence of the environment (notably temperature and water) on the pavement structure. The
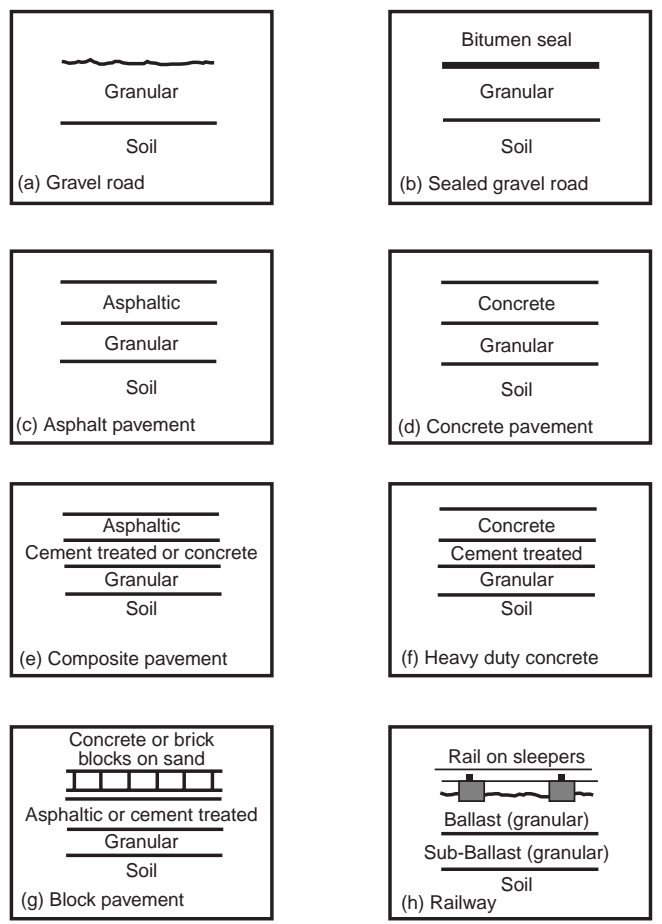

Fig. 1. Cross-sections of various pavement types proper use of geosynthetics for drainage, filtration, separation and reinforcement is also important, as are the uses of other ground improvement techniques such as stabilization and the effects of frost.

Increasingly, the profession is becoming concerned with the evaluation and maintenance of pavements rather than the design and construction of new works. Structural evaluation and the design of remedial treatment are rapidly expanding activities in which the role of soil mechanics, while not as significant as for new construction, is nonetheless of considerable importance. This paper does not attempt to cover all aspects of pavement engineering or to consider all pavement types. Rather, it concentrates on the role of soil mechanics and, hence, on the pavement foundation, which can broadly be defined as one or more layers of compacted unbound granular material placed over the subgrade soil (Fig. 2). The soil may be either undisturbed, in cuttings, or remoulded, on embankments. Since the interaction between the foundation and the bituminous or concrete construction placed over it is central to pavement design and to structural evaluation procedures, some discussion of bound materials and of failure mechanisms is required. This allows the proper application of soil mechanics principles for the foundation to be put in its correct context. In order to do this, only bituminous construction will be considered. Reference is made to rail-track construction but this topic is adequately covered by Selig \& Waters (1994).

The paper presents the design problem, explaining the background to current, essentially empirical, practice and presenting the most significant results of research carried out since the mid-1950s with emphasis on recent developments. Discussion covers design philosophy, theoretical analysis, material properties, laboratory tests, field testing, pilot-scale experiments and extensions of present knowledge to engineering practice.

Although pavement engineering procedures vary somewhat around the world, the essential features of present practice are generally common and rather empirical. In looking at the details and how

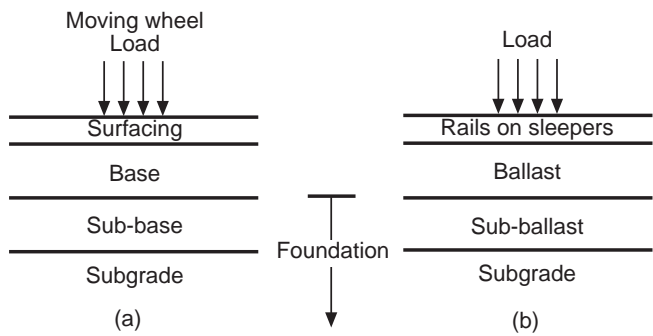

Fig. 2. Definition of pavement foundation: (a) road; (b) rail track 
these could be improved by implementation of research, the situation in the UK is considered.

A study of the major sources of soil mechanics papers, both journals and conferences, over the past thirty years clearly demonstrates that soil mechanics for pavements has become a very minor part of geotechnical engineering. Although there have been major research studies on soils and granular materials for pavements, these have generally not been published or discussed in serious soil mechanics journals or conferences. Moreover, as research has concentrated increasingly on heavy duty pavements, problems associated with the bituminous and concrete layers have dominated. The early stages of the UK's motorway reconstruction programme in the late 1970s clearly identified the need for sound foundation design (Cox, 1980). Excavations revealed wet and inadequate sub-bases with drainage that had often ceased to function or not been present. These revelations, together with the realization that some structural or surface maintenance of major highways was always going to be required at intervals in future, pointed to the need for improved foundation design and construction practice to avoid periodically having completely to reconstruct the pavement. Unfortunately, this was not accompanied by serious Department of Transport research into the real soil mechanics problems involved. However, the need for foundations which would not have to be replaced but could serve below rehabilitated pavements in future was apparent. An essential feature of this was the need for improved drainage design and maintenance.

The role of the Transport Research Laboratory (TRL) has always been central to developments in pavement engineering practice in the UK. After the second World War, they adopted US procedures for soil testing and pavement design (Davis, 1949). This was followed by an extensive programme of research on moisture conditions in subgrades lead by Dr David Croney. This work drew its inspiration from agricultural soil physics rather than from the emerging discipline of soil mechanics. Croney \& Coleman (1948) argued that since subgrade foundations were above the water table, the water conditions were similar to those of interest to agronomists. This significant investment in studies of ground water conditions below sealed surfaces continued for about 15 years, apparently in isolation from parallel developments in soil mechanics. The two met at the conference on Pore Pressure and Suction in Soils in 1960 at which it was apparent that differences of definition, of parameters and of philosophy had advanced to the point where bridging the gap was a non-trivial matter (Cooling et al., 1961). Application of the principle of effective stress was central to the problem. This and related matters are reviewed in the section on Pavement Design Developments. It is important to recognize that the background to present UK practice for the characterization of subgrades for pavement design developed from essentially different origins to those of Terzhagi, Skempton, Roscoe and the other pioneers of modern soil mechanics.

A programme of full-scale experiments on public roads was introduced by TRL in the 1960s. The performance of these has largely formed the basis for present UK design and maintenance practice. Although only $4 \%$ of the UK's road network is the responsibility of the Department of Transport, through the Highways Agency, the standards, specifications and design recommendations set by this body (Highways Agency, 1994b) dominate practice for most pavements in the highway sector.

The much smaller aircraft pavement sector has evolved its own procedures with little reference to UK highway practice but with a common root in US World War II developments, augmented by theory and practice since (British Airports Authority, 1993).

For railways, traditional empirical procedures have always dominated, although the British Rail Technical Centre in Derby did develop a method of design based on appropriate soil testing in the 1970s (Heath et al., 1972) but this was never formally implemented. Their subsequent work concentrated on maintenance techniques and understanding track/vehicle dynamic interactions. Over the past 20 years, the work of Professor Selig and his colleagues in the USA has brought a proper application of soil mechanics to railway geotechnology, but implementation of research remains sparse.

Quite apart from the independent development of subgrade research in the UK at TRL, the soil mechanics requirements for pavement engineering do differ significantly from those of importance in other geotechnical applications. The essential differences may be summarized as follows.

(a) Soil below pavements and granular materials in pavements exist above the water table but beneath a sealed surface, although this does not completely inhibit ingress of water. Hence, both saturated and partially saturated conditions can occur.

(b) Soils and granular materials in completed pavements are subjected to large numbers of load applications at stress levels well below their shear strength (as illustrated by the field data in Fig. 3(a) obtained from a full-scale trial at Wakefield (Brunton \& Akroyde, 1990).

(c) Under partially completed pavements, when construction traffic is applied directly to the granular layer, the number of load applications 
is fewer but the stress levels are much higher as shown in Fig. 3(b). These data were obtained from a haul road experiment at the Bothkennar soft clay site in Scotland (see p. 392).

(d) Under a single application of a moving wheel load, a pavement responds in an essentially resilient manner. However, irrecoverable plastic and viscous strains can accumulate under repeated loading. This presents the opportunity to separate the theoretical analysis of pave-

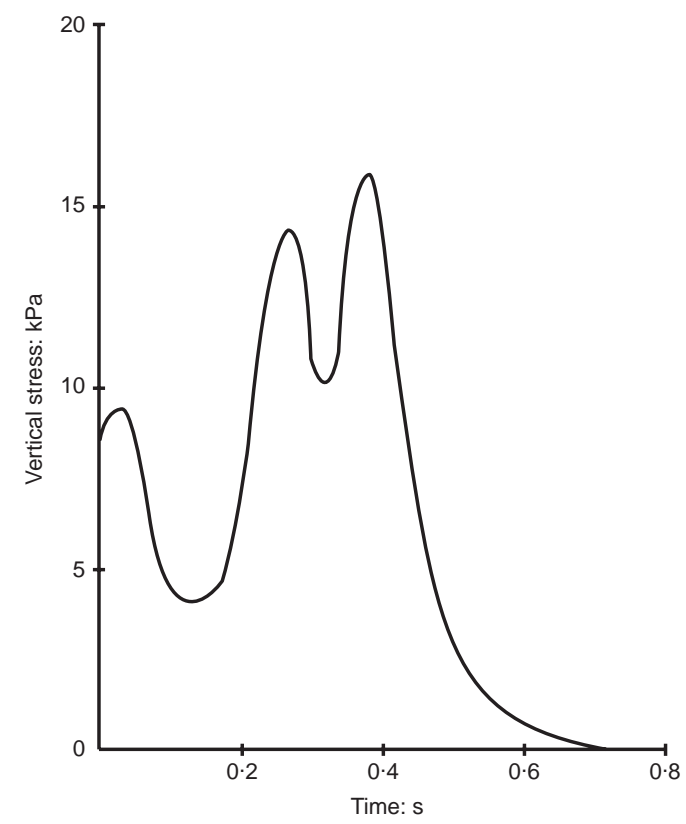

(a)

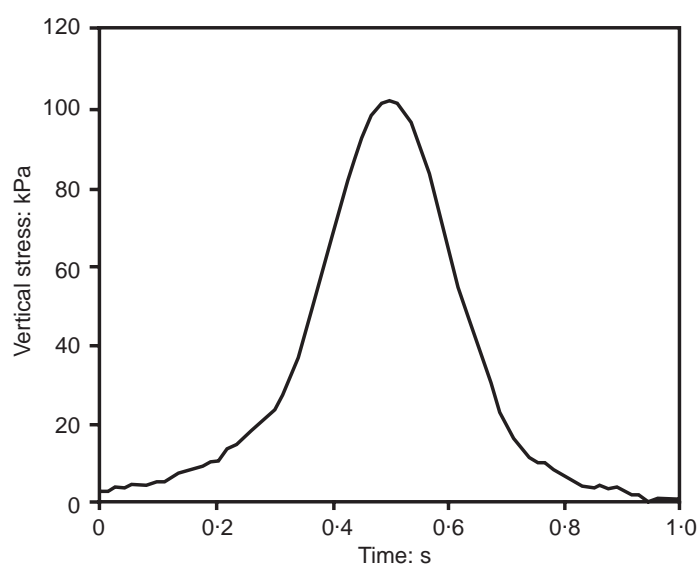

(b)

Fig. 3. In situ vertical stress measurements in subgrades: (a) below $165 \mathrm{~mm}$ asphalt construction at Wakefield; (b) below $350 \mathrm{~mm}$ granular layer at Bothkennar ments into two parts rather than to apply a single elasto-plastic (or elasto-visco-plastic) analysis as is common for monotonic loading problems in geotechnics.

Other branches of soil mechanics which have something in common with pavements include earthquake engineering, off-shore foundation engineering and machine foundation design. In all cases, there is the common theme of repeated or cyclic loading. It is significant to note that the late Professor Harry Seed, who contributed so much to understanding soil mechanics in the context of earthquake loading, began his interests in repeated loading with the pavement problem (Seed et al., 1955). Furthermore, when, the first major structures were being designed for North Sea oil exploitation in the $1970 \mathrm{~s}$, the experience of repeated loading of subgrades was used to evolve research programmes for clays of relevance to wave loading (Andersen et al., 1976).

These interactions between pavement soil mechanics and other areas involving cyclic loading have formed an important element of the author's work at the University of Nottingham since 1963. An attempt has been made to apply the principles of soil mechanics to the pavement problem within the overall context of developing improved methods of design and structural evaluation. Blending work on asphalt mechanics to that of soil mechanics has been a central theme, as has the evaluation of appropriate, simplified test methods to aid implementation in practice. This paper draws principally on the work carried out at Nottingham by the author and his colleagues, all of which has been made possible by the award of research contracts and grants from a wide range of organizations both from the UK and overseas. The work has parallelled that at TRL and, to an increasing extent in recent years, had some influence on the evolution of Highways Agency standards and the work of the British and European Standards organizations.

Space has prohibited any discussion in this paper of several important subjects including drainage, application of geosynthetics, stabilization, frost effects and the special problems associated with aircraft pavements.

\section{PAVEMENT ENGINEERING TOOLS \\ Theory}

There has been extensive application of the theory of elasticity to the analysis of layered pavement systems. Burmister (1943) developed the essential equations, and, following early sets of tabulated solutions, (e.g. Acum \& Fox, 1951) various computer programs were developed to assist in obtaining results in a convenient form. 
Today the most widely used are the BISAR (de Jong et al., 1973) and ELSYM 5 (Warren \& Diekmann, 1963) programs originally developed by researchers in the Shell and Chevron oil companies respectively. In both cases, the pavement layers are assumed to be linear elastic and values of stress, strain and deflection components at any defined points in the structure can be computed from given geometry and surface loading. Typical details are shown in Fig. 4. Wheel loading is represented by uniformly distributed pressure over a circular area and dual or multi-wheel configurations can be accommodated.

In real pavements, loading is transient, the soil and granular layers (the pavement foundation) have markedly non-linear stress-strain relationships, which are influenced by a range of variables, and the bituminous layer has properties which are sensitive to loading rate and to temperature. Fig. 5(a) shows the shear stress-strain relationship for a compacted silty clay determined from combining in situ measurements of total stress and of strain (Brown \& Bush, 1972). These were obtained from pilot-scale test pit experiments subjected to dynamic plate loading and superposition of in situ measurements at various depths and orientations. The non-linear stress-strain relationship is clearly illustrated. Similar data from measurements in a layer of compacted crushed rock are shown in Fig. 5(b) in the form of Young's modulus plotted against the first stress invariant (Brown \& Pell, 1967). Notwithstanding these non-linearities, the ability to carry out linear elastic structural analysis of pavements has proved extremely useful in developing design methods, particularly as the real characteristics of the constituent materials have become better appreciated.

The main justification for using elastic theory is

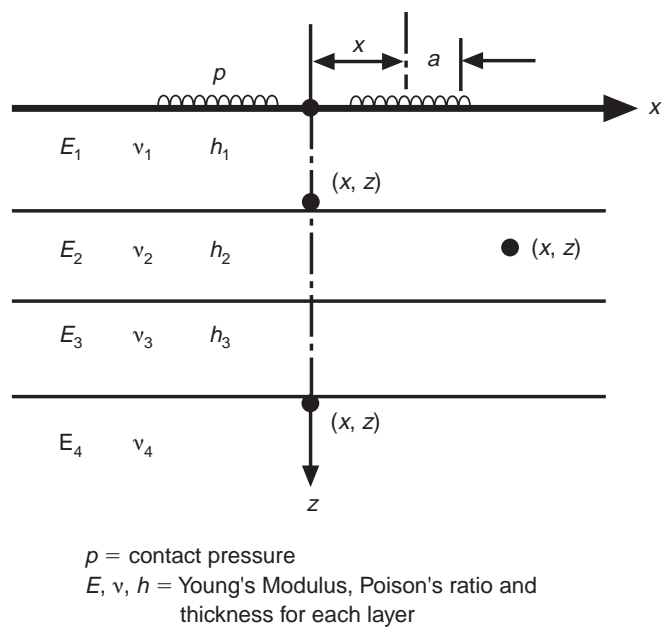

Fig. 4. Linear elastic system for pavement analysis

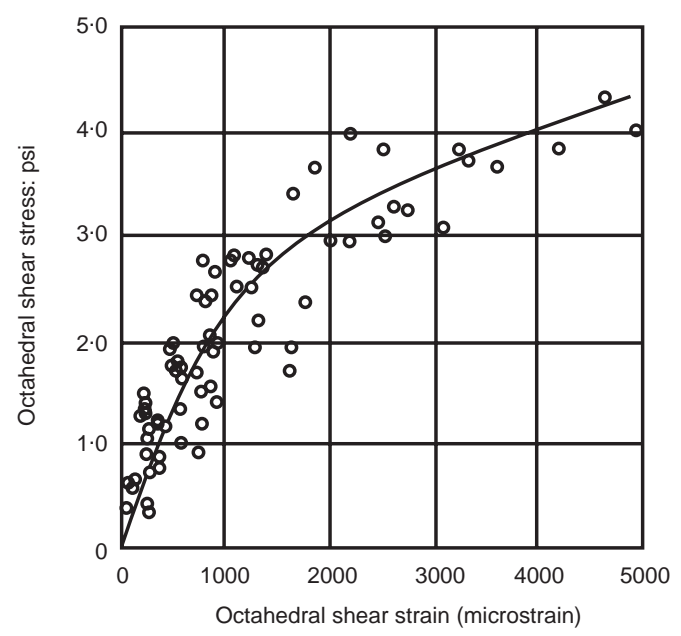

(a)

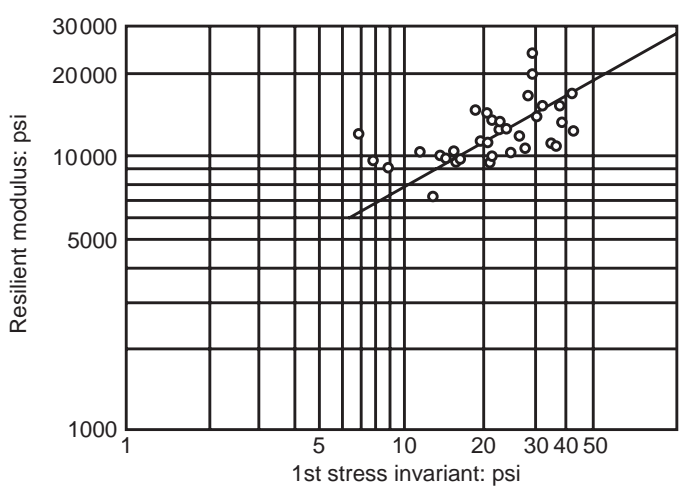

(b)

Fig. 5. Non-linearity from in situ measurements: (a) shear stress-strain relationship for silty clay (after Brown \& Bush, 1972); (b) resilient modulus against 1st stress invariant for crushed rock (after Brown \& Pell, 1967).

that under a single load application, most pavements will respond in a resilient manner. Any irrecoverable deformations will be small relative to the resilient component. Fig. 6 shows a vertical strain pulse measured within a bituminous layer as a result of a moving wheel load. There is a delayed elastic response but no residual strain. The validity of using linear elastic theory was the main objective of many full-and pilot-scale experiments carried out in the 1960s and 1970s. (e.g. Brown \& Pell, 1967, Bleyenberg et al., 1977).

Conventionally, each layer is characterized by a value of Young's modulus and Poisson's ratio. In view of the differences between real and idealized behaviour of pavement materials, the parameter 'resilient modulus' was introduced in California during the 1950 s following the pioneering work of 


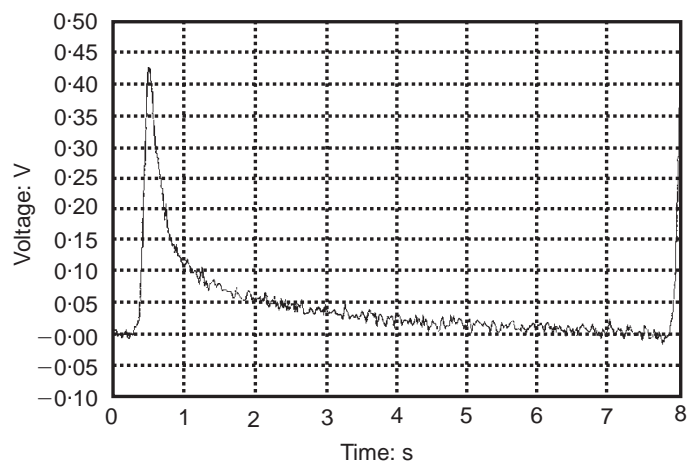

Fig. 6. Vertical strain pulse in bituminous pavement from in situ measurement

Francis Hveem, the State's Materials Engineer and Professor Harry Seed and his colleagues at the University of California, Berkeley. Hveem was first to recognize the importance of resilient properties for pavement foundations and to associate them with the incidence of fatigue cracking in bituminous surfacing (Hveem, 1955). Seed and his colleagues carried out repeated load triaxial tests on compacted soils and defined the resilient modulus as the magnitude of repeated deviator stress divided by the resilient axial strain, which makes it equivalent to a resilient Young's modulus. A similar definition was applied in later work by Hicks \& Monismith (1971) when testing compacted granular materials. This work is further discussed in the section on Pavement Design Developments.

In asphalt technology, the term 'stiffness' was introduced by Van der Poel (1954) and defined as uniaxial stress divided by uniaxial strain. When the strain component is essentially recoverable, this is again equivalent to Young's modulus but can be applied over a wide range of loading time and temperature conditions. Bituminous materials exhibit elastic, brittle behaviour at low temperatures and short loading times, viscous behaviour at the other end of the spectrum and visco-elastic response at intermediate conditions. For pavement design calculations, when moving traffic is considered under normal temperatures, the response of a bituminous mixture to a load pulse will be essentially resilient as illustrated in Fig. 6. Fine grained soils too, can behave in a visco-elastic manner, as shown in Fig. 7 taken from repeated load triaxial tests on saturated reconstituted silty clay (Hyde, 1974).

Linear elastic analysis can be used with reasonable confidence for pavements with thick bituminous or concrete layers but is inappropriate for unsurfaced or thinly surfaced pavements unless approximate account can be taken of non-linear behaviour as discussed below. For bituminous pavements under normal moving traffic conditions, once a vehicle speed and, hence, loading time is specified and a temperature condition known, the bituminous layer may be assumed to behave in an essentially linear elastic manner. Conversely, when the pavement response to load is dominated by the resilient properties of the granular materials and soil, their non-linear characteristics must be properly taken into account in theoretical analysis.

The non-linear stress-resilient strain characteristics of soils and granular materials under repeated loading are discussed in the section on Behaviour of Soils and Granular Materials under Repeated Loading. In pavement engineering, it has been usual to express the resilient modulus as a function of the applied stress level. To accommodate this in theoretical analysis, two general approaches have been adopted. The simplest involves an iterative procedure using linear elastic layered system solutions. The layers of granular material and soil are subdivided into sublayers to

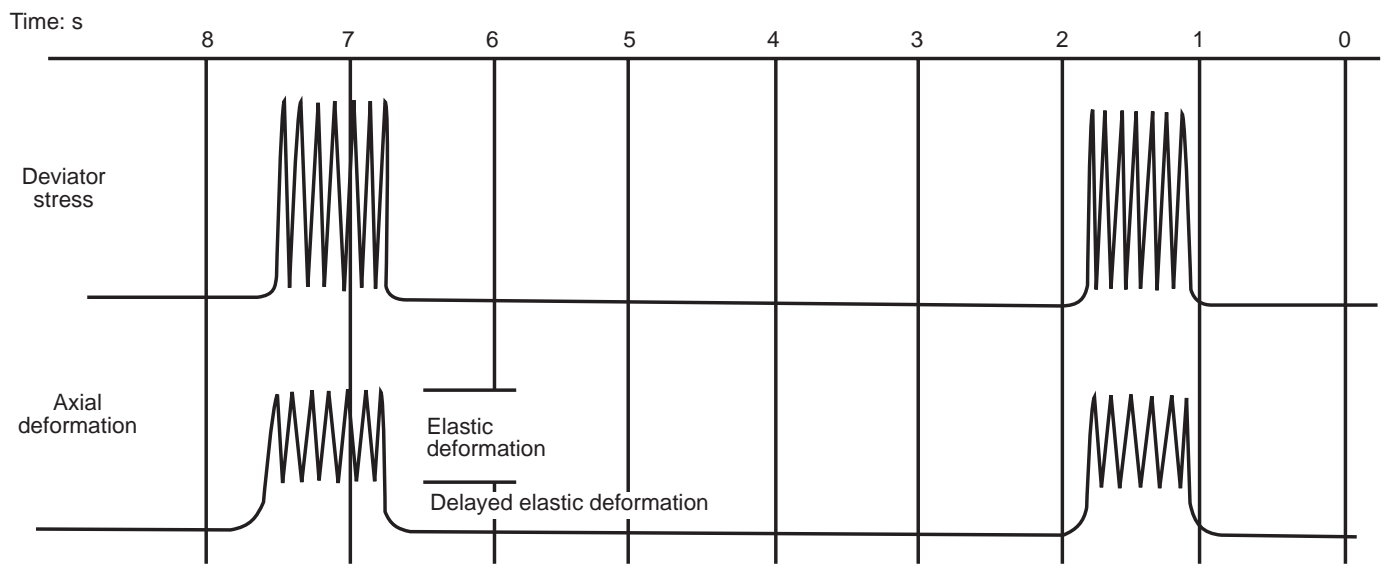

Fig. 7. Response of overconsolidated silty clay to bursts of undrained repeated loading (after Hyde, 1974) 
accommodate variations in resilient modulus caused by the changes in stress which occur with depth. The stresses involved are those due both to traffic loading and to overburden.

The general analytical procedure is as follows.

(a) Subdivide the real layers into sublayers - the greater the number the greater the accuracy.

(b) Estimate a value of Young's modulus for each layer. This may involve a single value for all the granular material layers and another single value for the subgrade.

(c) Compute the traffic plus self weight stresses at the centre of each layer. The actual stress components will depend on the non-linear model being used.

(d) Adjust the sublayer values of resilient modulus by way of the model and recompute stresses.

(e) Repeat the process until the values of resilient modulus used for all layers are compatible with the computed stresses.

This procedure takes no account of variations in stress which take place in the horizontal direction. Hence, the logical extension of the above simple analysis process is to adopt the finite element method. Most of the serious pavement analysis in recent times which accommodates non-linear stress-strain models has used one of a number of finite element packages which have been developed specially for the pavement problem. These include SENOL (SEcant modulus NOn-Linear analysis (Brown \& Pappin, 1981) and FENLAP (Finite Element Non-Linear Analysis for Pavements) (Brunton \& d'Almeida, 1992) developed at Nottingham, GT-PAVE (Tutumluer \& Barksdale, 1995) from Georgia Institute of Technology and, for rail track, ILLITRACK (Robnett et al., 1975) developed at the University of Illinois.

FENLAP uses an axisymmetric idealization of the pavement structure under a vertical circular load (Fig. 8). Various boundary conditions are available to the user but that illustrated in Fig. 8 d'Almeida (1993) appears to be most realistic. Duncan et al. (1968) suggested that analysis should extend to 50 times the radius of the loaded area in the vertical direction but could be limited to 20 times the radius horizontally. In order to minimize computing time, the lower boundary in FENLAP is represented as an elastic half space which can be characterized in various ways. It can include a rigid base which may be of use when analysing pavements over ground in which shallow rock or other rigid inclusion is present.

Simple, eight node rectangular elements are used with automatic mesh generation. Input data include unit weights of materials, water table position, estimated suction values and $K_{0}$ values. These last allow the user to recognize that significant lateral stresses can accumulate in gran- ular layers as a result of the compaction process. This is analogous to the results of overconsolidation in clays leading to $K_{0}>1$. It has proved difficult in practice to measure lateral residual stresses. Some results from box tests on railway ballast reported by Stewart et al. (1985) indicate $K_{0}$ values up to as high as 11 and the authors considered values up to 6 to be quite possible in practice.

The computation procedure in FENLAP takes place in two stages, dealing successively with self weight stresses followed by application of the wheel load. The stress-strain relationship for each material may be selected from a menu of possibilities. The bituminous layer is treated as linear elastic.

The self weight stresses dictate the starting values of Young's modulus and Poisson's ratio for each element. Stresses caused by wheel loading are then computed and added to the self weight values. An iterative procedure follows until the values of elastic parameters have stabilized. These are secant values but, since the effects of wheel loading are of primary interest, the chord values mobilized only by the wheel loading may be calculated. The corresponding stresses and displacements are those of interest in design. Fig. 9 illustrates these points.

One of the problems encountered by all researchers developing finite element analysis packages for systems involving compacted granular material over soil concerns the tendency for horizontal tensile stresses to be computed at the bottom of the granular layer. Since unbound materials have negligible tensile strength, aside from that induced by suction and particle interlock, adjustments to the computational procedures are normally applied to avoid false failure conditions developing in certain elements. Strictly speaking, if the constitutive models for the materials are precise, such corrections would not be needed. However, in reality they are.

In the SENOL program, a value of resilient Young's modulus equal to $100 \mathrm{MPa}$ is assigned to any element where the mean normal effective stress becomes tensile, this stress being the net value caused by overburden and by the wheel load. In FENLAP, a 'no-tension' procedure is adopted using the principle of stress transfer (d'Almeida, 1993). This involves specification of a nominal tensile strength. If a computed principal tensile stress exceeds this, it is set at zero and a redistribution of stresses computed. This applies for the tangential direction, which is also a principal stress direction. On the radial plane, the maximum compressive stress is assumed to remain constant, and the Mohr's circle is shifted to eliminate tensile stress as shown in Fig. 10.

Rowe et al. (1995) have recently developed a finite element program called PACE. This allows the 


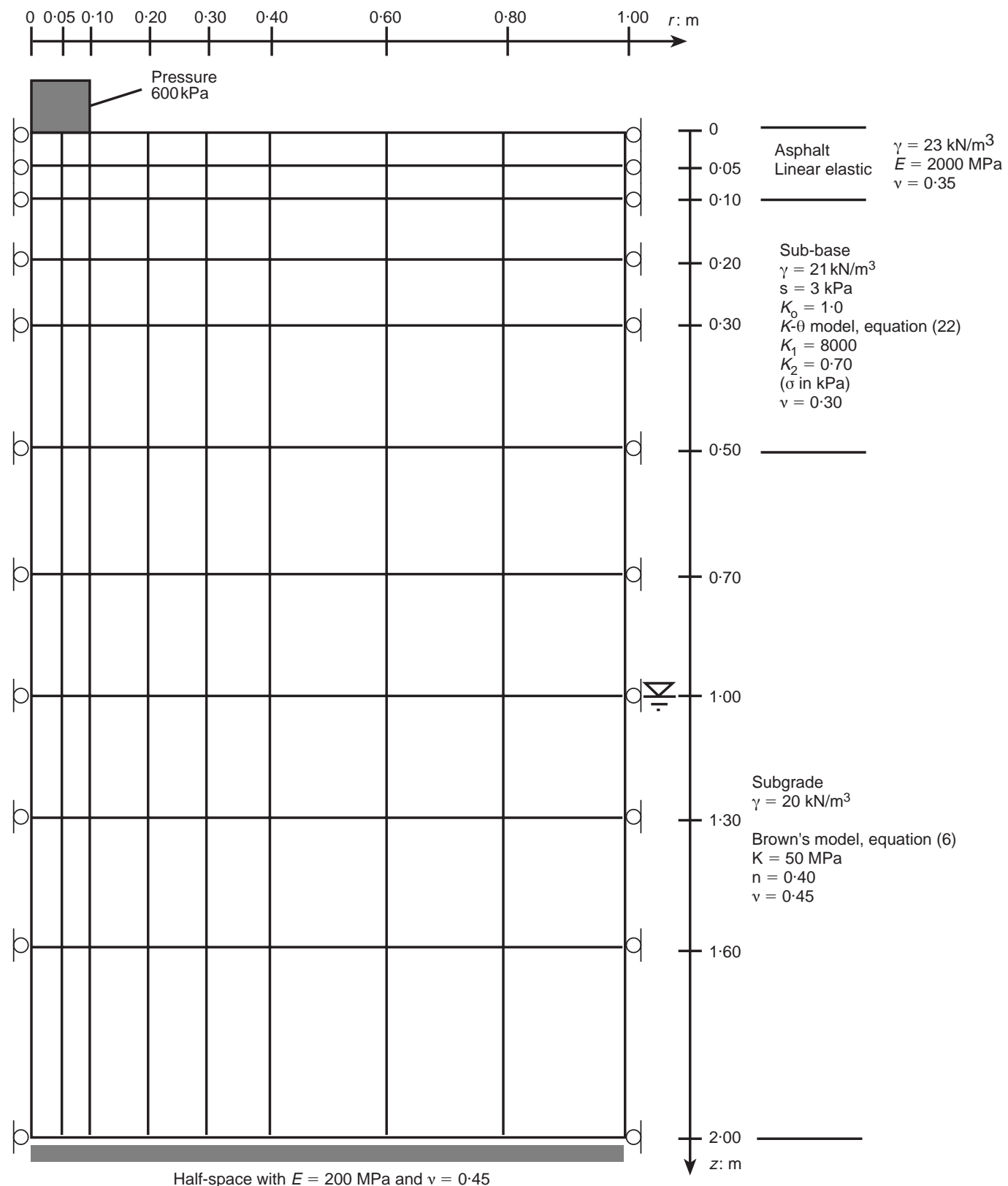

Fig. 8. FENLAP representation of pavement structure (after d'Almeida, 1993)

bituminous layers to be characterized by viscoelasto-plastic rheological models with a view to better representing the actual behaviour of bituminous mixtures under a range of loading and environmental conditions. At this stage in the program's development, the pavement foundation layers are modelled as linear elastic. This program does, however, provide improved computation of rutting in asphalt layers and allows values of dissipated energy under repeated loading to be determined as an indicator of fatigue cracking failure in bituminous layers (van Dijk \& Visser, 1977). In future, by combining the merits of FENLAP and PACE a comprehensive analysis package will be available to model flexible pavement behaviour more accurately.

An interesting theoretical model of rail track developed by Chang et al. (1979) at the University 


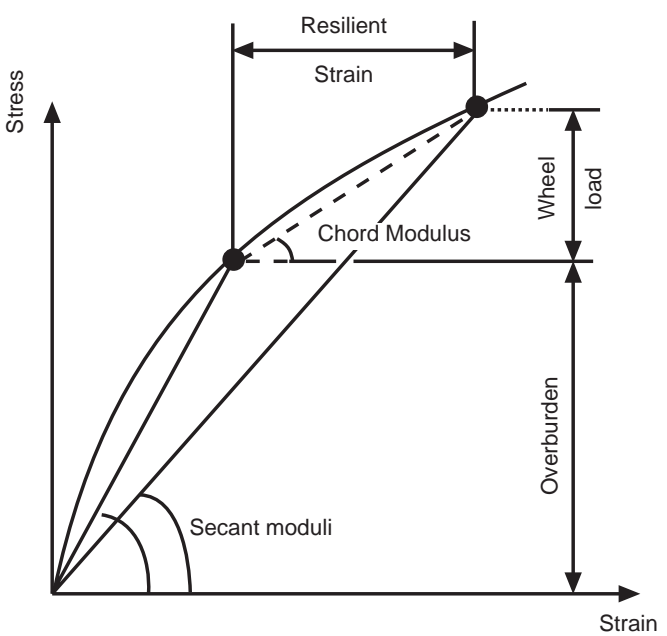

Fig. 9. Definition of resilient strain in finite element computations

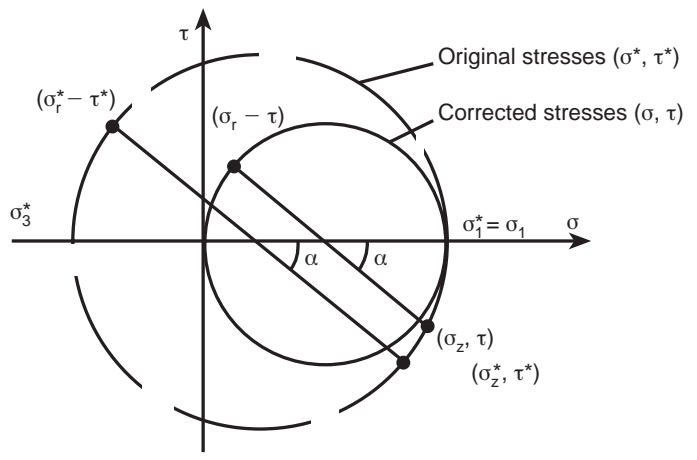

Fig. 10. Tensile stress correction in FENLAP (after d'Almeida, 1993)

of Massachusetts is known as GEOTRACK. Fig. 11 illustrates the elements. The rails are elastic beams supported by a set of 11 sleepers. The ballast, subballast and soil are modelled as a series of linear elastic layers. The non-linear characteristics of soils and granular layers are accounted for by an iterative procedure similar to that described for highway pavements.

\section{Pavement experiments}

Introduction. A large number of full-scale and pilot-scale experiments have been conducted to obtain an insight into the response of pavements to transient wheel loading. Appropriate instrumentation has been developed to monitor the key parameters. Other, more numerous experiments, have been concerned with monitoring pavement deterioration under traffic and environmental cycles. Such experiments have, generally, not

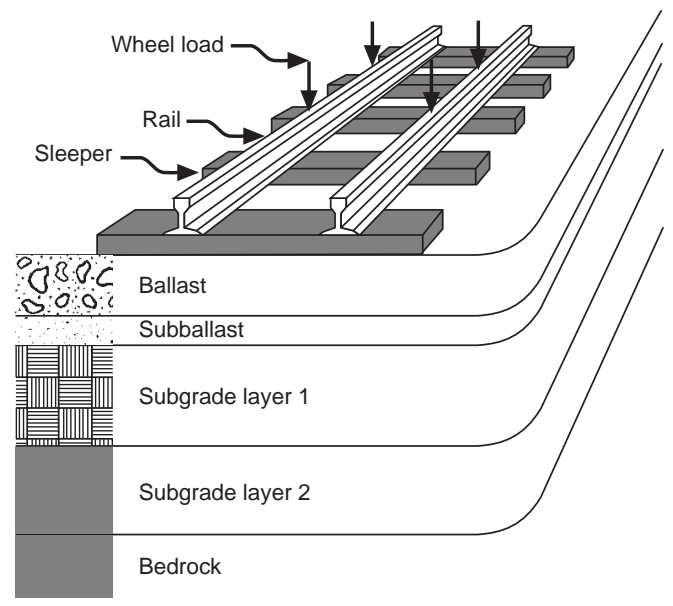

Fig. 11. Geotrack model for railtrack (after Selig \& Waters, 1994)

included much instrumentation, but have relied on superficial observations and measurements. The TRL's experiments on the A1 at Alconbury Hill (Lee \& Croney, 1962) and the AASHO Road Test (Liddle, 1962) in Illinois are classic examples of this type of experiment, the data from which have formed the basis for the empirical pavement design methods widely used today.

Accelerated loading devices. Another important series of experiments, principally concerned with pavement deterioration, are those involving accelerated loading devices at full scale. The most extensive programme was that carried out in South Africa using the Heavy Vehicle Simulator (HVS) (Walker, 1985). This device is mobile and several units were used on sites in different locations to test sections of pavement in their 'as built' condition. By using high wheel loads repeatedly and continuously over several weeks, the equivalent of many years' traffic loading could be applied. Several basic techniques were used to investigate how pavements deteriorated as a result of this loading regime. Careful trenching and examination of each layer after a period of trafficking allowed the development of failure mechanisms to be monitored. The vast data bank generated by the HVS test programme formed the basis for the South African pavement design system (NITRR, 1985a). Theoretical modelling was used to interpret the research results and extend them to design.

A similar accelerated loading device and test philosophy is used in Australia (Metcalf et al., 1985). Stationary test facilities either linear or circular have been used in other countries to study pavement behaviour under accelerated loading. These devices are stationary in the sense that they are positioned in one location and different 
pavement constructions are built for testing at that location.

Most of the data obtained from these accelerated loading devices have related to failure mechanisms, principally in the bound pavement layers. Consequently, little soil mechanics knowledge has been accumulated. One exception concerns the South African experiments involving injection of water into the granular layer and observations of the associated build-up of permanent deformation described by Freeme \& Servas (1985). Fig. 12 illustrates typical data for pavements with different qualities of granular layer. The advantages of using good quality dense crushed rock, type G1 (NITRR, 1985b) are apparent. The influence of effective drainage can also be noted.

At Nottingham, a pilot scale facility (Brown \& Brodrick, 1981a) has been used for over 20 years to study a range of pavement problems under controlled conditions. Loads up to $1.7 \mathrm{t}$ can be applied and speeds up to $16 \mathrm{~km} / \mathrm{h}$ on pavements constructed in a $1.5 \mathrm{~m}$ deep test pit, $4.8 \mathrm{~m}$ long and $2 \cdot 4 \mathrm{~m}$ wide.

Pavement instrumentation. For experiments involving in situ instrumentation, several transducers have proved effective in monitoring both response to individual wheel loads and the changes in stress, strain and deflection with repeated loading. In addition to these three parameters, temperatures and pore pressures have also been measured, the former with great success, using simple thermocouples, the latter with more limited success. This is unfortunate, since stress determination in and below pavements involves total stress, so without suction or pore pressure measurements, the effective stress state is not reliably known.

Appropriate instrumentation is reviewed in Brown (1978) and that applied in pilot and fullscale experiments at Nottingham is described by

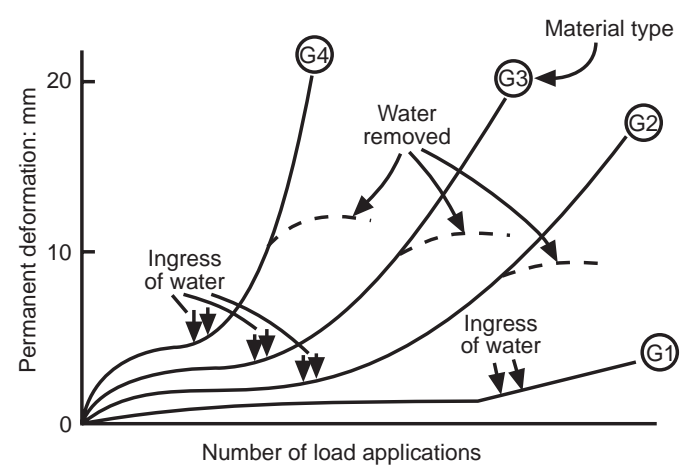

Fig. 12. Influence of water, drainage and granular material type on accumulation of permanent deformation (after Freeme \& Servas, 1985)
Brown \& Brodrick (1981b). The most useful instruments have proved to be a pressure cell incorporating a simple strain gauged diaphragm and inductance strain coils. For full-scale experiments carried out in South Africa and Australia, the multi-depth deflectometer has also proved extremely useful for measuring deflections at various points within the depth of a pavement (Basson et al., 1981).

A promising low cost technique for measuring water content is currently being used in the USA in pavement test sections forming part of the Federal Highway Administration's Long Term Pavement Performance experiments. The Time Domain Reflectometry (TDR) principle is utilized by inserting a three-pronged probe into the soil. The transmission and reflection of an electromagnetic pulse allow an apparent length of the probe to be determined. This is a function of the soil dielectric constant which is directly related to the volumetric water content using equations devised by Topp et al., (1984). The usual water content by mass can then be calculated knowing the dry density of the soil.

The Bothkennar pavement experiments. In 1987, the Science and Engineering Research Council purchased a soft clay site at Bothkennar near the Forth Estuary and established it for full-scale experimental geotechnical research. Full details of the site and results of extensive tests on the clay are described in Greenwood et al., (1992).

An unsurfaced pavement loop was constructed in 1989 incorporating 16 test sections with the principal objective of studying the reinforcing effects of various geosynthetics placed at the interface between a granular layer and the clay (Little, 1993). The data which were gathered on the performance of these sections under repeated truck loading were used to assess design methods for both reinforced and unreinforced haul roads.

Over 400 instruments were installed, nearly all sections being involved. The instrumentation layout was designed to measure specific effects related to assumptions in the design methods. Inductance strain coils were used to measure both transient strain under a passing wheel load and permanent strain accumulation under repeated loading. High air entry piezometers were installed $200 \mathrm{~mm}$ below formation level but proved unsuccessful in practice, since they were measuring suction and air easily entered the system. Standpipes were provided at four locations along the road to determine water table position.

Loading of the pavements was provided by a lorry with known axle weights driving down the centre line of the sections. Fig. 13(a) shows typical recorded outputs from a strain coil pair measuring vertical strain at formation level, while output from 


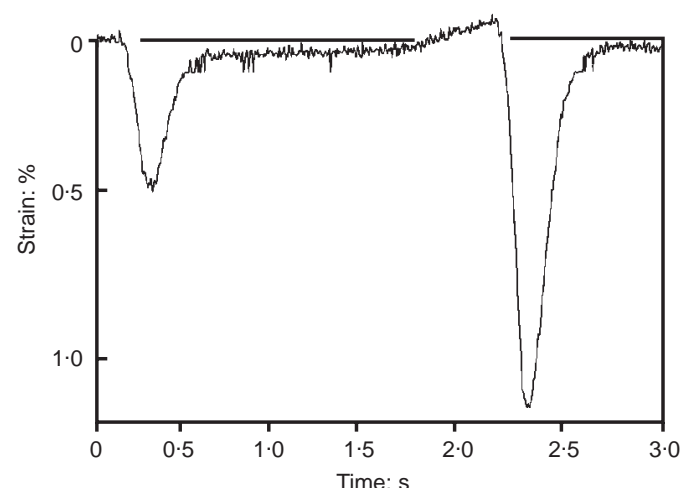

(a)

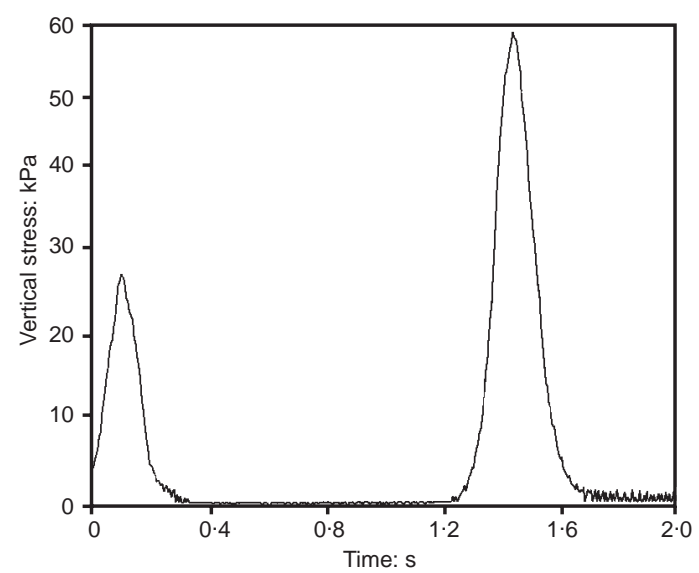

(b)

Fig. 13. In situ measurements from Bothkennar haul road experiments (after Little, 1993): (a) vertical strain at formation level; (b) vertical stress at formation level

a pressure cell at the same depth is presented in Fig. 13(b).

\section{Laboratory testing}

Figure 14 illustrates the general stress regime experienced by an element of material in or below a pavement structure as a result of a moving wheel load within the plane of the wheel track, that is, the longitudinal plane. There are pulses of vertical and horizontal stress accompanied by a double pulse of shear stress with a sign reversal on the vertical and horizontal planes. Fig. 15 shows the associated pattern of principal stresses illustrating the rotation of principal planes which takes place. For elements of material in the lower part of a bituminous or concrete layer, the horizontal stresses are tensile, elsewhere they are compressive.

One approach to laboratory testing is to select the equipment which reproduces the field situation.

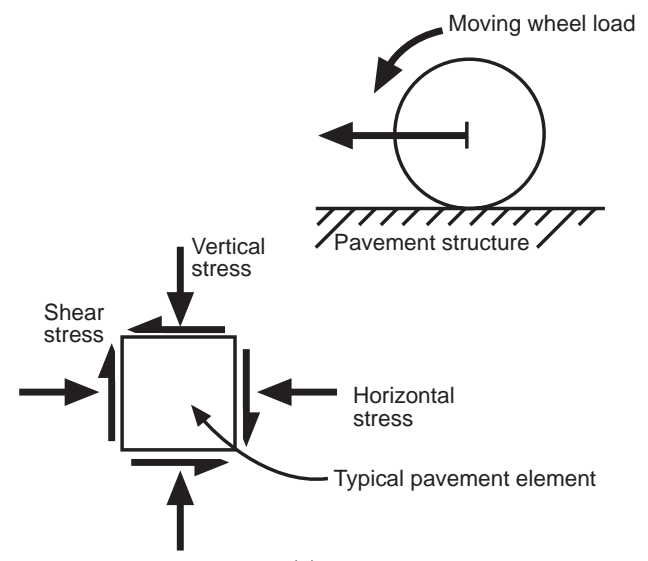

(a)

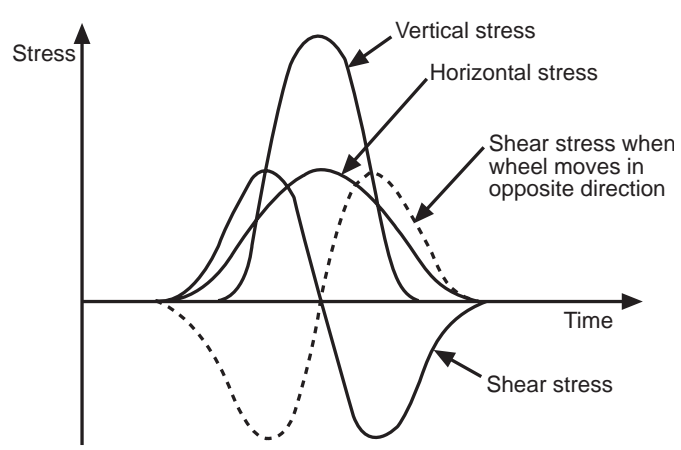

(b)

Fig. 14. Stress conditions under a moving wheel load: (a) stresses on pavement element; (b) variation of stresses with time

Clearly, for pavements this would demand complex facilities. A close match to field conditions can be obtained by use of a Hollow Cylinder Apparatus (HCA). This allows control of both normal and shear stress in a manner which can match the in situ case as shown in Fig. 16. Repeated load HCAs have been developed at the University of California, Berkeley (Alavi, 1992) principally to test bituminous materials, and at Nottingham for granular materials (Chan \& Brown, 1994).

Interest in the HCA was partly stimulated by the problems associated with the Simple Shear Apparatus (SSA), which also has the potential to reproduce the in situ stress regime. The most serious difficulties with the SSA were applications of uniform stress conditions and accurate measurement of stresses and deformations on the specimen under repeated loading conditions. Shaw \& Brown (1986) describe an SSA in which both the vertical and shear stresses can be applied cyclically, but for which the problems of stress measurement were identified. 

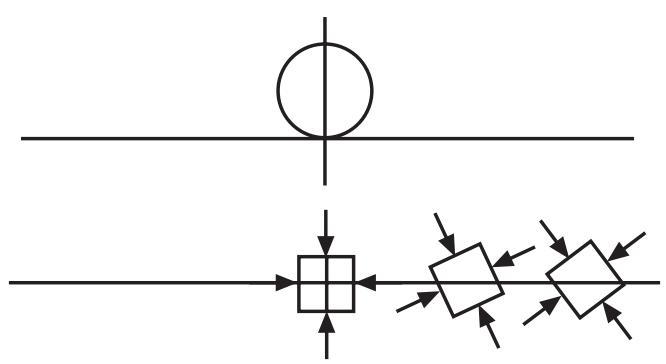

(a)

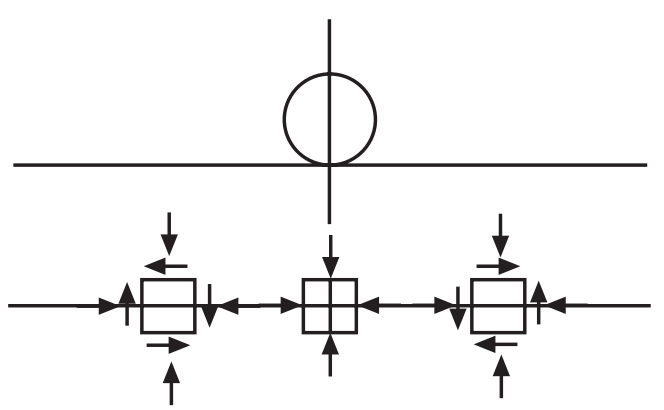

(b)

Fig. 15. Stresses on a pavement element: (a) principal stresses - element rotates; (b) no rotation - shear stress reversal

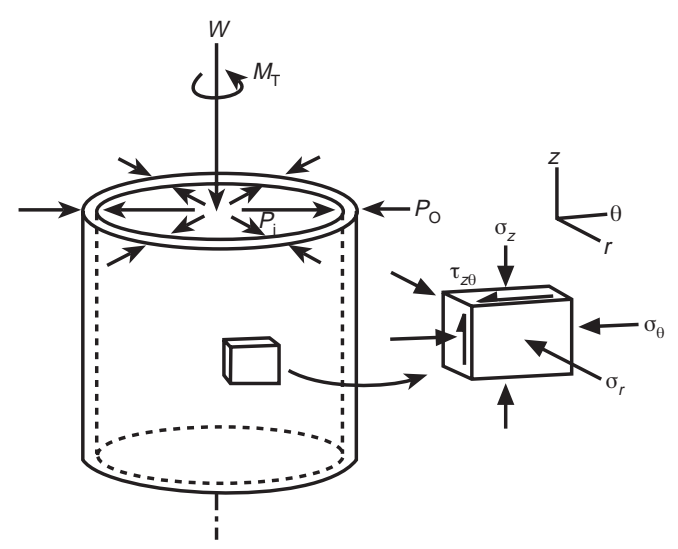

Fig. 16. Stress conditions in a Hollow Cylinder Test

Since the HCA and SSA are essentially research tools and have limited productivity, most testing of soils, granular materials and bound materials for pavements has involved simpler configurations. The approach has been either to concentrate on that part of the applied stress regime which is of most significance, or to carry out a test programme of a more fundamental nature using stress invariants. This latter approach allows the field stress regime to be expressed in terms of octahedral shear and normal stresses and to study material response in the laboratory under a range of values for these two parameters. This latter approach involves an inherent assumption that the materials are isotropic and presents problems in dealing with the rotation of principal planes. However, Brown (1975) demonstrated this approach for bituminous layers and Brown \& Bell (1977) adopted it in predictive calculations for rutting in bituminous pavements. Data reported by Chan \& Brown (1994) for granular materials indicated that shear reversal is only of significance when considering the development of plastic strains.

The invariant approach has formed the basis for the application of repeated load triaxial testing to studies of soils and granular materials in recent years (Boyce et al., 1976). Fig. 17 shows the

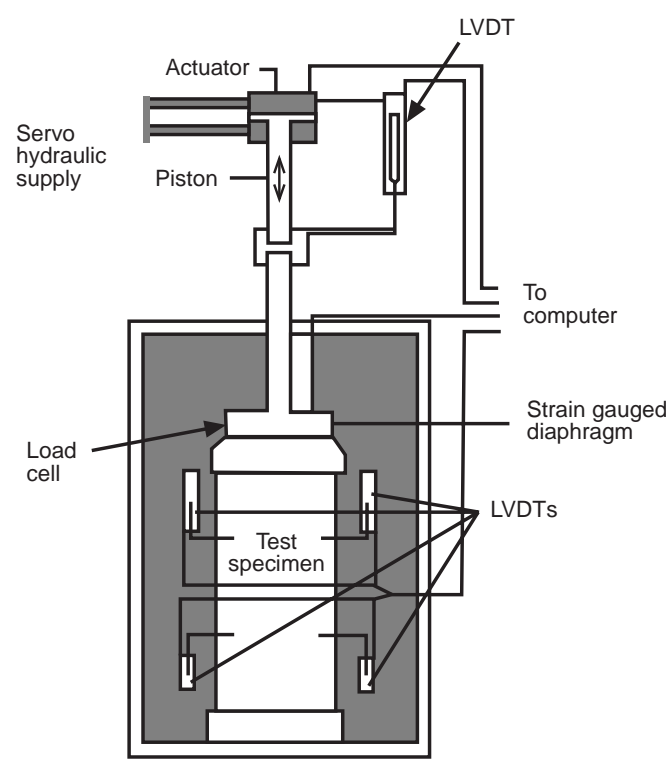

(a)

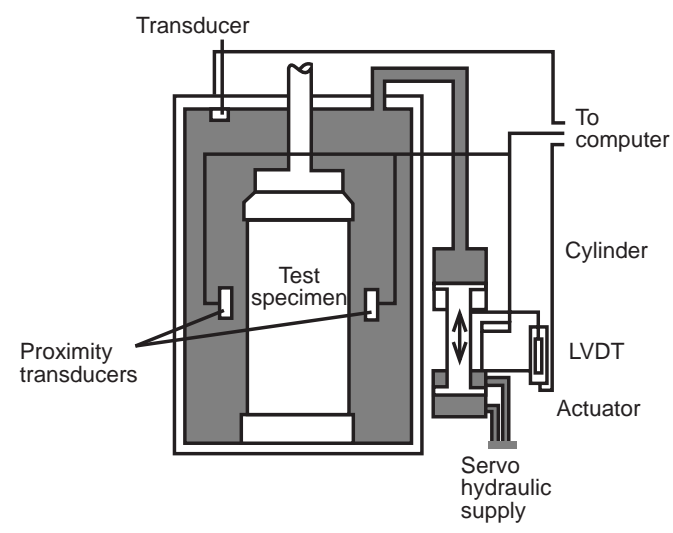

(b)

Fig. 17. Equipment for repeated load triaxial testing of soils (after Raybould, 1992): (a) axial stress and deformation system; (b) confining stress and radial deformation system 
apparatus developed at Nottingham for testing $75 \mathrm{~mm}$ dia. soil specimens under cyclic loading. The essential features are

(a) use of closed loop servo-hydraulic loading systems for cycling both deviator and confining stresses

(b) accurate measurement of axial and radial deformations directly on the test specimen using LVDTs and proximity transducers respectively

(c) measurement of axial load on the top platen

(d) measurement of pore pressure both at the bottom platen and near the centre of the specimen; the central transducer is located prior to consolidating reconstituted specimens but is not used for field samples

(e) computer control and data acquisition.

This equipment is fully described by Brown et al., (1980) and Raybould (1992). It has been used for studies relating to off-shore structure foundations (Brown et al., 1977) and earthquake loading (Raybould \& Brown, 1993) in addition to the pavement problem of interest here.

For testing granular materials with particle sizes up to $40 \mathrm{~mm}$, a larger repeated load triaxial apparatus was developed at Nottingham catering for $150 \mathrm{~mm}$ dia. specimens (Brown et al., 1989). Fig. 18 shows this apparatus which embraces most of the relevant features of the smaller soil testing facility. In this case, radial deformations are measured by cast epoxy strain hoops fitted with foil strain gauges. Similar apparatus has been used in France (Paute et al., 1993), while $400 \mathrm{~mm}$ dia. specimens were adopted in the Dutch equipment developed by Sweere (1990). He demonstrated that the large diameter was needed to accommodate particle sizes up to $40 \mathrm{~mm}$ since inaccurate results were obtained when using smaller specimens. Equally, if the grading is scaled down or the larger fractions omitted when using smaller specimens, unrepresentative data are obtained.

In recent times, simplified pieces of apparatus have been developed for use in engineering practice, derived from the more complex facilities used in research studies. For bituminous mixtures, the Nottingham Asphalt Tester (Cooper \& Brown, 1989), has emerged as a practical and reliable tool for measuring the key mechanical properties of bituminous materials. The development of comparable, simplified testing facilities for soils and granular materials has not progressed as far as for bituminous mixtures. This is somewhat surprising since repeated load triaxial testing has been used in the USA since the 1950s (Seed et al., 1955). The US Transportation Research Board issued a detailed guide for such testing in 1975 (Transportation Research Board, 1975) and there is an AASHTO specification for such tests

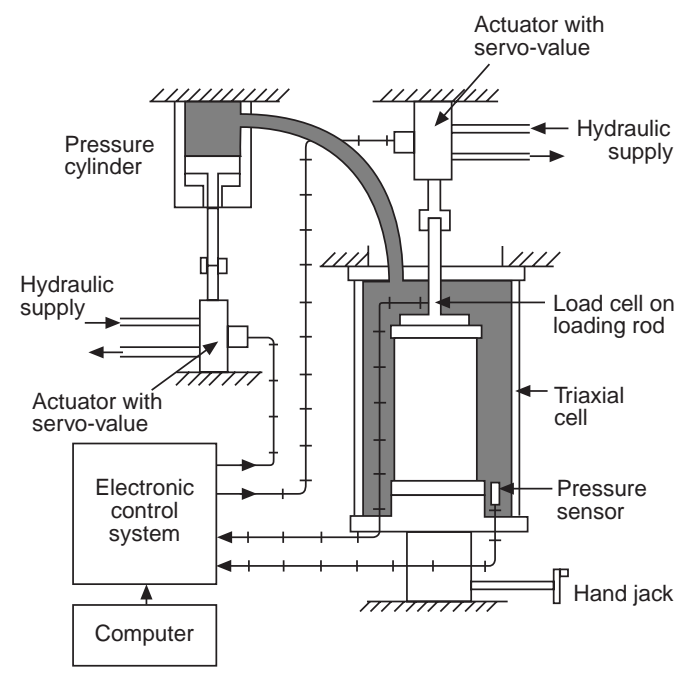

(a)

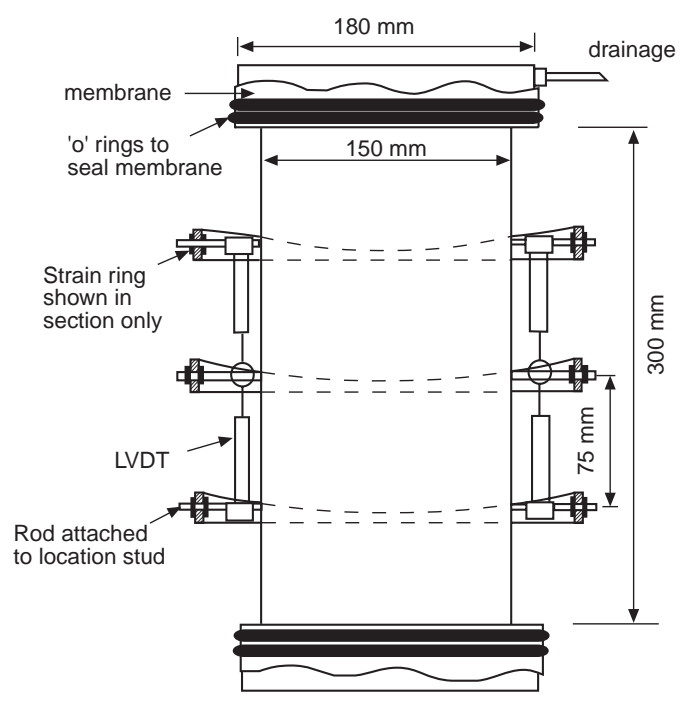

(b)

Fig. 18. Equipment for repeated load triaxial testing of granular materials (after Brown et al., 1989): (a) diagram of loading equipment; (b) position of strain transducers

(AASHTO, 1986). Because soils testing is inherently more difficult to perform than asphalt testing, simplified techniques present more of a challenge. One of the principal problems is that of preparing reliable and representative specimens. However, recent work at Nottingham, in conjunction with TRL, has endeavoured to develop practical tests for soils and granular materials which could be adopted for design purposes.

A pneumatically operated repeated load triaxial 
system for soil testing is shown in Fig. 19. It accommodates $100 \mathrm{~mm}$ dia. specimens in a standard cell and is fitted with 'on-specimen' deformation measuring transducers that are easy to assemble. Fig. 20 shows the technique used for axial deformation, the active element being a strain gauged phosphor bronze strip on an assembly weighing just $26 \mathrm{~g}$. Measurements are made at diametrically opposite locations. These transducers are for reading small resilient strains under repeated loading and can resolve to 28 microstrain. An external LVDT is used to measure the larger plastic strains and total strains in monotonic tests to failure.

For radial strain, the same proximity transducers are used as for the cyclic loading facility (Fig. 17(b)). The 'target' for each transducer is a $30 \mathrm{~mm}$ square of aluminium foil placed inside the latex membrane. Radial strains can be resolved to 10 microstrain. No provision is made for pore pressure measurement, since specimens will, in general, be partially saturated and independent soil suction determination is recommended.

The axial load is measured by a load cell formed from strain gauging a narrowed section of the loading rod inside the triaxial cell, a technique used earlier by Austin (1979). The applied load is controlled by an electro-pneumatic regulator fitted near the actuator. Deviator stresses up to $200 \mathrm{kPa}$ can be applied. The confining pressure medium

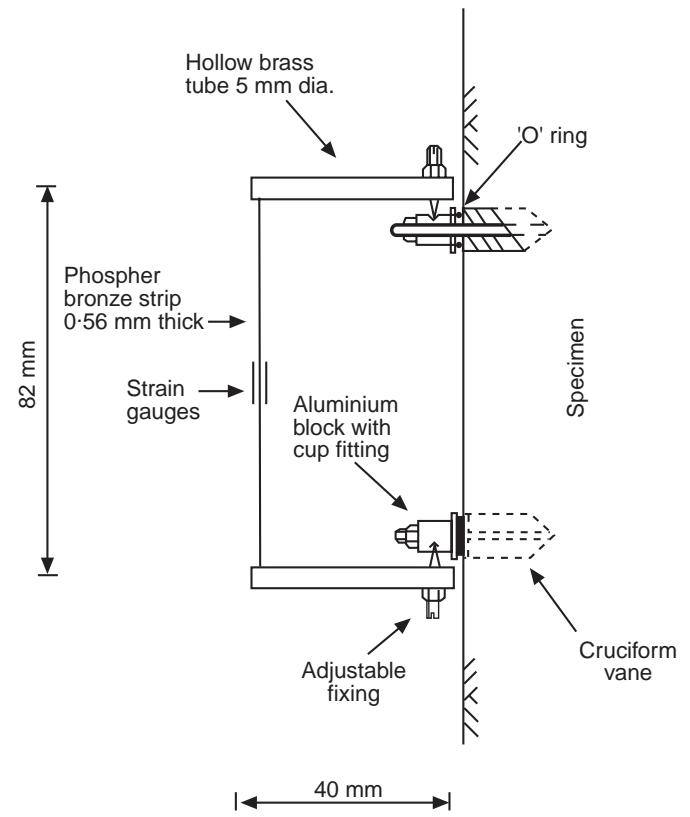

Fig. 20. Axial deformation measuring system for soils (after Cheung, 1994)

is air with a maximum value of $200 \mathrm{kPa}$ but with no facilities for cyclic application. A computerized system is used to control experiments and to monitor the data. A Windows environment with

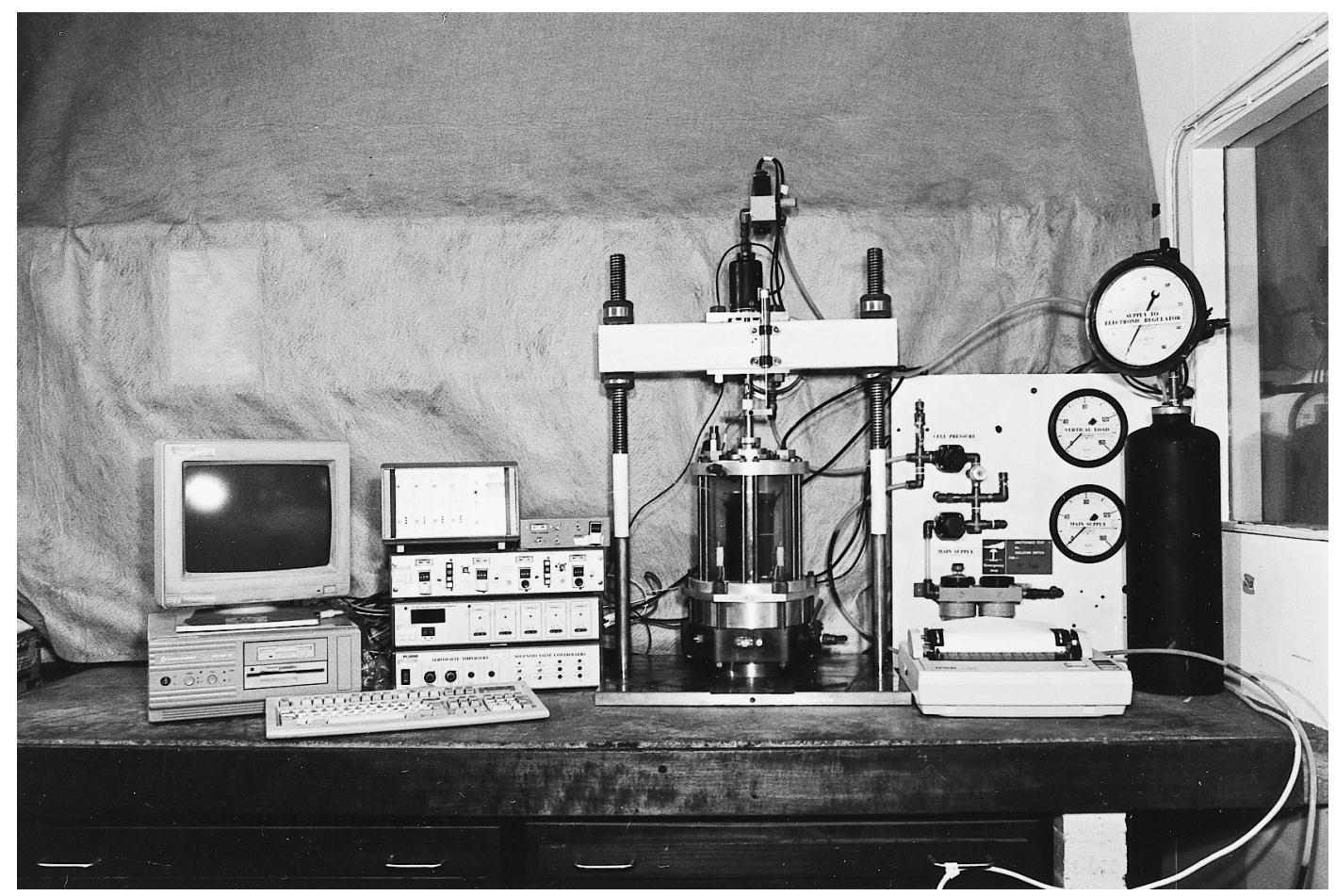

Fig. 19. Simplified repeated load triaxial system for soils (after Cheung, 1994) 
DCS software (Sousa \& Chan, 1991) provides a very user-friendly control and data acquisition system.

The equipment developed for granular materials is shown in Fig. 21. The test specimens are $280 \mathrm{~mm}$ in diameter which, following a study of work elsewhere, was considered adequate for particle sizes up to $40 \mathrm{~mm}$ recognizing that few particles of this size are actually included aggregate graded to this nominal maximum size.

The constant confining stress is applied by using a partial internal vacuum via porous fittings in both platens, thus allowing the triaxial cell to be dispensed with. This arrangement allows confining stresses up to $90 \mathrm{kPa}$. The axial load can be applied in three different ways depending on availability of facilities. If closed loop servohydraulics are available, then this system can provide the usual sophisticated load control for monotonic or repeated load tests. A suitable actuator is shown on the right of the test frame in Fig. 21.

A manually operated hydraulic actuator, as shown in Fig. 21 above the test specimen, can be used for simple repeated loading to determine

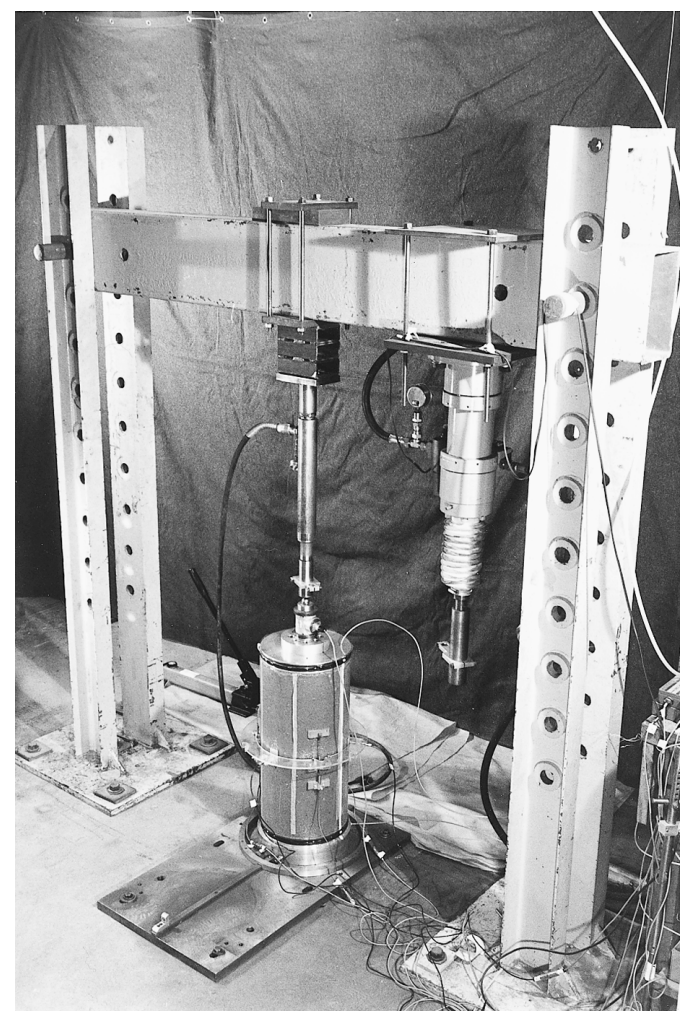

Fig. 21. Simplified repeated load triaxial system for granular materials (after Cheung, 1994) resilient characteristics which, for these materials, are not sensitive to loading rates. However, only a limited number of load applications can realistically be applied. A simple, manually operated falling hammer device is somewhat more suitable for repeated loading to study the accumulation of plastic strains. A $10 \mathrm{~kg}$ mass falling through heights up to $500 \mathrm{~mm}$ provides peak stresses up to $700 \mathrm{kPa}$. The hydraulic actuators shown in Fig. 21 are each capable of applying loads up to $100 \mathrm{kN}$ (deviator stresses of $1624 \mathrm{kPa}$ ). A load cell is located immediately above the top platen.

The test specimen is sealed with a pvc membrane while in the compaction mould, which is removed following application of the internal partial vacuum. The deformation measuring devices are shown in Fig. 22. Axial measurements are effected by LVDTs between blocks glued to the membrane. This technique was carefully checked to ensure that slippage between the membrane and the test specimen did not occur. The precision of measurement is 17 microstrain. The large deformations associated with monotonic tests to failure are measured with a $100 \mathrm{~mm}$ stroke LVDT inserted in the loading actuator, which can read to an

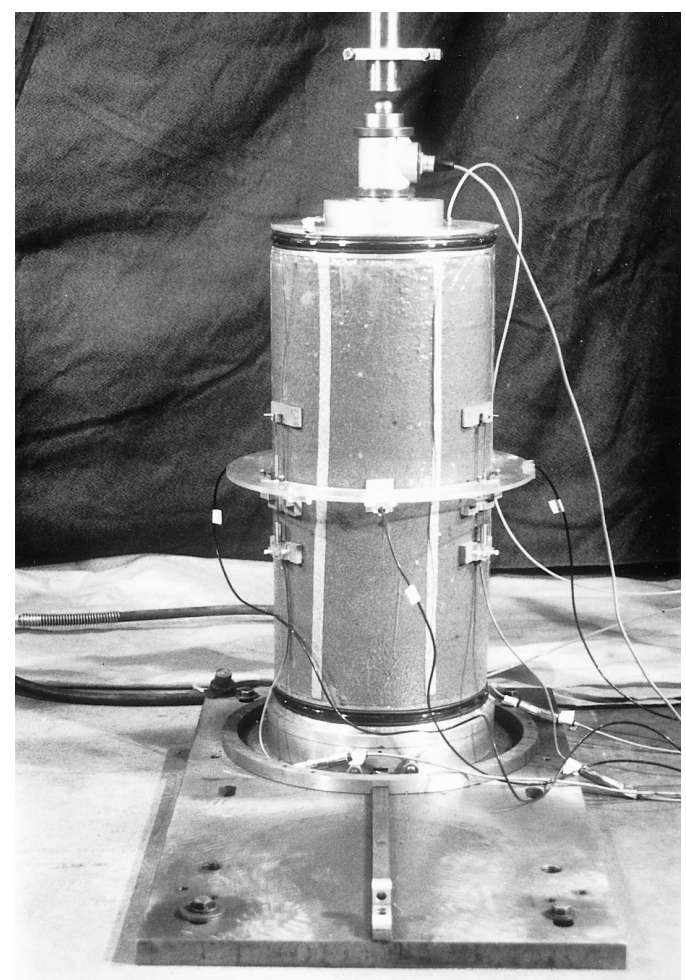

Fig. 22. Deformation measuring system for granular materials (after Cheung, 1994) 
accuracy of 86 microstrain. Radial deformation is obtained from three LVDT outputs, fitted to a perspex ring as shown in Fig. 22 with the cores being spring loaded against thin metal plates glued to the membrane. The perspex carrier ring is supported on three blocks which are also glued to the membrane. The precision of these measurements is 27 microstrain.

Although further development work is needed for the two triaxial facilities described above, they have the potential for use in engineering design practice to measure resilient modulus, permanent deformation characteristics and shear strength of soils and granular materials. Some typical results from several of the laboratory test methods reviewed here are given in the section on Behaviour of Soils and Granular Materials under Repeated Loading.

\section{Field testing}

Laboratory testing of small elements always raises questions about whether the results are representative of field conditions for the soil in bulk. Field testing, though more expensive, has therefore become an increasingly important part of geotechnical engineering. For pavement soil mechanics, static plate loading tests have been used for many years, initially to determine a 'modulus of subgrade reaction' in connection with concrete pavement design and as an indirect technique for assessing the California Bearing Ratio (Croney, 1977), a test discussed on pp. 412-416.

The static plate loading test is however, cumbersome and time consuming. More importantly, it does not reproduce real wheel loading conditions for which the time factor is important. In particular, a static test on material with a high degree of saturation can allow pore pressure dissipation and result in more favourable results than a transient load test which is essentially an undrained event.

Sweere (1990) conducted a useful review of in situ testing devices and concluded that a dynamic plate loading test was appropriate for assessing the resilient modulus of granular layers. This test is a special version of the more sophisticated Falling Weight Deflectometer (FWD) apparatus (Sorenson \& Hayven, 1982), the principles of each being shown in Fig. 23. In both cases, a load pulse is generated by a mass falling onto a spring above a load platen. The peak load is measured and, using the FWD, the deflected shape of the loaded surface is recorded from a set of geophones measuring at points up to a radius of some $2 \mathrm{~m}$ from the platen. A single electronic integration of the geophone velocity measurements yields deflections. In the dynamic plate loading test, only the deflection of the load platen is recorded. Using this parameter

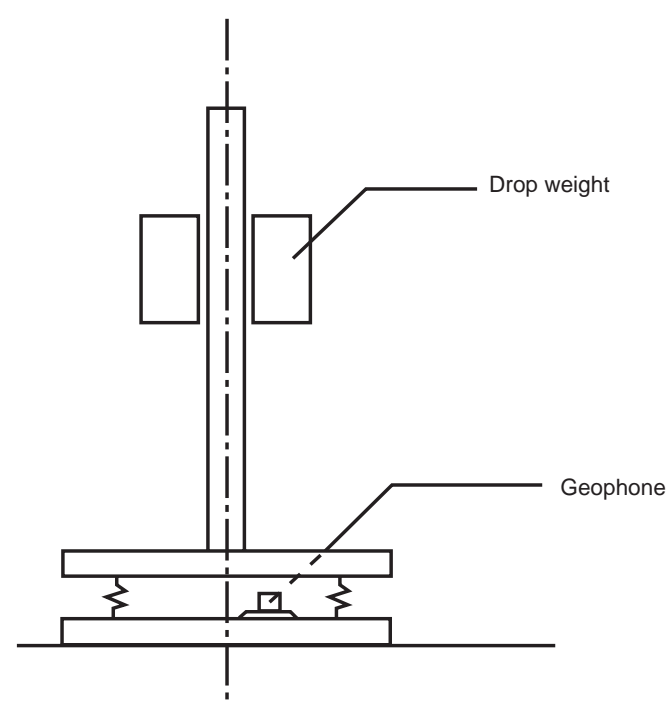

(a)

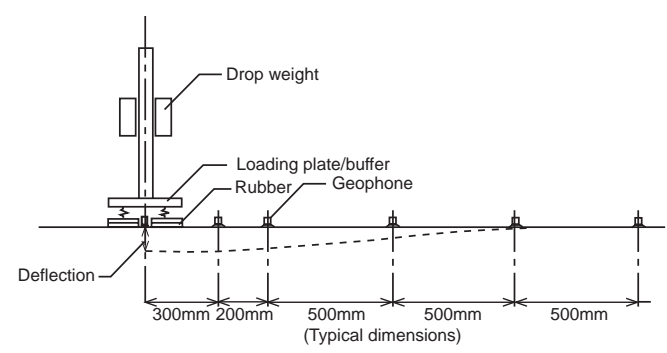

(b)

Fig. 23. Falling weight plate loading tests (after Sweere, 1990): (a) principle of dynamic plate bearing test; (b) principle of the falling weight deflectometer test

and the peak load, an 'effective foundation stiffness modulus' $\left(E_{\mathrm{f}}\right)$ can be computed using the equation:

$$
E_{\mathrm{f}}=\frac{2 p a\left(1-v^{2}\right)}{d_{1}}
$$

where $p$ is the contact pressure below the plate, $a$ is the plate radius, $v$ is Poisson's ratio and $d_{1}$ is the measured plate deflection.

The FWD is generally used for testing 'inservice' pavements to assess structural integrity (Brown et al., 1987). Analytical procedures have been developed which involve a back-analysis of the deflected surface under the given load to determine the effective resilient modulus of each principal pavement layer. The layer thicknesses need to be known and are obtained from coring or can be estimated from ground radar surveys (Highways Agency, 1994a). 
Several analytical procedures have been developed in the form of computer programs for backanalysis of deflection 'bowls'. The most reliable ones (e.g. Brown et al., 1986) take account of the non-linear resilient properties of soils and, where necessary, granular layers (e.g. Brunton \& d'Almeida, 1992) while bituminous or concrete layers are treated as linear elastic. The central analytical tools are those outlined previously but finite element analysis is not used routinely because of the computing time involved. This subject is further discussed in the final section. These procedures allow the parameters in simple non-linear resilient soil models to be calculated and, by matching theory to measurement by way of the surface deflection profile, provide a sound basis for further theoretical analyses of the pavement.

The basic back-analysis procedure can also be used when tests are conducted on pavement foundations, although the data tend to be less precise because of the rough surface, compared with a completed pavement, which can interfere with the geophones.

The procedure was used on the Bothkennar haul road experiments (d'Almeida, 1993) and on the A564, Derby Southern By-Pass, some typical results from which are presented on pp. 417-418.

\section{PAVEMENT FAILURE MECHANISMS Cracking}

Cracking of bituminous pavements under the influence of repeated wheel loading is a fatigue phenomenon. Fig. 24 shows a typical failure condition with a pattern of cracks in the wheel paths. Hveem (1955) was the first engineer to identify the relationship between fatigue cracking and the resilience of the supporting pavement structure, which was principally influenced by the soil characteristics. For the thin surfacing commonly used in the 1950s, Hveem's theory, illustrated in Fig. 25, relates to surface cracking outside the loaded area induced by horizontal tensile

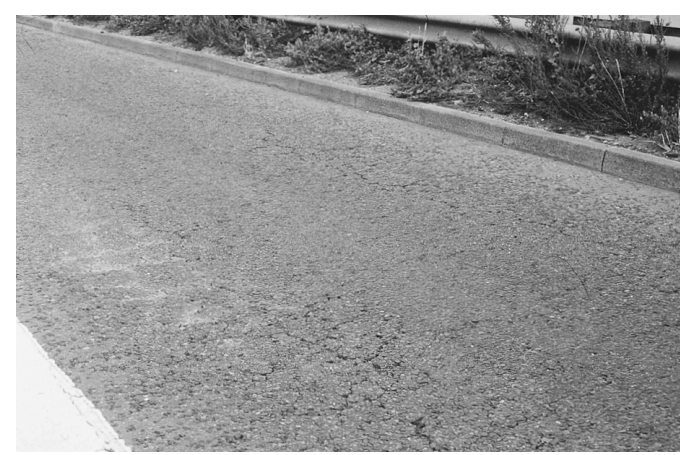

Fig. 24. Asphalt fatigue cracking failure

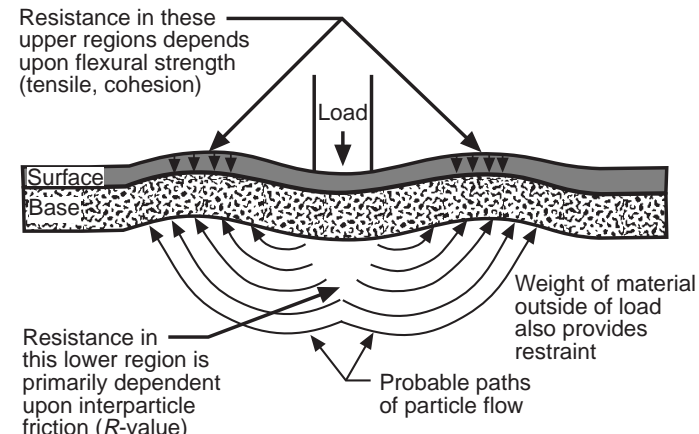

friction ( $R$-value)

Fig. 25. Illustration of failure modes (after Hveem \& Sherman, 1962)

stresses or strains resulting from flexure of the pavement. As thicker bituminous layers were introduced and in situ measurements were made of tensile strains, it became apparent that the maximum value occurred at the bottom of the layer rather than at the surface, as illustrated in Fig. 26 taken from Klomp \& Niesman (1967).

Laboratory studies in the 1950s and 1960s (e.g. Pell \& Taylor, 1969) revealed that crack initiation of bituminous mixtures under repeated flexure is controlled by the level of principal tensile strain. Fatigue relationships, such as that shown in Fig. 27, were developed for various bituminous mixtures. Consequently, the theoretical basis for design calculations to deal with fatigue cracking involves use of the horizontal tensile strain at the bottom of the bituminous layer as the principal design criterion. Numerous design methods have been
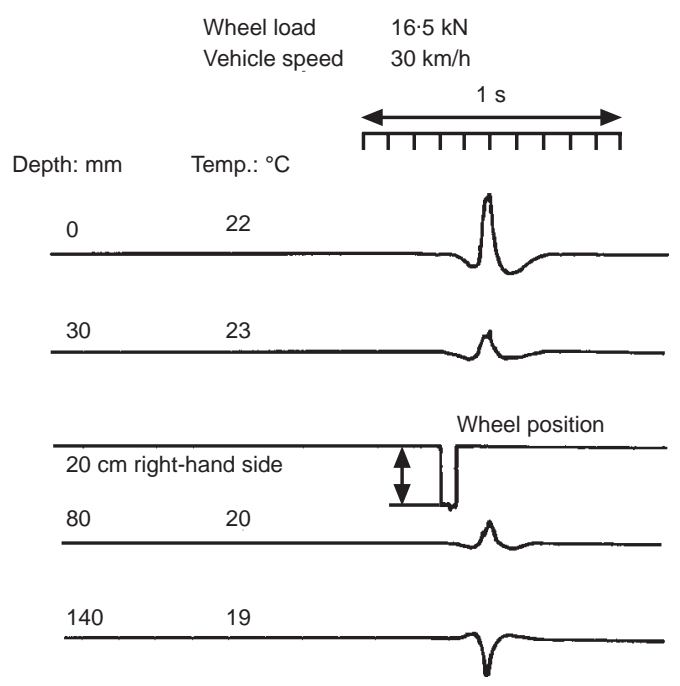

Fig. 26. In situ horizontal strain measurements in an asphalt layer under wheel loading (after Klomp \& Niesman, 1967) 
BROWN

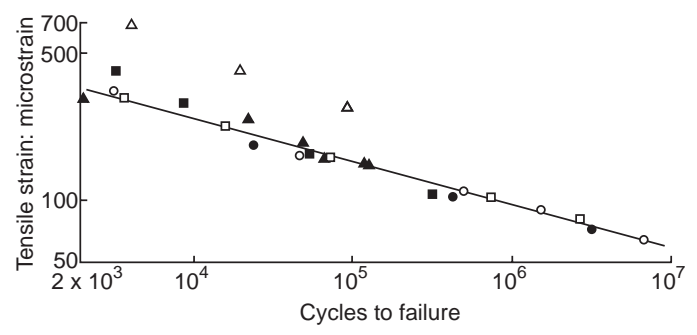

\begin{tabular}{|l|c|c|c|c|c|}
\hline Test Series & $F$ & \multicolumn{4}{|c|}{$G$} \\
\hline Temp. ${ }^{\circ} \mathrm{C}$ & +10 & 0 & +10 & +20 & +30 \\
\hline Symbol & $\mathbf{O}$ & $\mathbf{O}$ & $\mathbf{\square}$ & $\mathbf{\square}$ & $\Delta$ \\
\hline
\end{tabular}

\begin{tabular}{|l|c|}
\hline Test Series & $P$ \\
\hline Frequency & varies \\
\hline Symbol & $\boldsymbol{\Delta}$ \\
\hline
\end{tabular}

Fig. 27. Typical asphalt fatigue relationship (after Pell \& Taylor, 1969)

developed using linear elastic theory and incorporating this concept (e.g. Brown et al., 1985).

Research into crack propagation has revealed that, once a crack has been initiated, its rate of propagation depends on the tensile stress at the crack tip (Ramsamooj et al., 1972). There are, therefore, conflicting requirements between the need to avoid crack initiation, which requires a high asphalt stiffness, and to minimize crack propagation, which requires a low stiffness. The layer thickness is also influential. The general approach is to use low stiffnesses for bituminous surfacing which is less than $100 \mathrm{~mm}$ thick and high stiffnesses for the greater thicknesses which embrace all modern major pavement construction.

Theoretical analysis allows an indication to be obtained of the influence which soil resilient modulus has on the tensile stress and strain in the bituminous layer. A sensitivity analysis reported by Dawson \& Plaistow (1993) based on computations with the FENLAP program revealed that a change in the resilient modulus of the subgrade from 40 to $90 \mathrm{MPa}$ caused a change in the asphalt tensile strain criterion of less than $2 \%$. Changes in the resilient characteristics of the granular layer over a realistic range, using nonlinear models, were more significant, causing the asphalt tensile strain to vary by up to $70 \%$. These calculations involved bituminous layer thicknesses between 100 and $250 \mathrm{~mm}$ with stiffness modulus values of between 2 and $8 \mathrm{GPa}$. It would appear, therefore, that the cracking phenomenon is not greatly influenced by soil resilience when a reasonably thick bituminous layer is used. Conversely, the resilience of the supporting granular layer is very significant.

\section{Rutting}

The second traffic related failure mechanism in flexible pavements is rutting. This arises through the accumulation of vertical permanent strains in the wheel track (Fig. 28) which can, in principle, include contributions from all layers in the pavement. Some typical data from field experiments carried out on the A1 by Lister (1972) are shown in Fig. 29 to illustrate this point.

For thick asphalt pavements, rutting usually arises from permanent deformations in the bituminous layers, often the surface course. Interpretation of Lister's data for pavements with hot rolled asphalt surfaces and base layers over traditional foundations, by Brown \& Brunton (1984) indicated that a $20 \mathrm{~mm}$ rut might involve a $48 \%$ contribution from the bituminous layers. It is difficult to generalize about this matter, since permanent deformations will develop wherever there is a weakness in the structure. For heavily trafficked UK roads, this is likely to be in the surfacing, but for pavements with thin bituminous layers, the

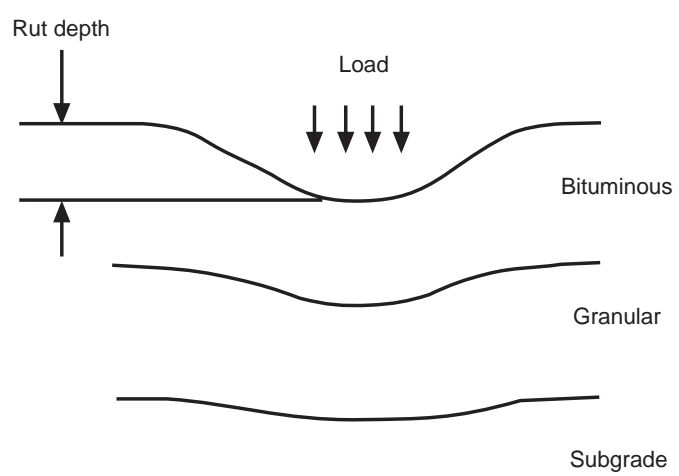

Fig. 28. Definition of rut depth

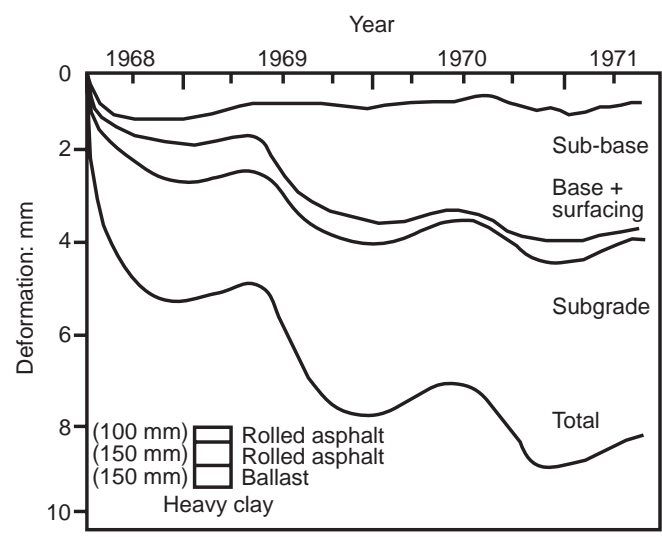

Fig. 29. Development of permanent deformation in TRL experiments at Alconbury Hill (after Lister, 1972) 
granular layer and subgrade are likely to dominate, particularly if drainage conditions are unsatisfactory.

For construction traffic operating on the pavement foundation, rutting is a major concern and must be limited to avoid undue damage to this layer or to the subgrade below. In the Bothkennar pavement experiments (Little, 1993), the granular layer contributed up to a third of the surface rut, but there were cases where all the deformation developed in the subgrade.

The sensitivity analysis carried out by Dawson \& Plaistow (1993) used the ratio of shear to normal stress as the parameter most likely to influence plastic strain developed in soils and granular materials. For unsurfaced pavements, the resilient characteristics of the granular layer were most influential for stress ratios at the top of both layers. A realistic range of parameters for the nonlinear resilient granular layer model indicated changes of up to 15 and $40 \%$ in the stress ratios for the top of the granular layer and of the subgrade respectively. The resilient modulus of the subgrade had some influence on the stress ratio at formation level.

In addition to quantifying the non-linear resilient characteristics of granular materials and soils, it is clearly necessary to understand the relationship between the accumulation of plastic strain and applied stress together with relevant variables that may influence this relationship.

\section{Rail track}

Failure mechanisms in rail track are well described by Selig \& Waters (1994). Under repeated loading, differential permanent strains develop in the ballast which cause the rail line and level to change and the ride quality to deteriorate. Fig. 30 (taken from Brown \& Selig, 1991) shows this pattern for a well established track with a stable subgrade subjected to periodic maintenance by tamping to restore the rail geometry. If the voids in the ballast are allowed to fill with fine material, a failure condition can

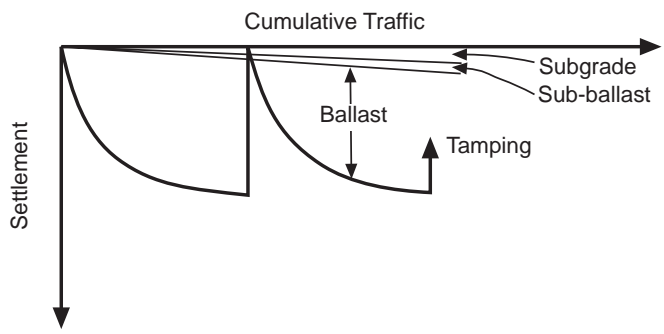

Fig. 30. Effects of traffic and tamping on rail track deformation (after Brown \& Selig, 1991) develop with high plastic strains, partly because of a decrease in permeability impeding drainage. One source of contamination is pumping of fines from the sub-ballast or subgrade if these materials become saturated.

Permanent deformation of the track is only influenced by the subgrade in the long term except when the track is newly constructed. Unless high water contents have developed, normal transient stress levels, on clay subgrades, tend to result in a stable situation after initial plastic strain development.

Fig. 31 presents field data from a full-scale rail track experiment in Colorado reported by Selig \& Waters (1994), showing the relative contributions to surface deformation of each layer in the structure. In this case, which involved a new track, about half the surface deformation arose from the ballast.

\section{BEHAVIOUR OF SOILS AND GRANULAR MATERIALS UNDER REPEATED LOADING Introduction}

The foregoing discussion on failure mechanisms in pavements suggests that an ability to design for prevention of failure requires a knowledge of how soils and granular materials respond to repeated loading of the type imposed by moving traffic. Under repeated loading, there are recoverable and irrecoverable components of deformation. The former dictate the value of resilient modulus, which is required to carry out structural analysis of pavements, while the latter needs to be quantified to deal with design to minimize rutting.

\section{Properties of the subgrade}

The mechanical properties of the subgrade are influenced by the imposed stress regime. This must be considered in two parts; that resulting from the equilibrium conditions established after construc-

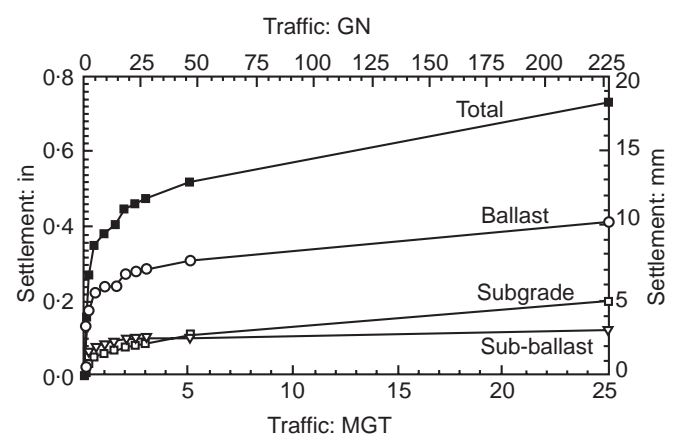

Fig. 31. Development of permanent deformation in rail track experiments at Colorado (after Selig \& Waters, 1994) 
tion, when moisture conditions have stabilized and that imposed transiently by a moving wheel load. These will be considered in turn.

Equilibrium stress conditions. The response of an element of soil to applied load depends crucially on its consolidation stress history and the current effective stress state. Since formation levels in subgrades exist above the water table, the determination of pore pressure and, hence, effective stress is generally not straightforward. Immediately above the water table, where the soil is saturated, the negative pore pressure is proportional to height above the water table. The proportionality breaks down as the soil becomes partially saturated at greater heights as illustrated in Fig. 32. The soil type will greatly influence this pore pressure distribution.

For fine-grained soils and shallow water tables, conditions which apply to most of the UK, the situation is simplified since saturated conditions may be assumed up to formation level, certainly for design purposes, and pore pressure can be determined. Unfortunately, there are very few field measurements of pore pressures above the water table. However, the experiments conducted in the 1950s by Black et al. (1958) are worth noting, not least because the results formed part of the background used to establish the current UK method for assessing pavement subgrade strengths. Fig. 33 shows the measurements made using tensiometers at various depths below concrete slabs. The original data have been replotted and the linear relationship between negative pore pressure and height above the water table superimposed. The soil profile consisted of a brickearth which was a mixture of sandy and silty clay above a sandy gravel where the water table was located.

The results in Fig. 33 are typical of the

$\nabla$ Pavement surface

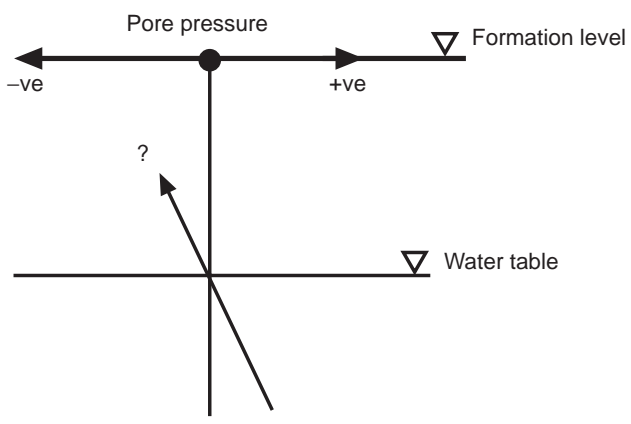

Fig. 32. Pore pressure in subgrade

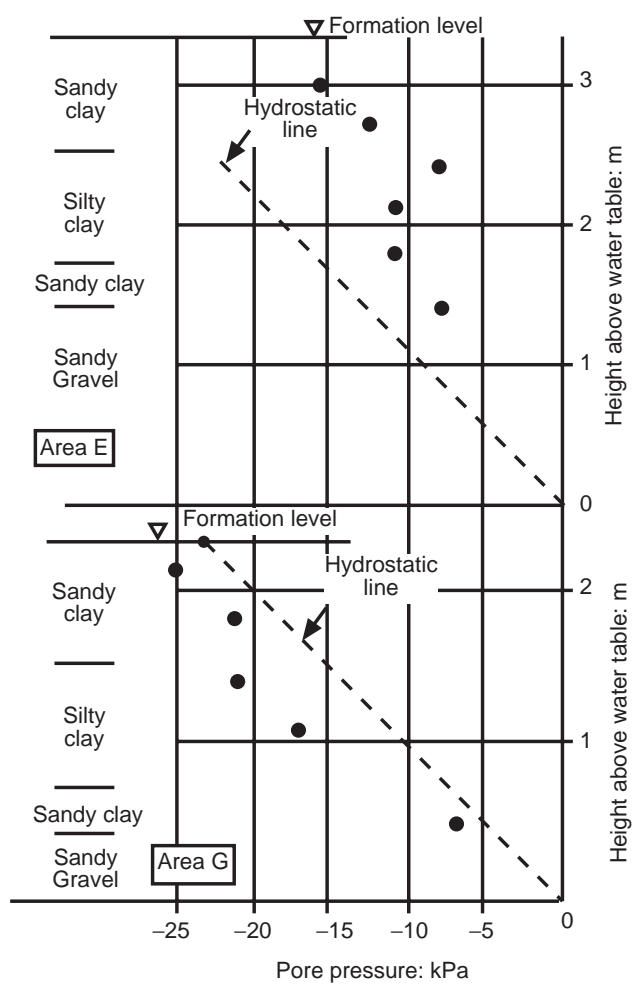

Fig. 33. Pore pressure measurements in RRL experiments below sealed surfaces (after Black et al., 1958)

measurements made at four locations. In Area E the negative pore pressures were below the hydrostatic values, while in Area $G$ slightly higher values were recorded. There were only small seasonal variations, supporting the concept of equilibrium water content under sealed surfaces. Use of the hydrostatic value for design when dealing with more highly plastic clays could probably be justified but good quality field data are clearly needed.

The soil beneath a pavement may be in its natural undisturbed state or be remoulded depending on whether the section of pavement is in a 'cut' or 'fill' area. These two situations require separate consideration.

For undisturbed clays, the stress history is represented by Fig. 34. The parameters used are

mean normal effective stress $p^{\prime}=\left(\sigma_{\mathrm{v}}^{\prime}+2 \sigma_{\mathrm{h}}^{\prime}\right) / 3$

deviator stress $q=\sigma_{\mathrm{v}}^{\prime} \sigma_{\mathrm{h}}^{\prime}$

where $\sigma_{\mathrm{v}}^{\prime}$ and $\sigma_{\mathrm{h}}^{\prime}$ are the vertical and horizontal effective stresses, respectively.

specific volume $\mathrm{v}=1+w G_{\mathrm{s}}=1+e$

where $w=$ water content, $G_{\mathrm{s}}=$ specific gravity of 

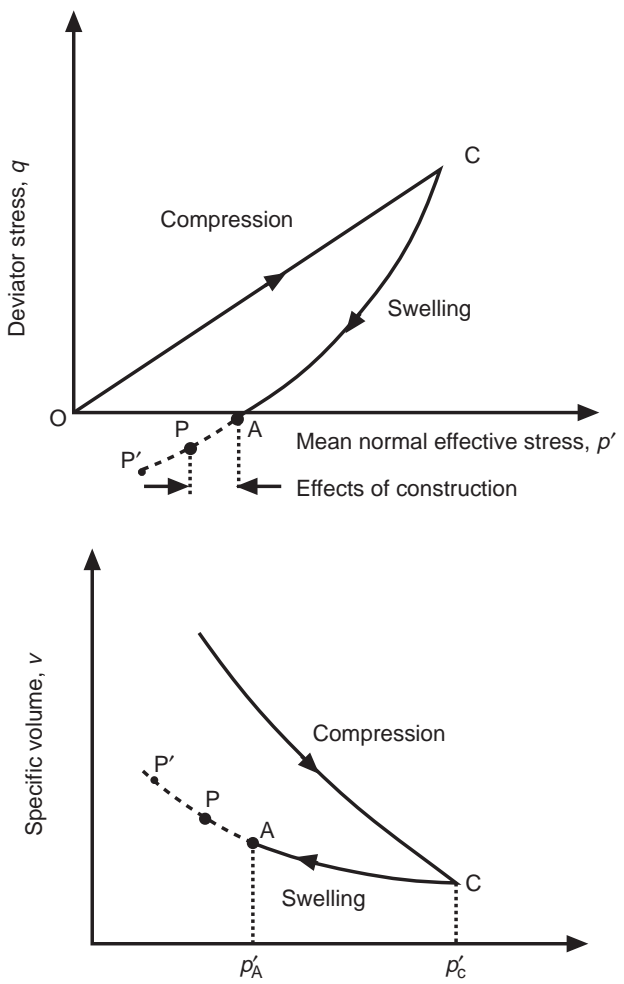

Mean normal effective stress, $p^{\prime}$

Fig. 34. Stress history for soil in 'cut'

soil soilds and $e=$ void ratio. Saturated conditions are assumed.

Fig. 34 shows preconsolidation involving compression to point $\mathrm{C}$ and subsequent swelling to point A, all under anisotropic conditions (zero lateral strains). This historical sequence generates an overconsolidated soil, being typical of a stiff clay deposit.

The construction operation involves three processes which will influence the effective stress in the soil. These are

(a) removal of overburden during earthworks construction

(b) lowering of the water table by provision of drainage

(c) addition of overburden due to the pavement construction.

The nett effect of these operations will be for the effective stress state to move from point $\mathrm{A}$ in Fig. 34 to point $\mathrm{P}$ by way of $\mathrm{P}^{\prime}$.

Fig. 35 shows an enlarged view of the plot of $p^{\prime}$ against $q$ to illustrate these three changes. Removal of overburden will cause no immediate change in effective stress but will reduce the deviator stress by $\mathrm{AB}$. As pore pressures reach equilibrium and further swelling occurs, the effective stress will

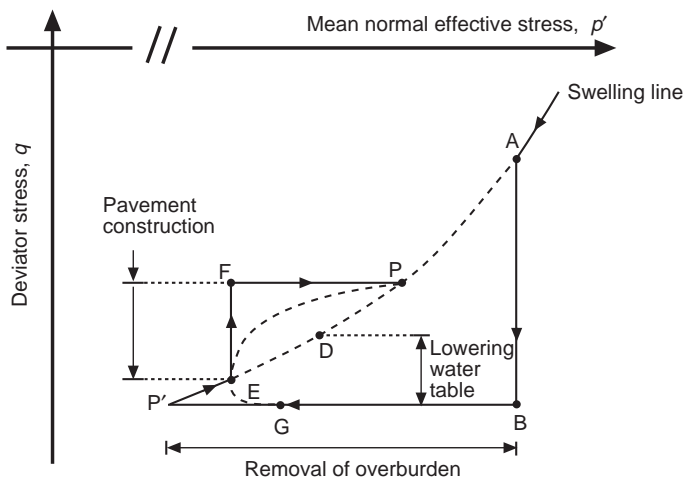

Fig. 35. Effects of construction operations on stress conditions in 'cut'

move from $\mathrm{B}$ towards $\mathrm{P}^{\prime}$. The extent to which it will approach $\mathrm{P}^{\prime}$ depends on the time scale and on the soil permeability and consolidation characteristics. It would be usual to install side drains to provide a lowering of the water table in a cutting. This process also takes time to become effective but would cause a reduction in pore pressure and an increase in effective stress along $\mathrm{P}^{\prime} \mathrm{E}$ towards $\mathrm{D}$. Construction of the pavement will almost certainly take place before point $\mathrm{D}$ is reached. This increases the overburden, say from $E$ to $F$ in terms of the deviator stress and, as the associated positive change in pore pressure dissipates, the effective stress will move towards equilibrium at $P$. In reality, because of the time needed for these water content changes to take place, the actual stress path during the entire construction operation is likely to be represented by the curved dotted line BGEP.

For soil which is cut, transported and compacted as fill in an embankment, the effective stress regime is rather different and less well understood. A suggested scenario is presented in Fig. 36. The scraper operation causes the soil to be taken to failure in an undrained state represented by $\mathrm{AB}$. The subsequent change in stress state will depend on the environment in which it is placed and compacted and on weather conditions. If conditions are dry and the soil is placed well above the water table, suctions will be high and the effective stresses will tend to increase to a point such as Q. If wet weather conditions pertain, the soil which is under suction will absorb water, reducing its effective stress and will move to a point such as $\mathrm{Q}^{\prime}$. Subsequently, equilibrium conditions which are likely to move it from $\mathrm{Q}^{\prime}$ towards $\mathrm{Q}$ will be established. This will be assisted by the addition of overburden through construction of the pavement. The nett effect of these operations is that the soil is likely still to be in an overconsolidated state but with a reduced overconsolidation ratio $p_{\mathrm{X}}^{\prime} / p_{\mathrm{Q}}^{\prime}$ compared with $p_{\mathrm{C}}^{\prime} / p_{\mathrm{A}}^{\prime}$ before excavation. 

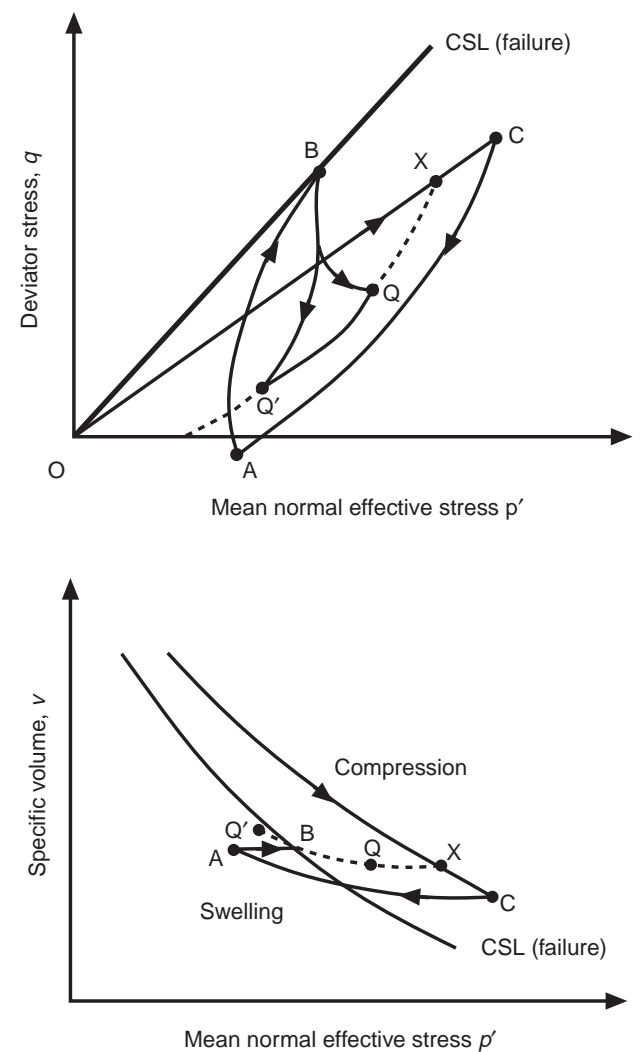

Fig. 36. Possible stress regime for construction in 'fill'
This discussion assumes that the soil remains in a saturated state throughout the sequence of events. While this may well be true for the cutting, on an embankment, the situation is less certain. Farrer (1979) reported pore pressures below the pavement in a $12 \mathrm{~m}$ high embankment of London clay. His measurements were consistent with the water table being at formation level four years after construction. This suggests that saturated conditions may be appropriate. Conceptually, it could be argued that the excavation and recompaction involve producing pieces of saturated soil which are then recombined into a saturated mass as a result of compaction. Even if some air is included, which seems likely, much of the soil mass will be in a saturated state and this assumption is appropriately conservative for design purposes.

Traffic stresses. A moving wheel load will result in a transient stress pulse being transmitted to the soil element. This might involve a change in total stress along a path such as PT in Fig. 37 for material at $\mathrm{P}$ in the cutting. Since the loading event is rapid, there will be no change in effective stress, so a transient pore press, $\delta u$, develops at peak stress. The effective stress follows the path PEP corresponding to the transient deviator stress of magnitude $q_{\mathrm{r}}$.

Soils are essentially elasto-plastic materials. Hence, the stress history for soil at $\mathrm{P}$ will have established a yield surface through $\mathrm{C}$, the preconsolidation stress, so that in the zone beneath this

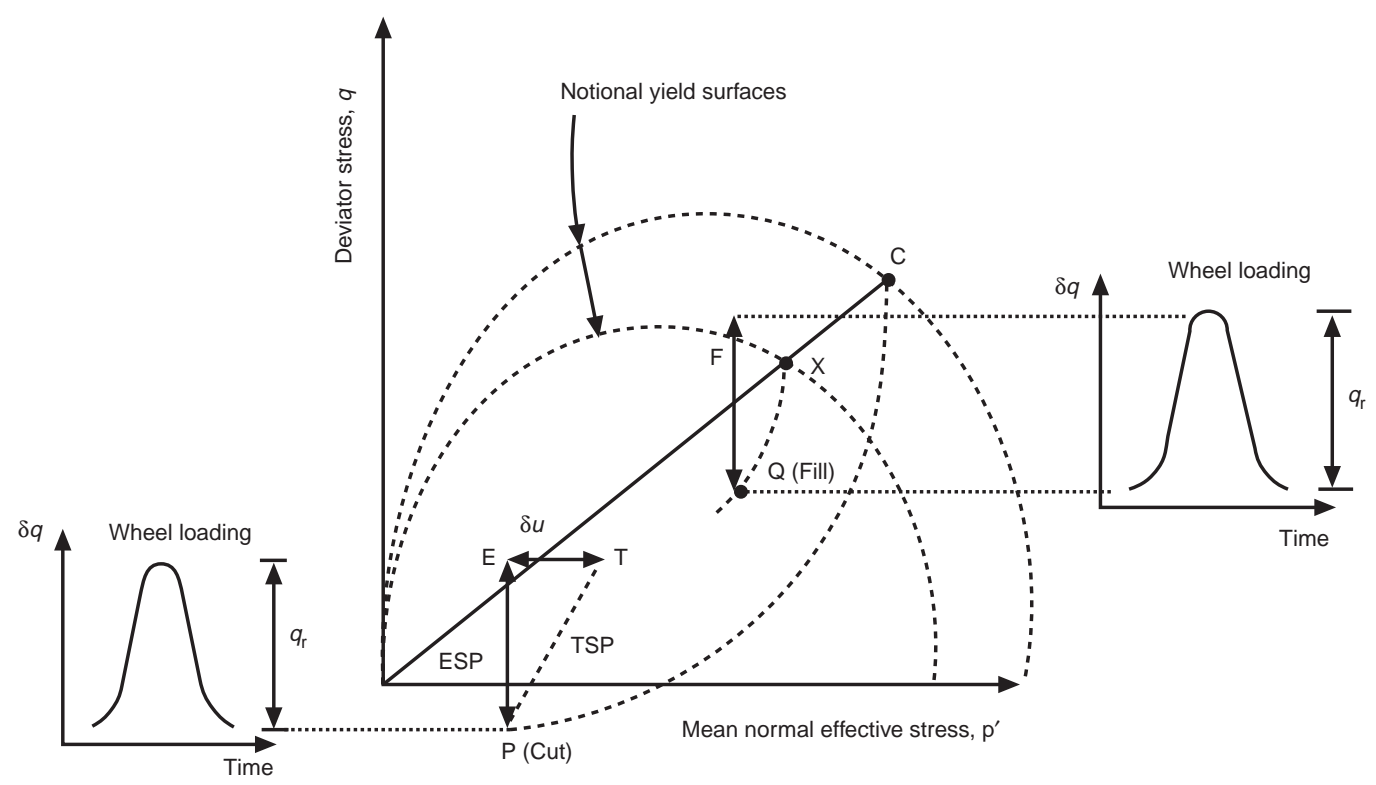

Fig. 37. Stress paths for wheel loading 
yield surface it should not develop plastic strains. Hence, the stress path PEP should result in soil behaving as a resilient material.

The soil on the embankment at point $\mathrm{Q}$ in Fig. 37 is much nearer to its associated yield surface. Hence, the same traffic induced stress, $q_{\mathrm{r}}$ will cause the effective stress to probe beyond the yield surface at $F$, resulting in some plastic strains developing.

An assumption of elasto-plastic behaviour is, however, too simple for dealing with transient load problems. O'Reilly et al., (1989) have demonstrated that silty clay responds in a viscous manner and that it is possible to apply transient stresses above the static yield surface without significant plastic strains developing immediately. However, under repeated loading, such strains may accumulate, their magnitude depending on the cyclic deviator stress amplitude.

A conceptual model was proposed which involves expansion of a viscous yield surface under repeated loading, the extent of the expansion depending on strain rate. These ideas represent an extension of the rate effects well known from monotonic tests on clays.

Further evidence of this type of behaviour under loading conditions relevant to pavements was reported by Brown et al., (1987) for overconsolidated silty clay. Reconstituted specimens were subjected to anisotropic compression in a triaxial cell leading to overconsolidation ratios of 6,12 and 18. These stress histories led to low effective stresses of 33-100 $\mathrm{kPa}$ representative of soil in cut below pavements. Traffic loading was simulated by applying $0.1 \mathrm{~s}$ deviator stress pulses with $0.25 \mathrm{~s}$ rest periods between. The specimens were tested undrained and careful pore pressure and deformation measurements were made using the equipment illustrated in Fig. 17.

The results indicated a possible threshold stress level, above which serious plastic strains accumulated and below which the strains and pore pressures were negligible. Fig. 38 illustrates this point for two specimens subjected to successive bursts of repeated loading at gradually increased deviator stress levels. These and related data showed that the threshold stress was at a deviator stress of 1.3 times the value of static yield over the range of initial effective stresses studied, supporting the concept of an expanding viscous yield envelope under repeated loading. This corresponds to a ratio of transient deviator stress to mean normal effective stress of about $1 \cdot 5$, recognizing that the initial deviator stress following consolidation was slightly negative (Figs 34 and 37).

A similar pattern emerged from the data obtained by Loach (1987) from repeated load triaxial tests on compacted specimens of three clays with degrees of saturation in excess of $85 \%$,

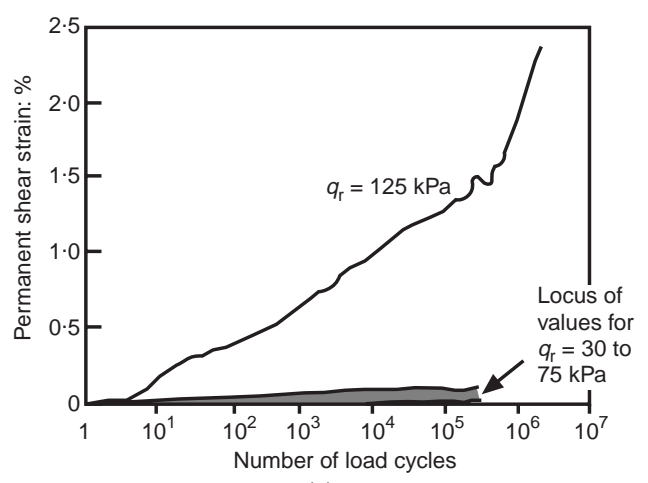

(a)

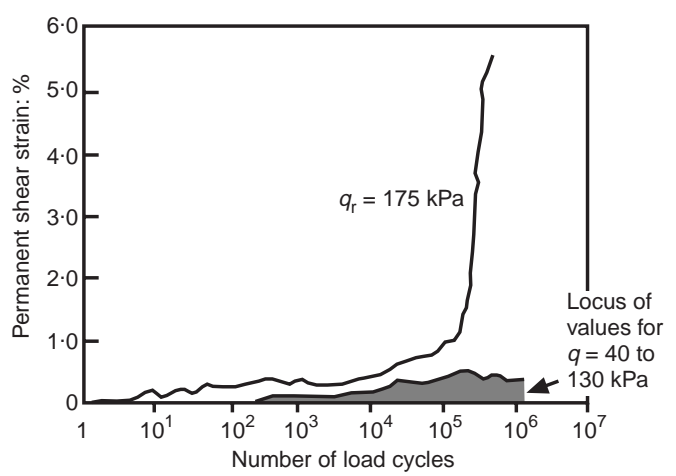

(b)

Fig. 38. Accumulation of plastic strain in reconstituted silty clay at $100 \mathrm{kPa}$ effective stress (after Brown et al., 1987): (a) overconsolidation ratio $=6$; (b) overconsolidation ratio $=18$

using apparatus similar to that shown in Fig. 19. While this study was principally concerned with resilient behaviour of the soils, the deviator stress at which permanent strains started to accumulate was recorded. These data are summarized in Fig. 39 showing the level of deviator stress as a function of the soil suction in each specimen.

These results suggest a simple design criterion

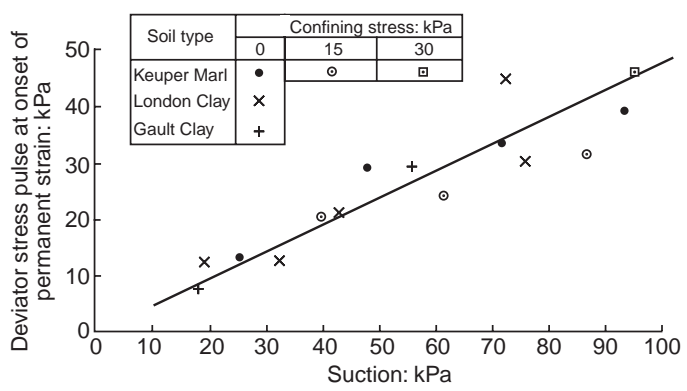

Fig. 39. Threshold deviator stress as a function of suction for three clays (after Loach, 1987) 
for subgrades to prevent any significant contribution to permanent deformation in the pavement. This would involve ensuring that the ratio of deviator stress to mean normal effective stress or soil suction was kept below a critical value. Brown \& Dawson (1992) used this approach for design and suggested a ratio of 2 for pavement foundations, recognizing that some plastic strain in the subgrade at this stage in the construction is permissible. They also noted that the reconstituted soil specimens (Brown et al., 1987) had been tested at a higher frequency than the compacted specimens (Loach, 1987), which will have influenced the result in view of the noted viscous behaviour.

Later, more extensive testing by Cheung (1994) on compacted clays using the apparatus shown in Fig. 19, produced data such as those shown in Fig. 40. These resulted from tests involving 1000 cycle bursts of repeated deviator stress at $2 \mathrm{~Hz}$ on compacted, unconfined specimens of Keuper Marl and London Clay, two of the soils tested by Loach (1987). The suction for the specimen featured in Fig. 40 was $44 \mathrm{kPa}$ leading to a threshold deviator stress, according to Loach, of $22 \mathrm{kPa}$. This point is seen to coincide with the sharp change in slope of the line in Fig. 40. However, not all of Cheung's data demonstrated this clear change in slope.

Cheung used an alternative approach to design suggesting that the plastic strain after 1000 cycles should be limited to $1 \%$. The deviator stress causing this $\left(q_{\mathrm{t}}\right)$ was related to soil suction, yielding ratios of $q_{\mathrm{t}} / \mathrm{s}$ of 0.8 for Keuper Marl, $\left(w_{\mathrm{L}}=33.7 \%, \quad w_{\mathrm{p}}=17 \cdot 6 \%\right), 0.4$ for Bothkennar clay $\left(w_{\mathrm{L}}=54.3 \%, w_{\mathrm{p}}=25.1 \%\right)$ and 0.5 for London Clay $\left(w_{\mathrm{L}}=76 \%, w_{\mathrm{p}}=25 \cdot 2 \%\right)$. The range of soil suction for Cheung's specimens was $20-80 \mathrm{kPa}$.

These various triaxial test results suggest that the allowable transient deviator stress is a function of the effective stress state of the soil. Since the initial stress state, particularly for compacted soil, is uncertain, precise application of these data is

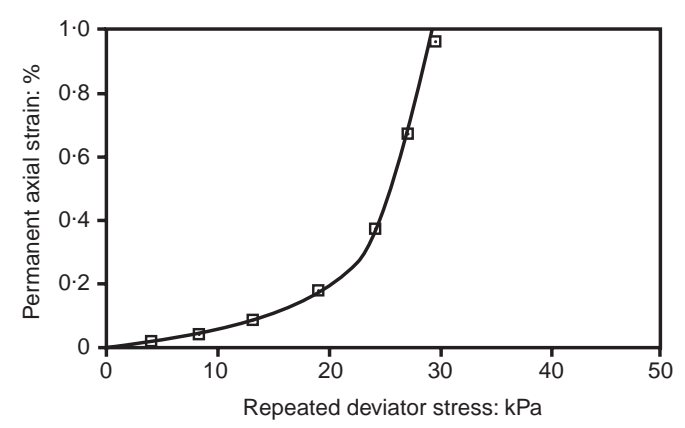

Fig. 40. Plastic strain after 1000 cycles against repeated deviator stress for compacted silty clay (after Cheung, 1994) difficult. However, a pragmatic approach is suggested in the final section of this paper. If the actual value of accumulated plastic shear strain after $N$ cycles is required, Cheung proposed the following relationship based on testing up to 1000 cycles

$$
\varepsilon_{\mathrm{p}}(N)=A\left(\frac{q_{\mathrm{r}}}{s}\right)^{b}(\log N+B)
$$

where $A, b$ and $B$ can be defined for the particular soil. Although equation (5) is only valid for relatively few load applications, this could still be of use in pavement foundation design where the number of construction traffic movements is limited.

Much more research has been devoted to the measurement of resilient soil properties under repeated loading. The parameter, resilient modulus, was introduced by Seed et al. (1962) and defined as repeated deviator stress divided by recoverable (resilient) axial strain in the triaxial test. They demonstrated that it varied with the magnitude of the repeated deviator stress, as shown in Fig. 41. Later work by Dehlen \& Monismith (1970) showed that suction also had an important influence. The first attempt to relate resilient modulus to the effective stress was reported by Brown et al. (1975) who, working with reconstituted silty clay, obtained the data in Fig. 42 for a range of initial specific volumes, overconsolidation ratios and initial effective stresses. These data were used to deduce the empirical relationship:

$$
E_{\mathrm{r}}=K\left(\frac{p_{0}^{\prime}}{q_{\mathrm{r}}}\right)^{n}
$$

where $K$ and $n$ depend on the soil type, $p_{0}^{\prime}$ is the initial mean normal effective stress and $q_{\mathrm{r}}$ is the

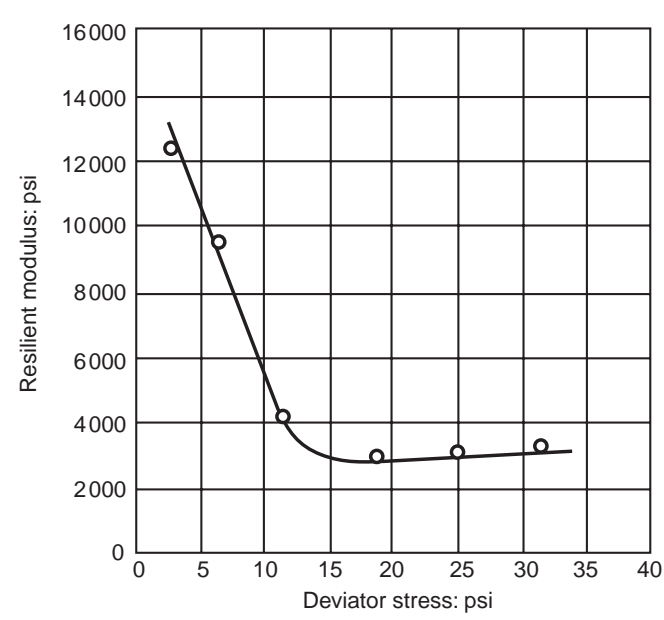

Fig. 41. Relationship between resilient modulus (after $10^{5}$ repetitions) and repeated deviator stress for a silty clay (after Seed et al., 1962) 


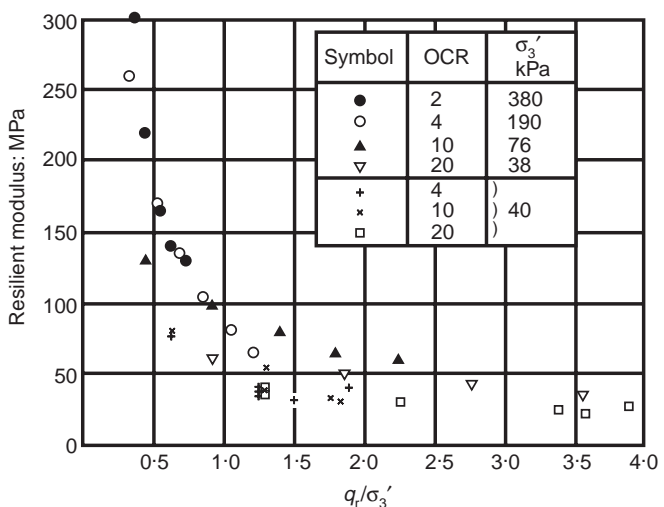

Fig. 42. Resilient modulus of reconstituted silty clay as a function of stress condition (after Brown et al., 1975)

repeated deviator stress. For saturated, undrained conditions, $E_{\mathrm{r}}=3 G_{\mathrm{r}}$ where $G_{\mathrm{r}}$ is the resilient shear modulus.

The more accurate experiments reported by Brown et al. (1987) using the apparatus shown in Fig. 17 yielded a slightly different empirical model of the form

$$
G_{\mathrm{r}}=\frac{q_{\mathrm{r}}}{C}\left(\frac{p_{0}^{\prime}}{q_{\mathrm{r}}}\right)^{m}
$$

where $C$ and $m$ depend on the soil type.

This was developed for $\left(q_{\mathrm{r}} / p_{0}^{\prime}\right)$ values between $0 \cdot 2-0 \cdot 6$ and resilient shear strains from $100-500$ microstrain $(0 \cdot 01-0 \cdot 05 \%)$. An important feature of these relationships is that they emphasize the importance of the stress ratio $\left(q_{\mathrm{r}} / p_{0}^{\prime}\right)$ and are independent of overconsolidation ratio and specific volume.

Experiments conducted on compacted specimens of the same silty clay, together with Gault Clay and London Clay using the simpler apparatus in Fig. 19 demonstrated that equation (7) for resilient shear modulus was applicable with $p_{0}^{\prime}$ replaced by suction (Brown et al. 1987).

This model reflects the non-linear resilient behaviour of clays and, when applied to pavement analysis, demonstrates a sharp increase in stiffness with depth as shown in Fig. 43 taken from Brown et al., (1987). It is also able to model the influence of water table position. Its main shortcoming is that unrealistically high values of resilient modulus are predicted at low deviator stresses. Dawson and Gomes Correia (1993) suggested an improved expression for resilient modulus as follows

$$
E_{\mathrm{r}}=D+E p_{0}^{\prime}-F q_{\mathrm{r}}
$$

in which $D, E$ and $F$ can be determined from the test data. Fig. 44 indicates the quality of fit for a set of tests on compacted London Clay. By examining Brown et al.'s data for Keuper Marl, London Clay and Gault Clay, together with data on Kaolin from

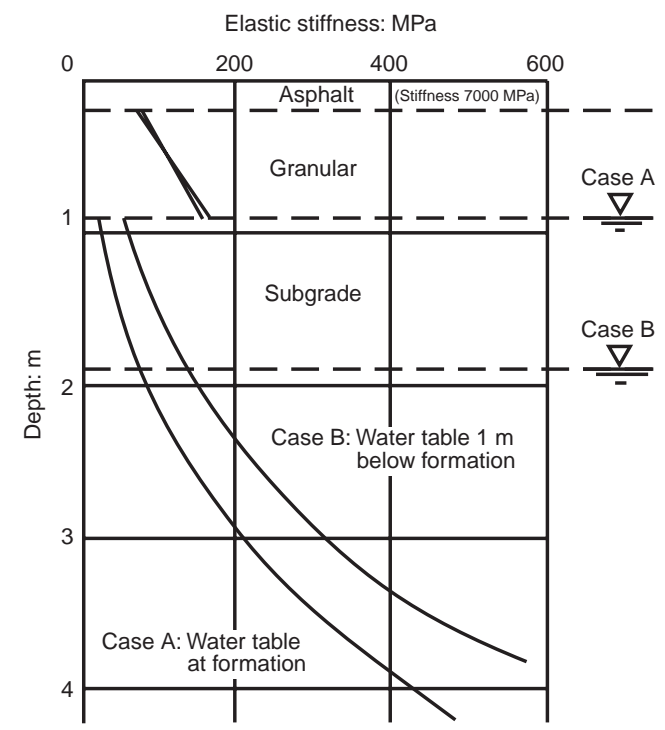

Fig. 43. Computed variations of resilient modulus with depth (after Brown et al., 1975)

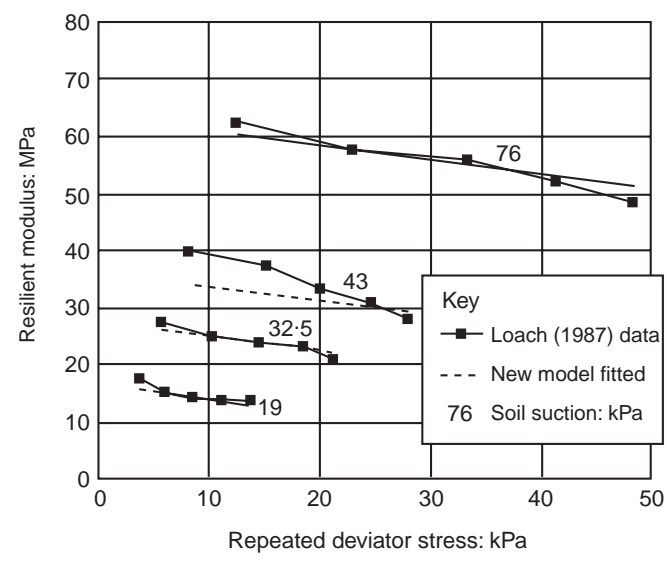

Fig. 44. Comparison of 'model' and data for resilient modulus of London Clay (after Dawson \& Correia, 1993)

Gomes Correia (1985), they were able to suggest an approximate general equation to estimate resilient modulus from the stress conditions and the plastic limit $w_{\mathrm{p}}$ as follows:

$$
E_{\mathrm{r}}=49200+950 p_{0}^{\prime}-370 q_{\mathrm{r}}-2400 w_{\mathrm{p}}
$$

in which $E_{\mathrm{r}}, p_{0}^{\prime}$ and $q_{\mathrm{r}}$ are in $\mathrm{kPa}$ and $w_{\mathrm{p}}$ is a percentage. The equation is compared with experimental data in Fig. 45 and applies only for resilient modulus values up to $80 \mathrm{MPa}$, which covers the practical range for clay subgrades in the UK. In the case of compacted clays, $p_{0}^{\prime}$ is taken as the soil suction. 


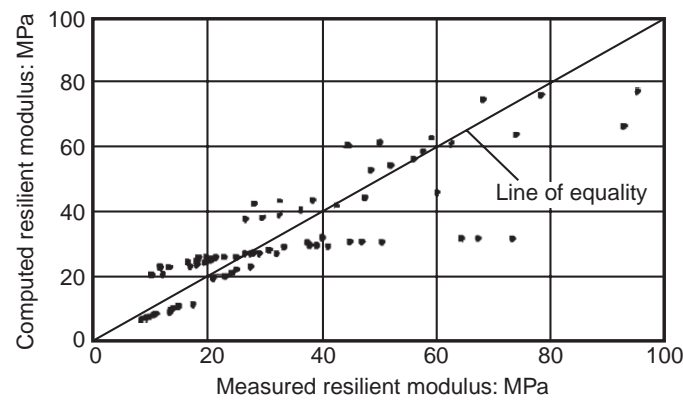

Fig. 45. Predicted against measured values of resilient modulus for clays (after Dawson \& Correia, 1993)

In other branches of geotechnical engineering, stress-strain non-linearity is expressed in terms of a relationship between a normalized shear modulus and shear strain. The normalizing parameter is the value of shear modulus $G_{0}$ at very low strains, that is, the maximum practical value.

Roblee et al., (1994) published the relationships shown in Fig. 46 drawn from cyclic loading tests largely associated with earthquake-related research Vucetic and Dobry (1991); Sun et al. (1988). The relationship between $G / G_{0}$ and cyclic shear strain is shown to depend on the plasticity index of the soil. Various proposals have been made for estimating $G_{0}$ for clays including

(a) Hardin \& Drnevich (1972) who gave it as a function of void ratio, overconsolidation ratio and mean normal effective stress

(b) Weiler (1988), who presented $G_{0}$ as proportional to undrained shear strength, the constant of proportionality depending on plasticity index

(c) Viggiani \& Atkinson (1995) who used the equation

$$
\frac{G_{0}}{p_{\mathrm{a}}}=H\left(\frac{p_{0}^{\prime}}{p_{\mathrm{a}}}\right)^{n} R_{0}^{s}
$$

in which $p_{\mathrm{a}}$ is a reference stress, such as atmos-

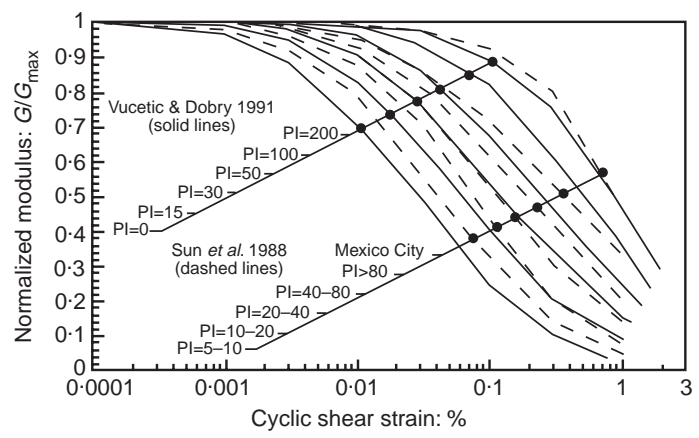

Fig. 46. Relationships between shear modulus and shear strain (after Roblee et al., 1994) pheric pressure, $R_{0}$ is overconsolidation ratio, and $H, n$ and $s$ are constants which may be estimated from the plasticity index.

Experimental techniques have also been used to measure shear modulus at very low strains, most commonly using the resonant column apparatus. Viggiani \& Atkinson (1995) present results from experiments involving piezoelectric bender elements. These allow shear waves to be transmitted through a triaxial test specimen and the velocity of propagation $V_{\mathrm{s}}$ to be measured. The maximum shear modulus is thus calculated from:

$$
G_{0}=\rho V_{\mathrm{s}}^{2}
$$

where $\rho$ is soil density.

In using these general relationships at strains other than very low values, it is necessary to distinguish between the shear modulus for monotonic loading and that for cyclic or rapidly repeated loading. At very low strains, the soil behaves in an essentially elastic manner, so the mode of loading is unimportant.

The stress dependent expression for resilient modulus, equation (7) should be consistent with the strain dependence shown in Fig. 46 if the data are reanalysed. The experiments reported by Brown et al., (1987) involved overconsolidation ratios of 6, 12 and 18 and initial mean normal effective stresses of 33, 65 and $100 \mathrm{kPa}$. Repeated loading was then conducted, undrained, with various levels of deviator stress. Using the data presented by Viggiani \& Atkinson (1995) the values of $G_{0}$ for the extreme cases of $R_{0}=6, p_{0}^{\prime}=100 \mathrm{kPa}$ and for $R_{0}=18, p_{0}^{\prime}=33 \mathrm{kPa}$ were calculated using the plasticity index of $19 \%$ reported by Brown et al. for their silty clay.

Equation (7) was based on curve fitting the data in Fig. 47 using a set of strain contours. For this soil, the relationship is

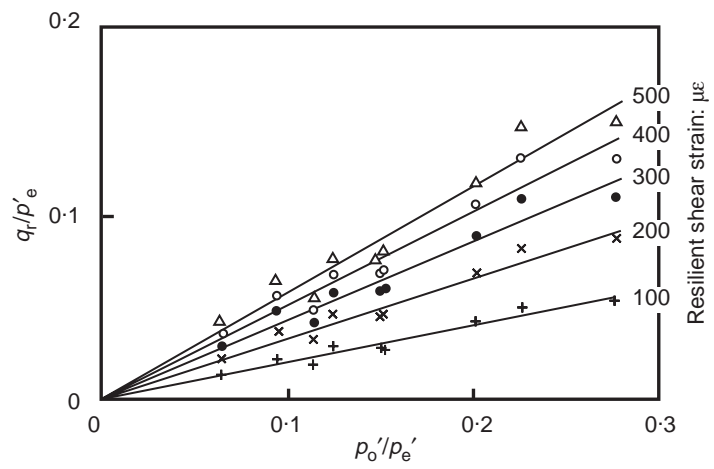

Fig. 47. Contours of resilient strain for reconstituted, overconsolidated silty clay (after Brown et al., 1987). $\left[p_{\mathrm{e}}{ }^{\prime}=\right.$ equivalent pressure (Schofield and Wroth, 1968)] 


$$
\varepsilon_{\mathrm{sr}}=1.11 \times 10^{-3}\left(\frac{q_{\mathrm{r}}}{p_{0}^{\prime}}\right)^{1.52}
$$

Since

$$
\begin{aligned}
G_{\mathrm{r}} & =\frac{q_{\mathrm{r}}}{3 \varepsilon_{\mathrm{sr}}} \\
G_{\mathrm{r}} & =\frac{29 \cdot 3 p_{0}^{\prime}}{\varepsilon_{\mathrm{sr}}^{0.34}}
\end{aligned}
$$

and

$$
\frac{G_{\mathrm{r}}}{G_{0}}=\frac{p_{0}^{\prime}}{58} \frac{1}{R_{0}^{0.2}} \frac{1}{\varepsilon_{\mathrm{sr}}^{0.34}}
$$

For the two stress history cases considered, and changing resilient shear strain $\varepsilon_{\mathrm{sr}}$ to resilient engineer's strain $\left(\gamma_{\mathrm{r}}\right)$, the parameter normally used, yields

$$
\frac{G_{\mathrm{r}}}{G_{0}}=\frac{0 \cdot 26}{\gamma_{\mathrm{r}}^{0.34}} \text { for } R_{0}=6, \quad p_{0}^{\prime}=100 \mathrm{kPa}
$$

and

$$
\frac{G_{\mathrm{r}}}{G_{0}}=\frac{0 \cdot 15}{\gamma_{\mathrm{r}}^{0.34}} \text { for } R_{0}=18, \quad p_{0}^{\prime}=33 \mathrm{kPa}
$$

in which $\gamma_{\mathrm{r}}$ is in $\%$ strain.

In Fig. 48 these relationships are plotted to indicate the range of Brown et al.'s results. A predicted relationship based on the data in Fig. 46 accumulated by Roblee et al., (1994) for a plasticity index of $19 \%$ is shown for comparison. It is seen to pass through the centre of the range defined by Loach's model for his experiments. An attempt was also made to use the Hardin \& Drnevich method to estimate $G_{0}$ for Loach's soil but this led to unrealistically high values.

The philosophy of expressing shear modulus in terms of deviator stress or shear strain is worth examining. In pavement engineering, the soil is subjected to a stress-controlled environment except for situations below very stiff pavements. This means that the strain which develops in the soil depends on the applied stress and the soil stiffness.

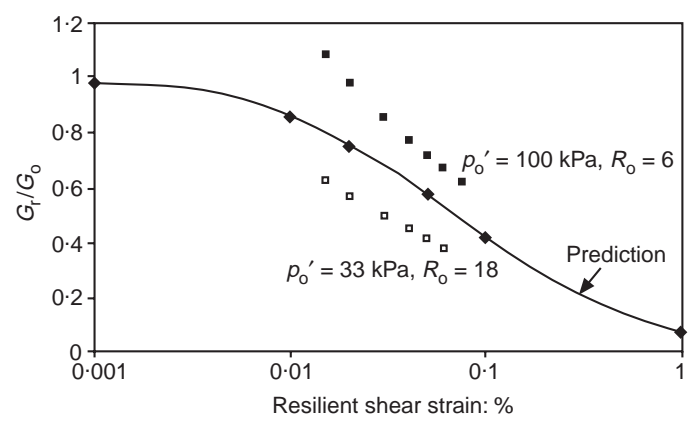

Fig. 48. Comparison of Loach model for resilient modulus with data from elsewhere
In earthquake engineering, from which the use of shear strain as the independent variable originates, the problem is one of strain control. This arises because the soil deposit is being deformed by the earthquake movements of the rock below and, in this case, the stress level is a function of the applied strain and the soil stiffness.

\section{Properties of the granular layers}

The resilient behaviour of granular material has been shown to be of prime importance for pavement analysis, both in connection with foundation design and for completed constructions. For these materials, both volumetric and shear strains need to be quantified since volume change will generally occur under repeated loading unless the degree of saturation is very high. Most of the research used to define the non-linear stressresilient strain behaviour of granular materials has used the dry state. Repeated load triaxial tests with the apparatus in Fig. 18 (Pappin \& Brown, 1980) generated the contours of shear and volumetric strain shown in Fig. 49 which formed the basis for defining stress-dependent bulk and shear moduli.

Noting that increments of deviator stress can cause volumetric strain and of mean normal stress can cause shear strain, Boyce (1980) used the theorem of reciprocity, implying:

$$
\frac{\partial \varepsilon_{v}}{\partial q}=\frac{\partial \varepsilon_{\mathrm{s}}}{\partial p^{\prime}}
$$

This led to the definition of expressions for resilient bulk $K_{\mathrm{r}}$ and shear $G_{\mathrm{r}}$ moduli as follows

$$
\begin{aligned}
K_{\mathrm{r}} & =\frac{K_{1} p^{\prime(1-c)}}{1-\beta\left(q / p^{\prime}\right)^{2}} \\
G_{\mathrm{r}} & =G_{1} p^{\prime(1-c)}
\end{aligned}
$$

where $\beta=(1-c) K_{1} / G_{1}$ and the parameters $K_{1}, G_{1}$ and $c$ need to be determined experimentally.

This model and the contours in Fig. 49 predict dilatant behaviour at high values of deviator stress. Lytton (1995) comments that this tendency for increase in resilient volumetric strain generates an increase in mean normal effective stress in a granular layer under load. This effectively 'prestresses' the material, inhibiting the development of tensile stresses and mobilizing higher stiffnesses.

Although Boyce's model satisfies the laws of thermodynamics, it does not fit experimental data as convincingly as design engineers might require. Jouve \& Elhannani (1993) proposed a more general model derived from Boyce's work, in which the elastic potential implied by the expression for $\beta$ was replaced, since its use did not conform with experimental evidence. However, the 


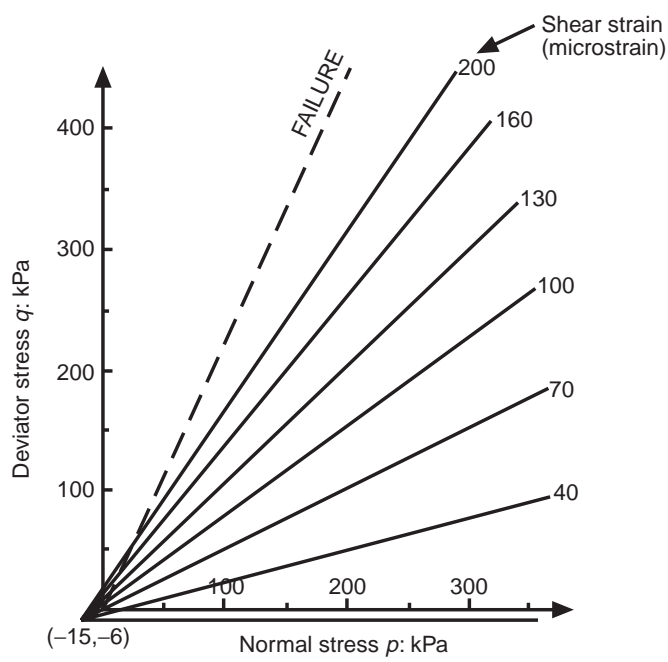

(a)

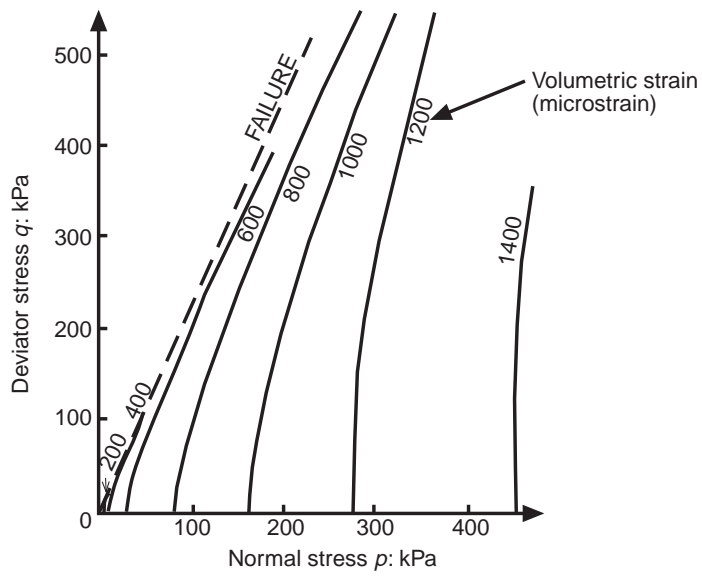

(b)

Fig. 49. Strain contours for crushed carboniferous limestone (after Pappin \& Brown, 1980): (a) normalized shear strain; (b) volumetric strain

modified model, which also allowed for anisotropic behaviour, required four or five parameters to be quantified. Sweere (1990) also suggested a practical modification to the Boyce model by allowing the exponent $c$ in equations (19) and (20) to be different for $K_{\mathrm{r}}$ and $G_{\mathrm{r}}$ and by removing the relationship between $\beta$ and the other parameters. This increases the number of parameters to be determined from three to five but gives a better fit to experimental data.

Because the modelling of resilient behaviour for granular materials is complex, simplified approaches have been adopted for design. The most trivial involves constant Poisson's ratio, usually $0 \cdot 3$, and a resilient modulus given by

$$
E_{\mathrm{r}}=H p^{\prime d}
$$

where $H$ and $d$ are constants for the material, or, in its more popular version, known as the $K-\theta$ model

$$
E_{\mathrm{r}}=K_{1} \theta^{K_{2}}
$$

where $K_{1}$ and $K_{2}$ are the constants and $\theta=3 p^{\prime}$.

This simple approach cannot be realistically used to compute stress conditions in a granular layer or a sand subgrade. However, it is of use for modelling a granular layer when effects in the bituminous material or the soil below are of interest. Equations (21) and (22) could be regarded as a lower bound to data of the type shown in Fig. 50 where the effects of both deviator stress and mean normal effective stress are illustrated. If resilient properties are defined in terms of the parameter $E_{\mathrm{r}}$, then a corresponding value of Poisson's ratio is required which should itself be stress-dependent as noted by Sweere (1990), although, in practice, a constant value, usually $0 \cdot 3$, is used.

An important aspect of the contours in Fig. 49 is the dependence on stress ratio $\left(\eta=q / p^{\prime}\right)$ which it emphasizes. This is in keeping with the frictional characteristics of the material and reflects similar behaviour to that observed for clays as illustrated in Fig. 47.

The models for resilient strain noted above are based on a pragmatic approach to pavement design in which the peak to peak values of stress and strain are considered. They ignore the detailed relationships within individual cycles. This is justified on the basis that the pavement problem is one in which very large numbers of cycles are involved and analysis at the micro level is of less importance than for problems involving small numbers of cycles. Reference should be made to O'Reilly (1985) and Pappin et al., (1992) for consideration of hysteresis effects and changes of stiffness within cycles based on experiments with dry granular materials.

Shaw \& Brown (1988) demonstrated that the 'contour model' behaviour of Fig. 49 developed from data in the axisymmetric triaxial test con-

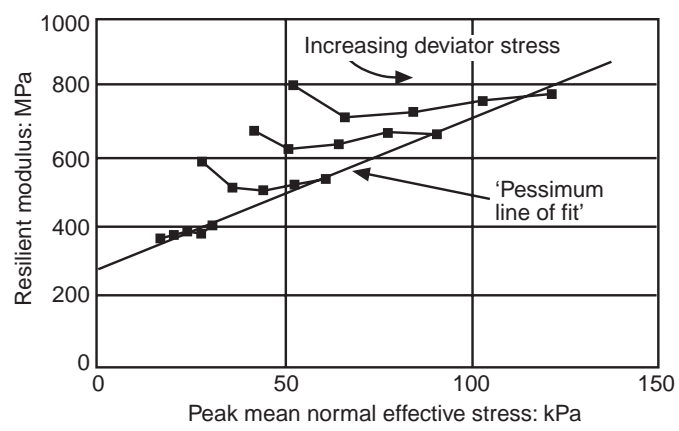

Fig. 50. Resilient modulus for crushed dolomitic limestone as a function of applied stresses 
figuration could be used successfully to predict resilient response in a biaxial apparatus. This involved the application of two independent principal stresses and was built to study the response of scaled-down railway ballast under conditions appropriate to the repeated loading and subsequent tamping operations to which such material is exposed.

Pappin et al. (1992) showed that the resilient response modelled for dry granular material is equally applicable to saturated and partially saturated conditions, provided the principle of effective stress is observed. In practice, estimation of the effective stress state in a pavement granular layer may not be straightforward.

Another factor to be considered in extrapolating triaxial test conditions to those in a pavement is the rotation of principal planes associated with shear stress reversal under a rolling wheel load (Figs 14 and 15). Using the Hollow Cylinder Apparatus (Fig. 16), Chan (1990) demonstrated that resilient strains were unaffected by this phenomenon. He also showed that the principal planes of strain remained coincident with those of stress. These findings are helpful in that they support the use of an invariant approach for pavement analysis and the use of relatively simple resilient strain models derived from triaxial tests rather than more complex apparatus.

It should be noted that, in general, the prediction of volumetric strain through the models discussed above is less satisfactory than that of shear strain.

The accumulation of plastic strain under repeated loading of granular materials has received relatively less experimental attention than the resilient strain-stress relationships. This is partly because the experiments are inherently destructive and many more specimens need to be tested to acquire adequate data compared with the lower stress level, essentially non-destructive, resilient strain tests for which multiple stress paths can be applied to a single specimen generating extensive data.

The threshold stress concept discussed for clays also appears appropriate for granular materials. The data of Boyce (1976) and of Pappin (1979) demonstrated that insignificant plastic strains develop if the peak stress ratio in repeated loading remains below $70 \%$ of static failure. Fig. 51 contrasts results for three stress paths with varying peak values and lengths taken from Pappin (1979). $\mathrm{He}$ demonstrated that the accumulation of plastic shear strain $\varepsilon_{\mathrm{sp}}$, after the first 100 cycles followed a relationship of the form

$$
\varepsilon_{\text {sp }}=\mathrm{f}(N) l_{\mathrm{r}}(\hat{\eta})^{t}
$$

in which $\mathrm{f}(N)$ depends on the number of load applications, $l_{\mathrm{r}}$ is the stress path length and $\hat{\eta}$ is

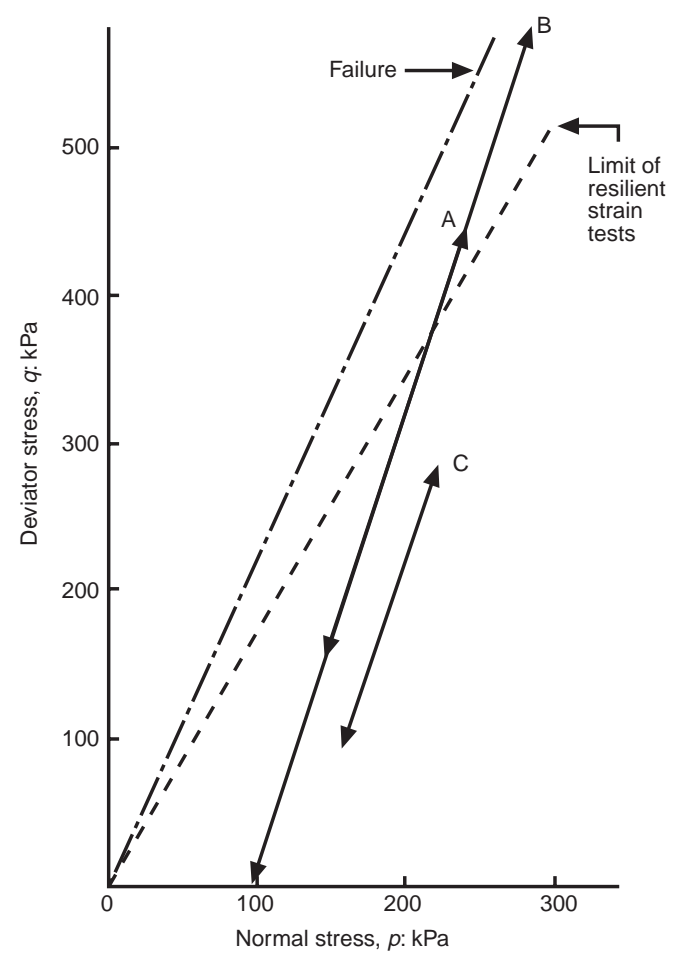

(a)

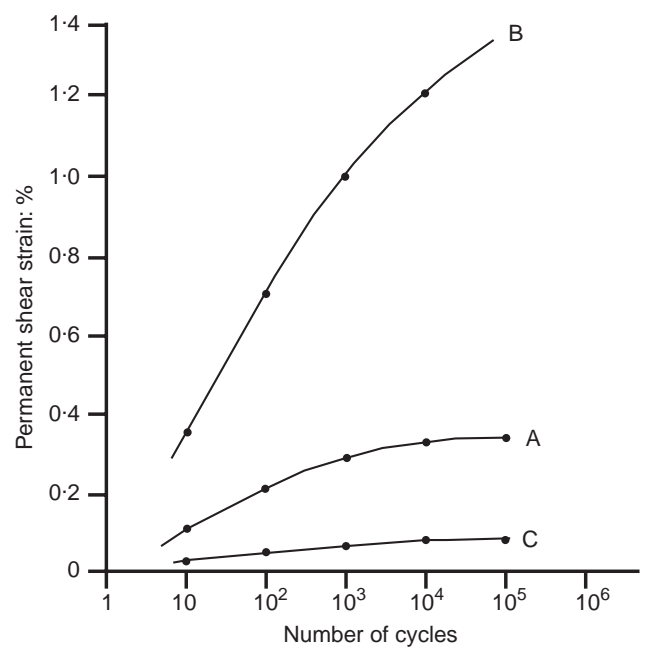

(b)

Fig. 51. Accumulation of plastic strain in crushed carboniferous limestone (after Pappin, 1979): (a) repeated stress paths applied; (b) plastic strain development

the peak ratio of deviator stress to mean normal effective stress. The parameter $t$ is dependent on the material under test. The first 100 cycles produced variable results and were regarded as a settling-in phase of the tests. It was considered more important 
to try to model the strain accumulation under the large numbers of cycles relevant to pavement loading. Pappin's results did not produce a corresponding expression for volumetric plastic strain.

Paute et al., (1993) describe the procedures derived from Pappin's work which are used in France to characterize permanent strains for granular materials. Only axial permanent strain is considered. Their data showed an experimental relationship between strain rate $\dot{\varepsilon}_{1 \mathrm{p}}$ (strain per cycle) and number of cycles which they expressed as

$$
\ln \dot{\varepsilon}_{1 \mathrm{p}}=a+b \ln N
$$

For plastic strain developed after 100 cycles $\left(\varepsilon_{\mathrm{p} 1}^{*}\right)$, this becomes

$$
\stackrel{*}{\varepsilon_{\mathrm{p} 1}}=A\left[1-(N / 100)^{-B}\right]
$$

where $B$ is positive.

The parameter $A$ was shown to relate to the peak applied stress ratio $\eta$ as follows

$$
A=\frac{\eta}{c-d \eta}
$$

in which $c$ and $d$ are constant for the material and $c / d=\eta_{\mathrm{f}}$, the stress ratio at failure. This hyperbolic relationship is similar to that proposed by Lentz \& Badady (1980) for sands. Equation (26) implies that as $\eta$ approaches failure, $A$, and therefore the accumulated strain, become very large.

Although empirical models have been developed to match the measured data for repeated load triaxial tests on granular materials, in particular cases, testing is still needed to determine the various parameters. The models therefore only provide a framework within which experience suggests that the data may be interpreted. Thom \& Brown (1988) proposed a series of stress paths that could be applied to evaluate routinely both resilient and plastic strain characteristics. These are illustrated in Fig. 52 and show 19 stress paths to deal with resilient response, all of which involve peak values below the threshold, and a single, 20th, path to characterize plastic strain. Finally, unless failure has developed under repeated loading, a monotonic test can follow to measure shear strength. About 20 cycles on each of the paths for resilient strain are adequate, while the more damaging paths for plastic strain could be applied for $10^{4}-10^{5}$ cycles. A frequency of $1 \mathrm{~Hz}$ is appropriate.

Chan's (1990) experiments with the Hollow Cylinder Apparatus demonstrated that shear reversal (rotating principal planes) does influence plastic strain accumulation under repeated loading. This is illustrated by the data in Fig. 53 from Chan \& Brown (1994) showing the increased rate of strain when shear reversal is introduced to a specimen initially subjected to triaxial stress conditions.

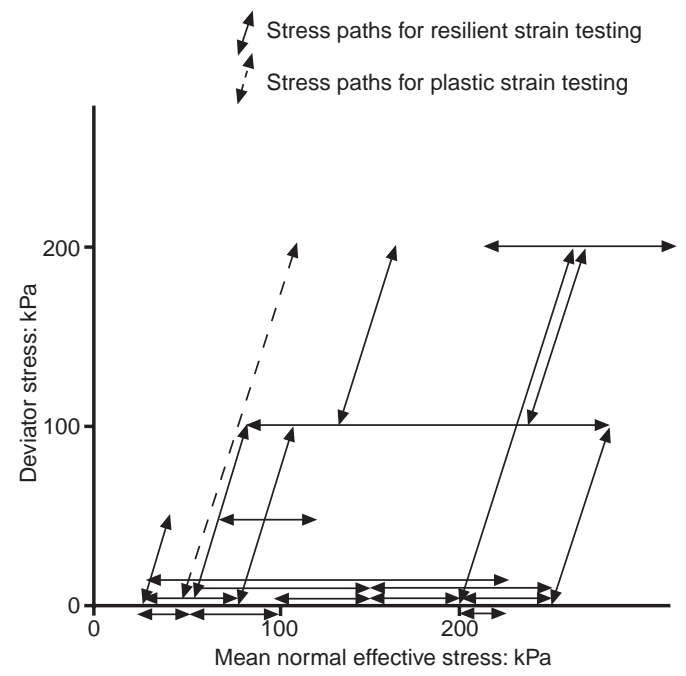

Fig. 52. Suggested repeated stress paths for testing granular material (after Thom \& Brown, 1988)

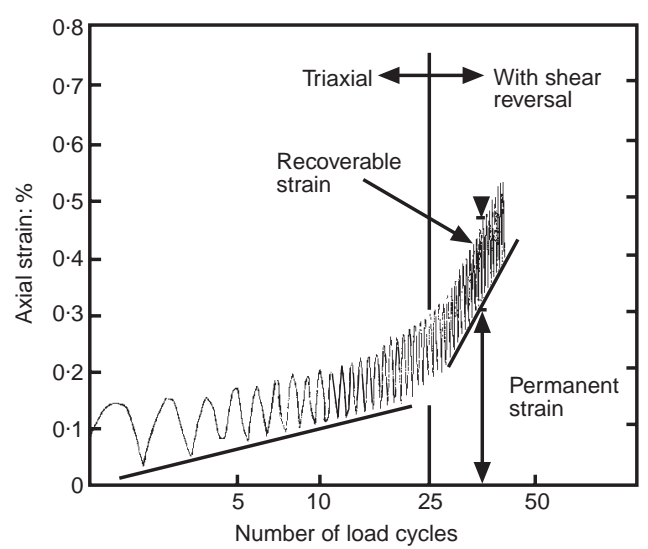

Fig. 53. Influence of shear stress reversal on accumulation of plastic strain in a dry crushed rock (after Chan \& Brown, 1994)

Brown \& Chan (1996) have shown that there is a difference between unidirectional and bidirectional shear reversal (representing one-way and two-way wheel loading respectively), the former leading to lower strains than the latter and hence smaller rut depths. Their work was based on both HCA and wheel tracking tests.

\section{PAVEMENT DESIGN DEVELOPMENTS \\ The CBR method}

Background. The most influential early work on pavement design and associated soil testing was carried out by the California Division of Highways. Porter (1938) presented early recommendations for pavement layer thicknesses, based on 
experience and the use of bearing value and expansion tests. The former, developed in 1929 and illustrated in Fig. 54, concerned resistance to displacement of the soil under wheel loading and the latter to volume increase on wetting. The bearing value test later became known as the California Bearing Ratio (CBR) test and is still universally used to test soils and granular materials by highway laboratories. It is worth examining how this empirical index test became so widely used and so strongly established in practice. Porter (1938) noted:

'... that the bearing values are not a direct measure of the supporting value of materials' and later, (Porter, 1950): ... 'the results are influenced only to a minor degree by elastic deformation'.

Shortly after Francis Hveem became the materials engineer for the state of California, the CBR test was phased out there and a much more rational approach adopted. This occurred between 1944 and 1947 (Vallerga, 1996) and was described in two major papers (Hveem \& Carmany, 1948; Hveem, 1955) which have remained classics.

Meanwhile, the US Army Corps of Engineers decided to adopt the CBR method of design during World War II in order to meet the challenges posed by new requirements for airfield pavements. They needed something practical, so extended the highway design curves to cope with the higher wheel loads applied by aircraft. Elastic theory was

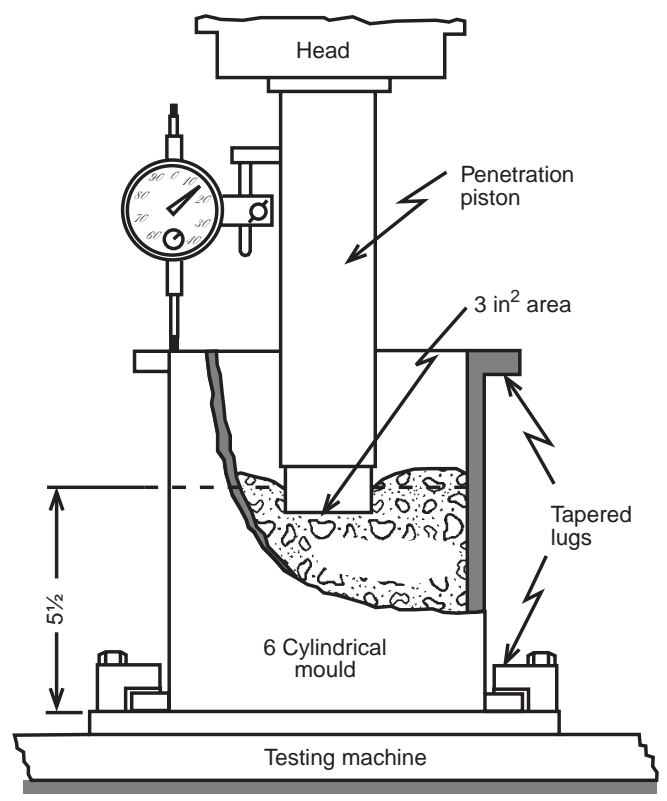

Fig. 54. Apparatus for Soil Bearing Test (after Porter, 1938) used by Middlebrooks \& Bertram (1950) since they appreciated that elastic deformations were important. The stress tables published by Jürgensen (1934) helped them to back-calculate shear stresses in the subgrade to deduce allowable values. Their layer thickness adjustments were confirmed by field loading trials and independent computations using different approaches.

Turnbull (1950) commented on the CBR test:

'... [it] is essentially a simple shear test and the CBR is an index of shearing strength'.

He noted that the CBR design curves gave a total thickness of pavement to prevent shear deformation in the soil.

The closing discussion of the ASCE Symposium that described these developments (ASCE, 1950) emphasized that the design curves were for operational runways to last 'days and weeks not years'. It is clear from this symposium that the CBR test was regarded as an index test for shear strength and that the design principles were based on prevention of subgrade shear failure in pavements with thin surfacings. The use of elastic theory ignored the stiffness of the bituminous surface and no repeated loading or resilient effects were considered. A serious constraint to the development of a proper theoretical treatment was the absence of solutions to the analytical problem posed by the layered pavement construction. Although Burmister (1943) developed the theory in 1943, it was not until Fox (1948) published his tables of solutions in 1948 that the first useful numbers became available.

In the UK, the American developments were taken seriously. Davis (1949) describes how the Road Research Laboratory (RRL) adopted the CBR method of design. He and Professor Skempton reanalysed the US Army Corps of Engineers' field trials data to assess the viability of the US design curves. The performance of UK roads at seven sites also helped with this process.

The CBR method was gradually adopted in the UK and elsewhere. It formed the basic method of pavement design in practice and, though refined over the years, is still very widely used. In the UK, the original thickness curves have been replaced but the CBR test remains as the recommended method for characterizing subgrades. Current practice is described in Volume 7 of the Design Manual for Roads and Bridges (Highways Agency, 1994b). Foundation layer thicknesses are empirically determined from simple charts based on subgrade CBR which may be estimated from plasticity data, approximate water table position, 'construction conditions' and choice of 'thick' or 'thin' pavement. An analytical approach may be used as an alternative and a 'stiffness modulus' for the subgrade can be estimated from the CBR using 
an empirical equation reported by Powell et al., (1984)

$$
E=17 \cdot 6 \mathrm{CBR}^{0.64} \mathrm{MPa}
$$

In view of the earlier observations, quoted above, to the effect that CBR relates to shear strength, confirmed in some detail by Black (1962), it is surprising that is should be used to estimate what is effectively the resilient modulus $E_{\mathrm{r}}$ of the soil. Brown et al., (1990) demonstrated that $E_{\mathrm{r}}$ was not a simple function of CBR but depended on soil type and the applied deviator stress level. Their results are summarized in Fig. 55. In Fig. 55(a), the dependence of the relationship on deviator stress for Keuper Marl is clear. In Fig. 55(b) results for three soils at a deviator stress of $40 \mathrm{kPa}$ are compared with equation (27) and the simpler, $M_{\mathrm{r}}=10 \mathrm{CBR}(\mathrm{MPa})$, frequently used in design. Sweere (1990) could find no correlation between the CBR and resilient modulus for a range of granular materials.

The research on subgrades which forms the background to current UK practice is reviewed

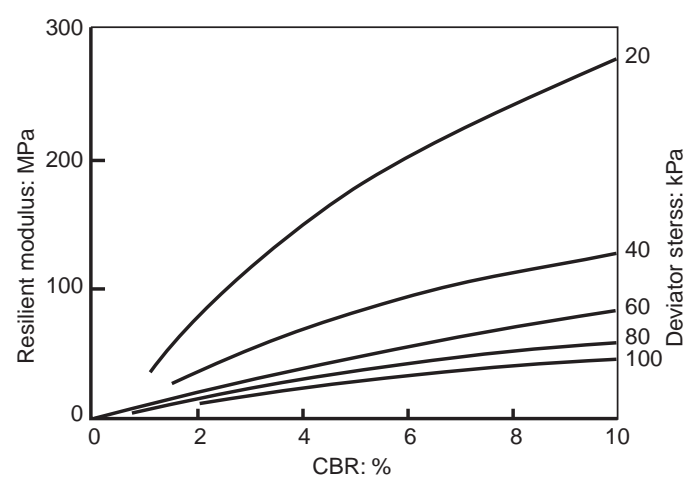

(a)

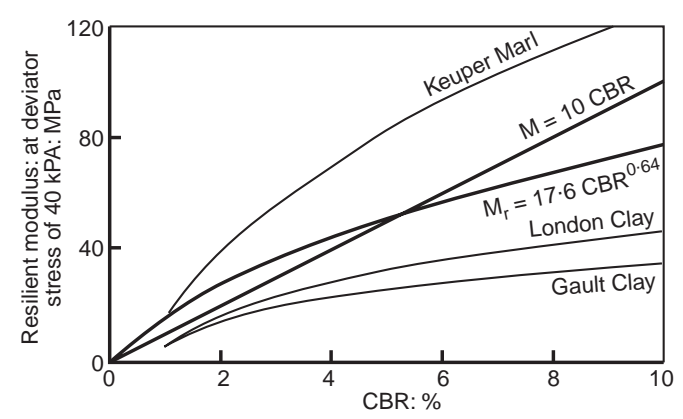

(b)

Fig. 55. Relationships between CBR and resilient modulus for clays (after Brown et al., 1987): (a) Keuper marl; (b) Three soils compared with empirical predictions at deviator stress of $40 \mathrm{kPa}$ below in an attempt to put matters into perspective in relation to the soil mechanics of pavements outlined in the previous section.

UK subgrade research. Between 1943 and 1961, Dr Croney and his colleagues at RRL conducted extensive research on pavement subgrades. Their work was aimed at the determination of water content profiles beneath pavements and they used soil suction as a major parameter taking, as their starting point, research done by agronomists, notably Schofield (1935). He proposed the $\mathrm{pF}$ scale for measuring soil suction, where the $\mathrm{pF}$ value is $\log _{10}$ (suction in cm of water). The 'p' comes from an analogy with the logarithmic scale of acidity $(\mathrm{pH})$ and the 'F' stands for 'Free energy'. Croney's definition of suction $(s)$ differs from that generally accepted in studies of partially saturated soils and known as matrix suction

$$
s=u_{\mathrm{a}}-u_{\mathrm{w}}
$$

where $u_{\mathrm{a}}$ is pore air pressure and $u_{\mathrm{w}}$ is pore water pressure.

Croney assumed $u_{\mathrm{a}}=0$ and defined suction as $-u_{\mathrm{w}}$ under zero external stress. The effect of applied total stress $p$ was taken into account by use of a 'compressibility coefficient' $\alpha$ as follows

$$
u=s+\alpha p
$$

in which $s$ is a negative quantity.

It is important to note that $p$ was defined by the experiments of Black et al., (1958) as a hydrostatic pressure whereas, in the practical application of the ideas to predictions of water content profiles in the field, Croney \& Coleman (1952) had regarded it simply as the vertical component of stress.

There has been difficulty over the years in understanding the correct definitions and application of the $\alpha$ parameter. A useful discussion can be found in Jones (1979) and Black (1979), though a study of Croney (1952) and Croney \& Coleman (1952) provide fuller explanations.

It is worth noting that, for saturated clays, $\alpha=1$ and hence

$$
s=u-p=-(p-u)
$$

where $p$ is the mean normal total stress.

As $s$ is a negative quantity, it follows that it is equal to the mean normal effective stress $p^{\prime}$ since

$$
p^{\prime}=p-u
$$

This has allowed some bridges to be built between conventional Terzhagi soil mechanics and the soil physics approach of Croney and his colleagues. (Croney, 1977). This link is also apparent in the expression for resilient modulus equation (7). Croney \& Coleman (1948) regarded the pavement as a two-layer elastic system and stated: 
'The maximum stress which the soil will carry without permanent deformation is the factor which decides the minimum thickness of construction'.

However, the main thrust of their work was to determine the equilibrium water content below a pavement since this related to soil strength. They did this with some success for both saturated and partially saturated conditions comparing predictions with field measurements (Black et al., 1958).

A fascinating aspect of the extensive investigations into water content - soil suction relationships, conducted by Dr Croney and his team, is the parallel which can be drawn with Critical State Soil Mechanics. Brady (1988) drew attention to the similarity between the soil suction - water content relationship for continuously disturbed London Clay (Croney \& Coleman, 1954) and the Critical State Line projection onto an effective stress $p^{\prime}-$ specific volume $v$ plane (Schofield \& Wroth, 1968). Once again, the equivalence of suction and effective stress is apparent. This matter has been investigated more recently by Ridley (1995) using Kaolin. He concluded that the suction-water content relationship is parallel to the critical state line but below it in $\mathrm{v}-p^{\prime}$ space.

Black (1962) developed a Suction Index method to predict CBR from plasticity data. He regarded the CBR as a measure of undrained shear strength since, experimentally, the procedure is like a smallscale bearing capacity test.

Black \& Lister (1979) used the large background knowledge on soil suction - water content relationships to develop a predictive method based on plasticity data. They selected a representative equilibrium suction value of $18 \mathrm{kPa}$ corresponding to a water table position $0.6 \mathrm{~m}$ below formation under a typical pavement construction. This was refined by Powell et al., (1984) in providing the background to current UK practice (Highways Agency, 1994b).

Notwithstanding the recognition that soil stiffness is an important parameter (Black \& Lister, 1979; Croney, 1977), current UK practice ignores it. Croney (1977) notes:

'The shear strength of soil is not of direct interest to the road engineer in connection with the behaviour of pavements under traffic. To provide a satisfactory subgrade, the soil should operate at stress levels within the 'elastic range' .... The pavement engineer is, therefore, more concerned with the elastic modulus of the soil and the behaviour under repeated loading'.

Grainger \& Lister (1962) developed repeated load triaxial test facilities at RRL to measure 'elastic moduli' but their early work was curtailed.
In an attempt to improve understanding of the CBR test and the interpretation of results from it, Hight \& Stevens (1982) carried out a critical review. They noted that the effective stress state in the mould is unknown and that there is no control of drainage. Using the finite element method, they explored relationships between CBR, stiffness and strength for four saturated clays. They concluded that CBR is a measure of undrained shear strength for stiff clays but cannot distinguish between low strain stiffnesses. Specimens with very different shaped stress-strain relationships can have the same CBR.

By allowing either a 2.5 or $5 \mathrm{~mm}$ penetration to be used in the determination of CBR inconsistences arise because different blends of stiffness and mobilized strength arise for different soils. The smaller value is more likely to correlate with stiffness. They recommended that soil suction should be measured in the test specimen and that it should be at the appropriate water content and effective stress to represent in situ conditions. Furthermore, it should either be intact (for cut) or compacted (for fill).

Nutt (1982) showed that lateral stresses developed during compaction have a significant effect on measured CBR for partially saturated soils. He concluded that there was no simple relationship between CBR and either strength or stiffness.

Noting that Hight and Stevens considered the full load-penetration curve could be used to improve the estimate of stiffness, Loach (1987) obtained data from reconstituted and compacted soils. He also carried out some repeated load CBR tests, typical results of which are shown in Fig. 56 for an overconsolidated silty clay. In general, the initial slopes of the load-penetration curves, whether in cycle 1 or subsequently, correlated with CBR, although there was experimental difficulty in obtaining accurate values of penetration. Since CBR did not correlate with resilient modulus, it was concluded that the CBR test configuration is not helpful in determining soil stiffness for pavement design.

This critical review of UK developments in

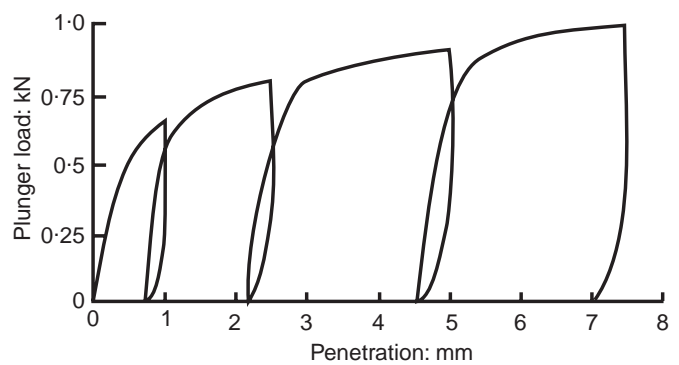

Fig. 56. Repeated load CBR tests on reconstituted silty clay (after Loach, 1987) 
subgrade soil mechanics reveals the need for improved test methods to quantify the resilient modulus. Such equipment has been available for many years and has emerged from being a research tool to a practical test for design application. This matter is further discussed in the final section.

\section{The rational approach}

While the US Army Corps of Engineers were enthusiastically embracing the CBR approach to pavement design, Hveem and his colleagues in California were devising new tests and developing theories as to how pavements developed failure conditions. Fig. 25 is the classical cross-section they drew to demonstrate cracking and deformation. They invented the Stabilometer test to measure the frictional characteristics of unbound materials and the Cohesiometer to determine tensile strength of surfacing. The Stabilometer, shown in Fig. 57, is still used today and is a form of triaxial test from which a resistance value $R$ is determined using the equation

$$
R=\frac{1-\left(\sigma_{\mathrm{h}} / \sigma_{\mathrm{v}}\right)}{100}
$$

where $\sigma_{\mathrm{h}}$ is measured for a typical value of $\sigma_{\mathrm{v}}=$ $1100 \mathrm{kPa}$.

Hveem \& Carmany (1948) state that $R$ is a measure of the ratio of maximum shear stress to major principal stress $\left(\tau / \sigma_{1}\right)$ as follows

$$
100 R=1-\left(\sigma_{\mathrm{h}} / \sigma_{\mathrm{v}}\right)=\left(\tau / \sigma_{1}\right)
$$

However, simple analysis of the Mohr's circle reveals that

$$
1-\left(\sigma_{\mathrm{h}} / \sigma_{\mathrm{v}}\right)=q / \sigma 1=2 \tau / \sigma_{1}
$$

where $\sigma_{1}=\sigma_{\mathrm{v}}$ and $q=\sigma_{\mathrm{v}}-\sigma_{\mathrm{h}}=2 \tau$

Notwithstanding the disputed factor of two, $R$ is seen to be a reasonably fundamental measure of

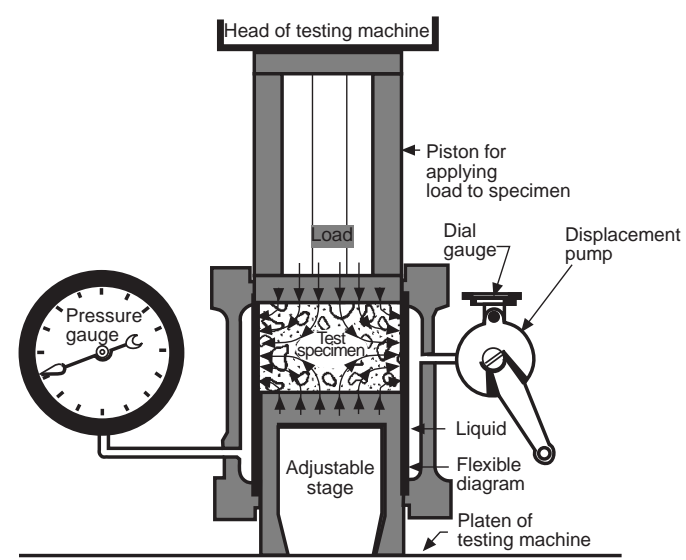

Fig. 57. The Hveem stabilometer (after Hveem \& Carmany, 1948) shear to normal stress at failure and, hence, relates strongly to the angle of shearing resistance.

Hveem \& Carmany (1948), recognized that the 'dynamic modulus of elasticity' for the subgrade was a parameter of relevance to understanding the fatigue cracking of asphalt surfaces and that monotonic loading would not be adequate for its determination. Hveem (1955) in his classical paper to the Highway Research Board developed the theme of resilient behaviour of pavements. He devised a repeated load version of the Stabilometer test known as the Resiliometer to characterize subgrades. There was an appreciation of the fact that a low stabilometer value (strength) does not always correlate with high resilience. By collating field measurements of surface deflection with the incidence of cracking, he was able to suggest allowable deflection values for different pavement constructions. This led to the worldwide adoption of surface deflection measurement as a routine method for assessing the structural condition of pavements.

The $K$-mould devised by Handy \& Fox (1987) and evolved by Semmelink \& de Beer (1993, 1995) has similarities to the Resiliometer. Lateral stress is mobilized by an elastic support system with a stiffness which can be varied between 15-60 MPa, designed to simulate in situ conditions. This provides a state somewhere between $K_{0}$ (zero lateral strain) and unconfined. Preliminary results have been obtained for resilient properties and for permanent deformation characteristics of granular materials.

The pioneering work of Hveem and his colleagues combined theoretical concepts, field observations and the development of innovative laboratory tests in a co-ordinated manner which is still a model for good research and development.

Professor Seed and his colleagues at the University of California at Berkeley followed the lead established by Hveem. They developed the repeated load triaxial test and introduced the term 'modulus of resilience' (Seed et al., 1955). This was later changed to 'resilient modulus' (Seed et al., 1962) which is defined on p. 406 where the stress dependence of resilient modulus is illustrated by Fig. 41. Seed et al., (1962, 1965) demonstrated that deflection in repeated plate loading tests could be predicted using their laboratory data and appropriate elastic theory.

The early work on fatigue testing of bituminous mixtures was also pursued at Berkeley under Professor Carl Monismith (Monismith et al., 1961) and, quite independently, at Nottingham by Professor Peter Pell (Pell, 1962).

An understanding of the non-linear properties of soils and granular materials evolved simultaneously at Berkeley and Nottingham in the 1960s. Hicks \& Monismith (1971) reported comprehensive data for 
granular materials from repeated load triaxial tests while Brown \& Pell (1967) and Brown \& Bush (1972) deduced results from in situ measurements (e.g. Fig. 5).

The increasing availability of linear-elastic theoretical solutions for pavement analysis from the mid 1960s combined with the ability to carry out relevant laboratory tests on soils, granular materials and bituminous materials led to the development of several analytically based pavement design methods in the 1970s and 1980s (e.g. Claessen et al., 1977, Brown et al., 1984). These methods have generally used two design criteria, the tensile elastic strain of the bottom of the bituminous layer, to deal with fatigue cracking, and the vertical elastic strain at the top of the subgrade. This latter was derived from back-analysis of pavements of known performance with respect to rut development and is a semi-empirical attempt to deal with this failure mechanism using a linear elastic based theory for design. (Brown \& Brunton, 1984).

Little serious soil mechanics is incorporated in most of the available design methods based on a mechanistic approach although the effects of nonlinear behaviour in soil and granular materials are taken into account either directly or indirectly by most of them.

The validity of theoretical models for pavement systems has been quite widely studied with comparisons between computed and measured values of the key design parameters generally giving reasonable confidence for use of the theory in design.

The use of back-analysis to determine resilient properties has been widely implemented in practice (Brunton et al., 1992). It is a good example of the sensible use of analytical techniques and only gives plausible results when the non-linear properties of the subgrade and, in certain cases, the sub-base are taken into account. The programs LEAD and FEAD developed by d'Almeida et al., (1993) allow the two parameters in each of equations (6) and (22) to be determined through an iterative procedure. The bituminous or cement treated layers are assumed to be linear elastic and effective stiffnesses are computed for these. The effective stiffness accounts for the reduction in stiffness caused by cracking and general deterioration relative to the 'as built' value for the undamaged layer.

Fig. 58 shows a typical profile of vertical elastic strain through a pavement structure. Summation of this strain with depth yields the surface deflection. The large contribution from the subgrade is apparent, demonstrating the importance of proper characterization of resilient properties for the soil.

An attraction of using theory in back analysis is that the model is calibrated to the structure through the matching of surface deflection profiles. The

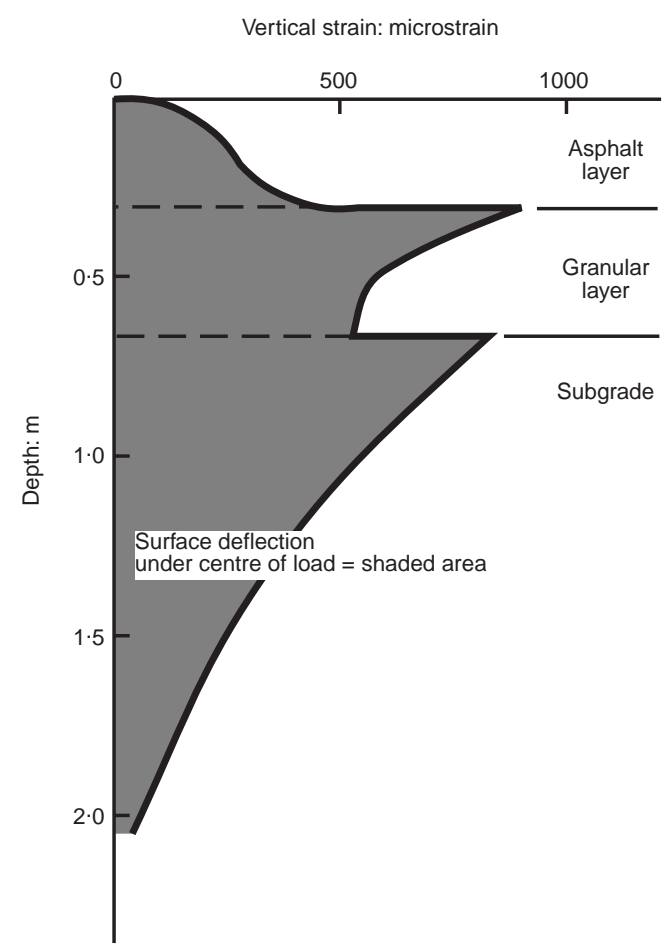

Fig. 58. Typical variation of resilient vertical strain with depth through an asphalt pavement (after Brown et al., 1987)

resulting resilient moduli of its layers can then be used with some confidence in design calculations to assess residual life and determine structural requirements for future life. This may take the form of a strengthening overlay or of partial reconstruction.

The technique has recently been used in conjunction with a case study to compare new ideas on pavement foundation design with current empirical practice. Two sections of the A564 Derby Southern By-Pass were tested at various stages of construction. One section was in cut and the other on an embankment. The soil was a silty clay in both cases, the capping was locally won sand and gravel, the sub-base was crushed limestone in the cutting and granite on the embankment and the road base was a dense bituminous material. The FWD was used to obtain deflection data and the results were back-analysed to determine effective resilient moduli for pavement layers as construction proceeded. The data in Table 1 for the section in cut show how the capping and subgrade mobilized higher resilient moduli when covered by sub-base and road base owing to increased confining stress and decreased deviator stress in keeping with the non-linear stress-strain relationships. 
Table 1. Back-analysed effective values of resilient modulus for road in cutting

\begin{tabular}{l|c|c}
\hline \multirow{2}{*}{ Pavement layer } & \multicolumn{2}{|c}{ Effective $E_{\mathrm{r}}:$ MPa } \\
\cline { 2 - 3 } & Test on capping & Test on road base \\
\hline Road base & - & 3200 \\
Sub-base & - & 240 \\
Capping & 90 & 200 \\
Subgrade & 70 & 200 \\
\hline
\end{tabular}

Table 2 shows values of equivalent foundation stiffness computed using equation (1) and the central deflection measurement only. The values increased as tests were conducted successively on the subgrade, capping and sub-base of the embankment. This shows the effect of building up the foundation on the stiffness of support provided to layers placed above.

\section{A PRACTICAL APPROACH TO PAVEMENT FOUNDATION DESIGN \\ Introduction}

This section outlines an approach to pavement foundation design based on the use of theoretical concepts and measured properties of the soil and granular layer. It is based on research carried out for the TRL reported by Thom et al. (1993) and Dawson et al. (1993). The objective was to produce a relatively simple, implementable system using reasonably priced facilities which could be adopted by design laboratories.

\section{Philosophy}

Fig. 59 shows the sequence of design and testing proposed by Dawson et al. (1993). It includes laboratory testing of representative samples of the subgrade and the aggregates(s), design calculations using analytical techniques and field measurements as construction proceeds to provide a check on the design.

\section{Materials testing}

The simplified repeated load triaxial apparatus in Fig. 19 can be used to determine resilient properties and permanent deformation characteristics of soils. These are modelled by equation (8) for the resilient modulus and a simplified version

Table 2. Equivalent foundation stiffness values for road on embankment

\begin{tabular}{l|c}
\hline \multicolumn{1}{c|}{ Test on } & $\begin{array}{c}\text { Equivalent foundation } \\
\text { stiffness: } \mathrm{MPa}\end{array}$ \\
\hline Subgrade & 30 \\
Capping & 50 \\
Sub-base & 90 \\
\hline
\end{tabular}

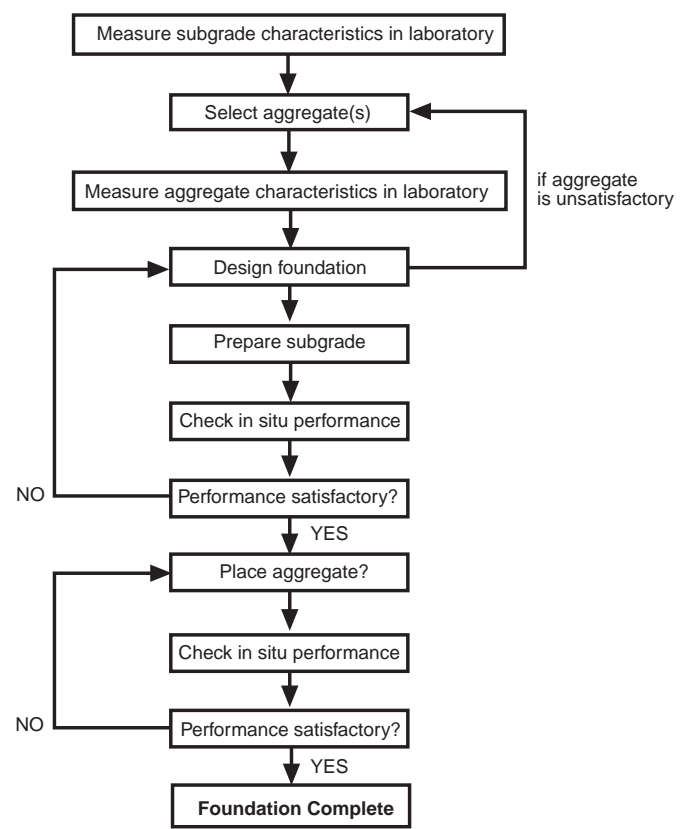

Fig. 59. Proposed procedure for pavement foundation design (after Dawson et al., 1993)

of equation (5) for the plastic strain accumulated after $N$ load applications

$$
\varepsilon_{\mathrm{p}}(N)=A \log N\left(q_{\mathrm{r}} / s\right)^{B}
$$

The shear strength is also determined.

A similar procedure is recommended for characterizing the granular materials to be used in capping and in sub-base. The equipment is shown in Fig. 21. The resilient modulus is modelled using the simple equation (22) in which $\theta$ is taken as total stress because the suction will not usually be known. Simple repeated load tests allow the constants to be determined for the equations. Since permanent deformation resistance correlates with the angle of shearing resistance $\phi^{\prime}$ only strength testing is needed for this property.

\section{Design criteria}

The design criteria fall into two categories, those concerned with rutting and those concerned with the resilient behaviour of the foundation. The rut at sub-base level may result from plastic strain accumulation in the aggregate layer(s) alone, in the subgrade alone or within all layers.

The resilient behaviour of the foundation can be expressed as an equivalent value for the structure based on its resilient surface deflection under load. Two loading situations arise: that due to the construction of the bound layers above and that resulting from traffic once the pavement is com- 
plete. The former affects constructability of the bituminous layer and the latter influences its longterm performance.

\section{Analytical techniques}

A quasi-failure analysis using the wedge model in Fig. 60 is proposed to deal with rutting in the granular material. The force $P$ required to push the central wedge down by the allowable rut depth (say $40 \mathrm{~mm}$ ) is computed using static equilibrium techniques. Resistance to $P$ is mobilized by the values of apparent cohesion $c$ and angle of shearing resistance, $\phi$ for the aggregate layers and the allowable deviator stress on the subgrade $q_{\mathrm{a}}$. This is determined from equation (35) using an allowable plastic strain of $0 \cdot 6 \%$ for the required number of load applications $N$. This strain level is regarded as a tentative suggestion at present. Full details of the wedge model are described by Thom et al. (1993). An iterative computation is used to obtain a solution.

For the situation where the rutting is entirely contributed by the subgrade and for the determination of equivalent foundation resilient modulus, linear elastic layered system analysis is used. The non-linear resilient properties of the materials are accounted for by using the iterative approach described on p. 389. This allows compatibility of stresses and resilient moduli to be established. For the subgrade rutting criterion, the deviator stress at formation is calculated and equation (35) used to check whether the allowable strain of $0.6 \%$ is exceeded.

The equivalent foundation stiffness is determined using the computed surface deflection for the layered system and calculating the resilient modulus for an equivalent semi-infinite elastic half space using equation (1). The analysis described above can be performed using the PAFODE computer program developed by Dawson \& Thom (1994).

\section{Validation of the method}

Preliminary validation of the design method has been carried out using performance data from full-scale trials at Bothkennar and Loughborough (Dawson et al., 1993). The predictions of rut depth development using the wedge model are compared with measurements in Fig. 61. Results for the Loughborough trials are satisfactory but for Both-

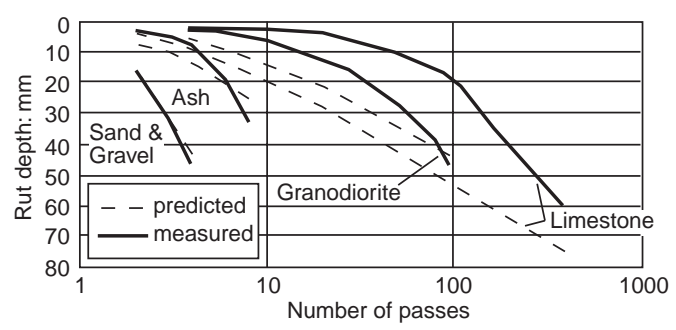

(a)

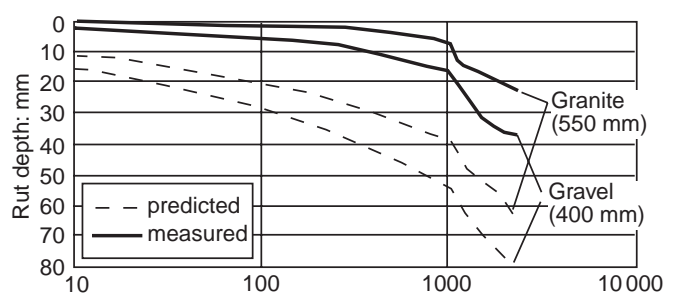

(b)

Fig. 61. Predicted rut depths compared with measurements at full-scale (after Dawson et al., 1993) (a) Loughborough trials; (b) Bothkennar trials

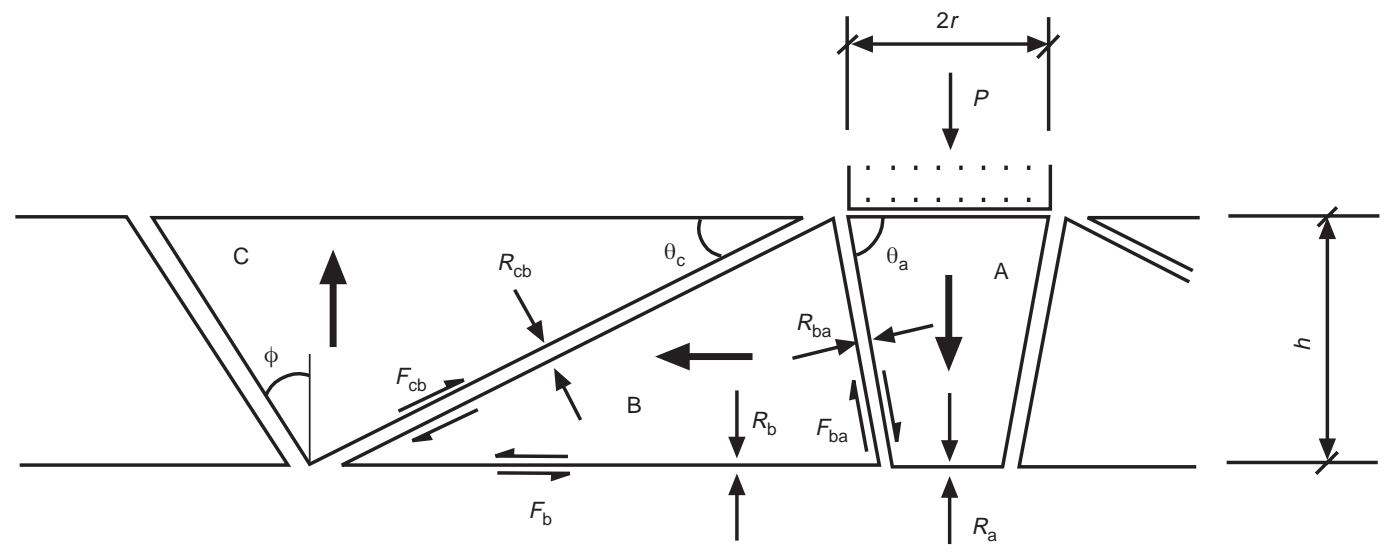

Fig. 60. Proposed 'wedge model' for calculating rutting in pavement foundations (after Thom et al., 1993) 
kennar the model overpredicted rutting. The laboratory test data to support the Bothkennar calculations were less complete than for the Loughborough tests.

The method clearly needs to be used more extensively for a wider range of materials and conditions and to be refined. It is, however, considered to provide the basis for improved design of pavement foundations in the future.

\section{Railtrack design}

Li (1994) presents a good summary of procedures for the determination of granular layer thicknesses in railtrack. He describes a method developed at the University of Massachusetts which uses the GEOTRACK program for modelling response to wheel loading. The design criteria are vertical plastic strain and vertical permanent deformation at formation level. The former is to prevent plastic flow, which leads to progressive failure of the top of the subgrade, while the latter relates to the overall deformation of the subgrade. Varying the thickness of the granular layers influences the transient deviator stress level in the subgrade and, hence, the plastic strain $\varepsilon_{\mathrm{p}}$. The plastic strain after $N$ cycles is computed by the following equation, derived from repeated load triaxial tests on clays

$$
\varepsilon_{\mathrm{p}}=A\left(q_{\mathrm{r}} / c_{\mathrm{u}}\right)^{m} N^{b}
$$

in which $A, m$ and $b$ are experimentally determined, $N$ is the number of load applications, $c_{\mathrm{u}}$ is the undrained shear strength and $q_{\mathrm{r}}$ is the repeated deviator stress.

\section{CONCLUSIONS}

This wide ranging review of soil mechanics in pavement engineering has outlined the techniques which are available to study the problem using theory, laboratory testing and field experiments. It has primarily been concerned with bituminous pavements for highways but other pavement types obey similar principles. The particular characteristics of railtrack have also been described.

It was considered helpful to place present knowledge and practice in a historical perspective, since pavement soil mechanics has developed, to some extent, in isolation from mainstream geotechnics. It is ironic that much of the research on repeated loading of soil and granular materials has been quite sophisticated and comparable in quality with that developed in other fields of soil mechanics, but procedures used in current practice remain empirical and backward. Much the same can be said of theoretical modelling.

The background knowledge accumulated from research presents an opportunity for improving current practice. A simplified approach to founda- tion design has been outlined which, with a little further development, could provide the basis to upgrade present practice. One feature of this is the simplified test procedures for materials which could be made more user-friendly in the manner achieved for bituminous materials using the Nottingham Asphalt Tester (Cooper \& Brown, 1989). A wide range of soils and granular materials, under a variety of conditions, needs to be tested.

Further research is needed, notably to obtain a better understanding of the effective stress state in pavement foundations. This will require good quality, long-term field monitoring using moisture and suction measuring techniques for which there have been recent advances. The significant improvement in understanding of partially saturated soils through the work of Wheeler \& Karube (1995), Alonso et al. (1990) and Fredlund \& Rahardjo (1993) provides a sound basis to improve the models used for pavement design. These could be combined with elasto-visco-plastic models for bituminous materials to provide a comprehensive theoretical framework for flexible pavements in the future.

Little or nothing has been reported herein on the vital matter of pavement drainage. Suffice it to say that improvements in the effectiveness and reliability of drainage so that water conditions below pavements remain stable and water contents at reasonable levels continue to be a desirable aim.

\section{ACKNOWLEDGEMENTS}

In preparing this Rankine Lecture, the Author has drawn liberally on the research carried out by his colleagues at Nottingham University over many years. The successive research staff who have contributed new ideas and brought a variety of skills to bear on both experimental and theoretical work have provided a stimulating environment and a large source of information. Particular thanks are expressed to: Ahmed Lashine, Adrian Hyde, John Boyce, Jack Pappin, Simon Loach, Peter Ansell, Phil Shaw, Joao d'Almeida, Bob Overy, Mike O'Reilly, Matthew Raybould, Alex Tam and Peter Little, all of whom have moved on to other places, and to present colleagues at Nottingham and SWK Pavement Engineering Ltd; Andrew Dawson, Nick Thom, Ron Jones, Ian Richardson, Barry Brodrick, Francis Chan, Lam Wah Cheung and John Nutt. Grateful thanks are also extended to Carolyn Parkinson and Hayley Drabble, who dealt with the text and figures respectively.

Without the work of all these people, this lecture would not have been possible.

Permission was granted by the Highways Agency to conduct tests on the A564 Derby Southern By-Pass and particular thanks are expressed to Tarmac Construction Ltd. and to Scott 
Wilson Kirkpatrick, the consulting engineers, and in particular to Phil Staten, their Geotechnical Resident Engineer who facilitated the work.

The Author is also indebted to Professor Carl Monismith from the University of California at Berkeley and to Barney Vallerga from Oakland, California for the provision of information on early developments in their State.

The invitation to deliver a Rankine Lecture is very special and a great honour. The Author will be eternally grateful to the British Geotechnical Society's Committee under Andrew Lord for giving him the privilege of being able to respond on this, the 36th occasion.

The research at Nottingham University has been funded by a large number of organizations over the years including the Science and Engineering Research Council, the Transport Research Laboratory, the Building Research Station, British Rail, Shell, the US Air Force and the US Army. This support is gratefully acknowledged.

On a personal note, the Author would like to thank his wife, Maryse, for constant encouragement in this endeavour through the sleepless nights and the long days in the study.

\section{REFERENCES}

Acum, W. E. A. \& Fox, L. (1951). Computation of load stresses in a three layer elastic system, Géotechnique 2, 293-300.

Alavi, S. H. (1992). Viscoelastic and permanent deformation characteristics of asphalt-aggregate mixes tested as hollow cylinders and subjected to dynamic axial and shear loads, $\mathrm{PhD}$ thesis, University of California.

Alonso, E. E., Gens, A. and Josa, A. (1990). A constitutive model for partially saturated soils, Géotechnique 40, No. 3, 405-430.

American Association of State Highway and Transportation Officials (1986). Standard method of test for resilient modulus of subgrade soils. AASHTO Designation: T272-82.

American Society of Civil Engineers (1950). Discussion, Development of CBR flexible pavement design method for airfields - a symposium, Trans. Am. Soc. Civ. Engrs, 115, 555-589.

Andersen, K. H., Brown, S. F., Foss, I., Pool, J. H. \& Rosenbrand, W. F. (1976). Effect of cyclic loading on clay behaviour, Proc. Conf. Design and Construction of Offshore Structures, Institution of Civil Engineers, 75-79.

Austin, G. (1979). The behaviour of Keuper Marl under undrained creep and repeated loading, $\mathrm{PhD}$ thesis, University of Nottingham.

Basson, J. E. B., Wijnberger, O. J. \& Skultety, J. (1981). The Multidepth Deflectometer: a multi-stage sensor for the measurement of resilient deflections and permanent deformations at various depths in road pavements, Report No. RP/3.81, NITRR, CSIR, Pretoria.

Black, W. P. M. (1979). Reply to discussion on road subgrades, Clay fills, 243-244. London: Institution of
Civil Engineers.

Black, W. P. M. (1962). A method of estimating the California Bearing Ratio of cohesive soils from plasticity data, Géotechnique 11, No. 1, 14-21.

Black, W. P. M., Croney, D. \& Jacobs, J. C. (1958). Field studies of the movement of soil moisture, Road Res. Tech. Paper No. 41, DSIR, HMSO.

Black, W. P. M. \& Lister, N. W. (1979). The strength of clay fill subgrades: its prediction and relation to road performance, Clay fills, 37-48, London: Institution of Civil Engineers.

Bleyenberg, W. G., Claessen, A. I. M., van Gorkum, F., Heukelom, W. \& Pronk, A. C. (1977). Fully monitored motorway trials in the Netherlands corroborate linear elastic design theory, Proc. 4th Int. Conf. Structural Design of Asphalt Pavements, Ann Arbor, Michigan, 1, 75-98.

Boyce, J. R. (1976). The behaviour of a granular material under repeated loading, $\mathrm{PhD}$ thesis, University of Nottingham.

Boyce, J. R. (1980). A non-linear model for the elastic behaviour of granular materials under repeated loading, Proc. Int. Symp. soils under cyclic and transient loading, Swansea, 285-294.

Boyce, J. R., Brown, S. F. \& Pell, P. S. (1976). The resilient behaviour of a granular material under repeated loading, Proc. Aust. Road Research Board 28, 8-19.

Brady, K. C. (1988). Soil suction and the Critical State, Géotechnique 38, No. 1, 117-120.

British Airports Authority (1993). Aircraft pavements: pavement design guide for heavy aircraft loading, Internal Report No. P2833-RP-CE-001-01.

Brown, S. F. (1975). Improved framework for predicting permanent deformation in asphalt layers, Transp. Res. Record No. 537, Transportation Research Board, Washington, DC, 18-30.

Brown, S. F. (1978). State-of-the-art report on field instrumentation for pavement experiments, Transp. Res. Record No. 640, Transportation Research Board, Washington, DC, 13-28.

Brown, S. F., Andersen, K. H. \& McElvaney, J. (1977). The effect of drainage on cyclic loading of clay, Proc. 9th Int. Conf. Soil Mech. Foundation Engng, Tokyo, 2, 195-200.

Brown, S. F., Austin, G. \& Overy, R. F. (1980). An instrumented triaxial cell for cyclic loading of clays, Geotech. Testing J., ASTM, 3, No. 4, 145-152.

Brown, S. F. \& Bell, C. A. (1977). The validity of design procedures for the permanent deformation of asphalt pavements, Proc. 4th Int. Conf. Structural Design of Asphalt Pavements, Ann Arbor, Michigan, 1, 467-482.

Brown, S. F. \& Brodrick, B. V. (1981a). Nottingham pavement test facility, Transp. Res. Record No. 810, Transportation Research Board, Washington, DC, 6772.

Brown, S. F. \& Brodrick, B. V. (1981b). Instrumentation for the Nottingham Pavement Test Facility, Transp. Res. Record No. 810, Transportation Research Board, Washington, DC, 73-79.

Brown, S. F. \& Brunton, J. M. (1984). Improvements to pavement subgrade strain criterion, J. Transp. Engng Am. Soc. Civ. Engrs, 110, No. 6, 551-567.

Brown, S. F., Brunton, J. M. \& Stock, A. F. (1985). The analytical design of bituminous pavements, Proc. 
Insth Civ. Engrs, 79, Pt. 2, 1-31.

Brown, S. F. \& Bush, D. I. (1972). Dynamic response of model pavement structure, J. Transp. Engng, Am. Soc. Civ. Engrs, 98, TE4, 1005-1022.

Brown, S. F., O’Reilly, M. P. \& Pappin, J. W. (1989). A repeated load triaxial apparatus for granular materials, in Unbound Aggregates in Roads, London, Butterworth, 143-158.

Brown, S. F. \& Chan, F. W. K. (1996) Reduced rutting in unbound granular pavement layers through improved grading design, Proc. Instn Civ. Engrs Transport, 117, 40-49.

Brown, S. F. \& Dawson, A. R. (1992). Two-stage approach to asphalt pavement design, Proc. 7th Int. Conf. Asphalt Pavements, Nottingham, 1, 16-34.

Brown, S. F., Lashine, A. K. F. \& Hyde, A. F. L. (1975). Repeated load triaxial testing of a silty clay, Géotechnique 25, No. 1, 95-114.

Brown, S. F., Loach, S. C. \& O'Reilly, M. P. (1987). Repeated loading of fine grained soils, Contractor Report 72, Transportation Research Laboratory.

Brown, S. F., O'Reilly, M. P. \& Loach, S. C. (1990). The relationship between California Bearing Ratio and elastic stiffness for compacted clays, Ground Engng, 23, No. 8, 27-31.

Brown, S. F. \& Pappin, J. W. (1981). Analysis of pavements with granular bases, Transp. Res. Record No. 810, Transportation Research Board, Washington, DC, 17-22.

Brown, S. F. \& Pell, P. S. (1967). An experimental investigation of the stresses, strains and deflections in a layered pavement structure subjected to dynamic loads, Proc. 2nd Int. Conf. Structural Design of Asphalt Pavements, Ann Arbor, Michigan, 487-504.

Brown, S. F. \& Selig, E. T. (1991). The design of pavement and rail track foundations, Chapter 6 in Cyclic loading of soils: from theory to design, Blackie, Glasgow and London, 249-305.

Brown, S. F., Tam, W. S. \& Brunton, J. M. (1986). Development of an analytical method for the structural evaluation of pavements, Proc. 2nd Int. Conf. Bearing Capacity of Roads and Airfields, Plymouth, 1, 267-276.

Brown, S. F., Tam, W. S. \& Brunton, J. M. (1987). Structural evaluation and overlay design: analysis and implementation, Proc. 6th Int. Conf. Structural Design of Asphalt Pavements, Ann Arbor, Michigan, 1, 1013-1028.

Brunton, J. M. \& Akroyde, P. M. (1990). Monitoring the performance of a full-scale experimental pavement, Proc. 3rd Int. Conf. Bearing Capacity of Roads and Airfields, Trondheim, 585-594.

Brunton, J. M. \& d'Almeida, J. R. (1992). Modeling material non-linearity in a pavement backcalculation procedure, Transp. Res. Record No. 1377, Transportation Research Board, Washington, DC, 99-106.

Brunton, J. M., Armitage, R. J. \& Brown, S. F. (1992). Seven years' experience of pavement evaluation, Proc. 7th Int. Conf. on Asphalt Pavements, Nottingham, 3, 17-30.

Burmister, D. M. (1943). Theory of stresses and displacements in layered systems and application to the design of airport runways, Proc. Highway Res. Board, 23, Washington, DC, 126-148.

Chan, F. W. K. (1990). Permanent deformation resistance of granular layers in pavements, $\mathrm{PhD}$ thesis, University of Nottingham.

Chan, F. W. K. \& Brown, S. F. (1994). Significance of principal stress rotation in pavements, Proc. 13th Int. Conf. Soil Mech. Foundn Engng, Delhi, 4, 18231826.

Chang, C. S., Adegoke, C. W. \& Selig, E. T. (1979). A study of analytical models for track support systems, Transp. Res. Record No. 733, Transportation Research Board, Washington, DC, 12-19.

Cheung, L. W. (1994). Laboratory assessment of pavement foundation materials, $\mathrm{PhD}$ thesis, University of Nottingham.

Claessen, A. I. M., Edwards, J. M., Sommer, P. \& Ugé, P. (1977). Asphalt pavement design - the Shell Method, Proc. 4th Int. Conf. Structural Design of Asphalt Pavements, Ann Arbor, Michigan, 1, 39-74.

Cooling, L. F. et al. (1961), Discussion on Session 3: Roads and Runways and Agriculture in Pore pressure and suction in soils, London, Butterworth, 143-151.

Cooper, K. E. \& Brown, S. F. (1989). Development of a simple apparatus for the measurement of the mechanical properties of asphalt mixes, Proc. Eurobitume Symposium, Madrid, 494-498.

Cox, B. (1980). Reconstruction, including design planning and execution from the engineer's point of view, Highway Engr., 27, No. 12, 13-15.

Croney, D. (1952). The movement and distribution of water in soils, Géotechnique 5, No. 1, 1-16.

Croney, D. (1977). The design and performance of road pavements, London, HMSO.

Croney, D. \& Coleman, J. D. (1948). Soil thermodynamics applied to the movement of moisture in road foundations, Proc. 7th Int. Conf. Appl. Mech., London, 3, 163-177.

Croney, D. \& Coleman, J. D. (1952). The estimation of the vertical moisture distribution with depth in unsaturated cohesive soils, Road Note No. 1709, DSIR, HMSO.

Croney, D. \& Coleman, J. D. (1954). Soil structure in relation to soil suction $(\mathrm{pF})$, J. Soil Sci. 5, No. 1, $75-84$.

d'Almeida, J. C. G. R. (1993). Analytical techniques for the structural evaluation of pavements, $\mathrm{PhD}$ thesis, University of Nottingham.

d'Almeida, J. R., Brown, S. F. \& Thom, N. H. (1994). A pavement evaluation procedure incorporating material non-linearity. Non-destructive testing and back-calculation of moduli. (2nd Vol.), American Society for Testing and Materials, STP 1198, 218-232.

Davis, E. H. (1949). The California Bearing Ratio method for the design of flexible roads and runways, Géotechnique 1, No. 4, 249-263.

Dawson, A. R., Brown, S. F., Thom, N. H. \& Cheung, L. W. (1993). Improvements to road foundation design: laboratory tests and design method, Report PRG 93023, University of Nottingham.

Dawson, A. R. \& Plaistow, L. (1993). Parametric study flexible pavements, Flexible Pavements, Balkema, 229-237.

Dawson, A. R. \& Gomes Correia, A. (1993). The effects of subgrade clay condition on the structural behaviour of road pavements, Flexible Pavements, Balkema, $113-119$.

Dawson, A. R. \& Thom, N. H. (1994). Software manual 
for the program PAFODE, Report PRG 94004, University of Nottingham.

Dehlen, G. C. \& Monismith, C. L. (1970). Effect of nonlinear material response on the behaviour of pavements under traffic, Highway Res. Record No. 310, Highway Research Board, Washington, DC, 1-16.

de Jong, D. L., Peutz, M. G. F. \& Korswagen, A. R. (1973). Computer program BISAR: layered systems under normal and tangential loads, Koninklike Shell Laboratorium, Amsterdam, Rep. No. AMSR 0006.73.

Duncan, J. M., Monismith, C. L. \& Wilson, E. L. (1968). Finite element analysis of pavements, Highway Res. Record No. 228, Highway Research Board, Washington, DC, 18-33.

Farrer, D. M. (1979). Settlement and pore-water pressure dissipation within an embankment built of London clay, Clay fills, 101-106. London, Institution of Civil Engineers.

Fox, L. (1948). Computation of traffic stresses in a simple road structure, Road Res. Tech. Paper No. 9, DSIR, HMSO.

Fredlund, D. G. \& Rahardjo, H. (1993). Soil mechanics for unsaturated soils, John Wiley, Chichester.

Freeme, C. R. \& Servas, V. P. (1985). Advances in pavement design and rehabilitation, in Accelerated Testing of Pavements, CSIR, Pretoria.

Gomes Correia, A. (1985). Contribution à l'étude mechanique des sols soumis à des changements cycliques, Dr Eng. thesis, Ecole Nat. des Ponts et Chaussées, Paris.

Grainger, G. D. \& Lister, N. W. (1962). A laboratory apparatus for studying the behaviour of soils under repeated loading, Géotechnique 12, No. 1, 3-14.

Greenwood, D. A. et al. (1992). Bothkennar Soft Clay test site: Characterization and lessons learned, 8th Géotechnique Symp., Géotechnique 52, No. 2, 161378.

Handy, R. L. \& Fox, D. E. (1987). K-tests for subgrade and base evaluation, Proc. Annual Transp. Convention, CSIR, Pretoria, 6.

Hardin, B. O. \& Drnevich, V. P. (1972). Shear modulus and damping in soils I. Measurements and parameter effects, J. Geotech. Engng Div., Am. Soc. Civ. Engrs, 102, No. GT9, 975-987.

Heath, D. L., Shenton, M. J., Sparrow, R. W. \& Waters, J. M. (1972). Design of conventional rail track foundations, Proc. Instn Civ. Engrs, 51, No. 2, 251-267.

Hicks, R. G. \& Monismith, C. L. (1971). Factors influencing the resilient response of granular materials, Highway Res. Record No. 345, Highway Research Board, Washington, DC, 15-31.

Hight, D. W. \& Stevens, M. G. H. (1982). An analysis of the California Bearing Ratio test in saturated clays, Géotechnique 32, No. 4, 315-322.

Highways Agency (1994a). Use and limitations of ground penetrating radar for pavement assessment, HA72/94, HMSO.

Highways Agency (1994b). Design manual for roads and bridges: Vol 7, Pavement design and maintenance, HMSO.

Hveem, F. N. (1955). Pavement deflections and fatigue failures, Highway Res. Board Bulletin No. 114, Washington, DC, 43-87.

Hveem, F. N. \& Carmany, R. M. (1948). The factors underlying the rational design of pavements, Proc.
Highway Res. Board, 28, Washington, DC, 101-136.

Hveem, F. N. \& Sherman, G. B. (1962). California method for the structural design of flexible pavements, Proc. Int. Conf. Structural Design of Asphalt Pavement, Ann Arbor, Michigan, 851-866.

Hyde, A. F. L. (1974). Repeated load triaxial testing of soils, $\mathrm{PhD}$ thesis, University of Nottingham.

Jones, R. H. (1979). Discussion on road subgrades, Clay fills, 243, London, Institution of Civil Engineers.

Jouve, P. \& Elhannani, M. (1993). Application des modèles non-linéaires au calcul des chaussées souples, Bulletin de liaison des Laboratoires des Ponts et Chaussées, No. 190, 30-35.

Jürgenson, L. (1934). Application of elastic theory and plasticity to foundation problems, J. Boston Soc. Civ. Engrs, 242.

Klomp, A. J. G. \& Niesman, Th. W. (1967). Observed and calculated strains at various depths in asphalt pavements, Proc. 2nd Int. Conf. Structural Design of Asphalt Pavements, Ann Arbor, Michigan, 671-688.

Lee, A. R. \& Croney, D. (1962). British full-scale pavement design experiments, Proc. Int. Conf. Structural Design of Asphalt Pavements, Ann Arbor, Michigan, 114-136.

Lentz, R. W. \& Balady, G. Y. (1980). Simplified procedure to characterise permanent strains in sand subjected to cyclic loading, Proc. Int. Symp. Soils under Cyclic and Transient Loading, Swansea, 280294.

Li, D. (1994). Railway track granular layer thickness design based on subgrade performance under repeated loading, $\mathrm{PhD}$ thesis, University of Massachusetts.

Liddle, W. J. (1962). Application of AASHO road test results to the design of flexible pavement structures, Proc. Int. Conf. Structural Design of Asphalt Pavements, Ann Arbor, Michigan, 42-51.

Lister, N. W. (1972). The transient and long term performance of pavements in relation to temperature, Proc. 3rd Int. Conf. Structural Design of Asphalt Pavements, London, 1, 94-100.

Little, P. H. (1993). The design of unsurfaced roads using geosynthetics, $\mathrm{PhD}$ thesis, University of Nottingham.

Loach, S. C. (1987). Repeated loading of fine grained soils for pavement design, $\mathrm{PhD}$ thesis, University of Nottingham.

Lytton, R. (1995). Foundations and pavements on unsaturated soils, Keynote Address, 1st Int. Conf. on Unsaturated Soils, Paris.

Metcalf, J. B., McLean, J. R. \& Kadar, P. (1985). The development and implementation of the Australian Accelerated Loading Facility (ALF) program, in Accelerated Testing of pavements, CSIR, Pretoria.

Middlebrooks, T. A. \& Bertram, G. E. (1950). Adaptation to the design of airfield pavements, Development of CBR flexible pavement design method for airfields - a symposium, Trans Am. Soc. Civ. Engrs, 468-471.

Monismith, C. L., Secor, K. E. \& Blackmer, W. (1961). Asphalt mixture behaviour in repeated flexure, Proc. Assoc. of Asphalt Paving Techn., 30, 188-222.

National Institution for Transport and Road Research (1985a). Structural design of interurban and rural road pavements, TRH4, CSIR, Pretoria.

National Institute for Transport and Road Research (1985b). Guidelines for Road Construction Materials, 
TRH 14, CSIR, Pretoria.

Nutt, J. L. (1982). Finite element modelling of partially saturated soils for a study of the California Bearing Ratio test, MSc thesis, Imperial College, University of London.

O’Reilly, M. P. (1985). Mechanical properties of granular materials for use in thermal energy stores, $\mathrm{PhD}$ thesis, University of Nottingham.

O'Reilly, M. P., Brown, S. F. \& Overy, R. F. (1989). Viscous effects observed in tests on an anisotropically normally consolidated silty clay, Géotechnique $\mathbf{3 9}$, No. 1, 153-158.

Pappin, J. W. (1979). Characteristics of a granular material for pavement design, $\mathrm{PhD}$ thesis, University of Nottingham.

Pappin, J. W. \& Brown, S. F. (1980). Resilient stressstrain behaviour of a crushed rock, Proc. Int. Symp. Soils under cyclic and transient loading, Swansea, 1, 169-177.

Pappin, J. W., Brown, S. F. \& O'Reilly, M. P. (1992). Effective stress behaviour of saturated and partially saturated granular material subjected to repeated loading, Géotechnique 42, No. 3, 485-497.

Paute, J-L., Hornych, P. \& Beraben, J.-P. (1993). Repeated load triaxial testing of granular materials on the French network of Laboratoires des Ponts et Chaussées, Flexible Roads, Balkema, 53-64.

Pell, P. S. (1962). Fatigue characteristics of bitumen and bituminous mixes, Proc. Int. Conf. Structural Design of Asphalt Pavements, Ann Arbor, Michigan, 310-323.

Pell, P. S. \& Taylor, I. F. (1969). Asphaltic road materials in fatigue, Proc. Assoc. Asphalt Paving Tech., 38, $371-422$.

Porter, O. J. (1938). The preparation of subgrades, Proc. Highway Res. Board, 18, No. 2, Washington, DC, 324-331.

Porter, J. (1950). Development of the original method for highway design, Development of CBR flexible pavement design method for airfields - a symposium, Trans. Am. Soc. Civ. Engrs, 115, 461-467.

Powell, W. D., Potter, J. F., Mayhew, H. C. \& Nunn, M. E. (1984). The structural design of bituminous roads, Lab. Report 1132, TRRL.

Ramsamooj, D. V., Majidzadeh, K. \& Kauffmann, E. M. (1972). The analysis and design of the flexibility of pavements, Proc. 3rd Int. Conf. Structural Design of Asphalt Pavements, London, 692-704.

Raybould, M. R. (1992). The response of silt-clay mixtures to cyclic loading, $\mathrm{PhD}$ thesis, University of Nottingham.

Raybould, M. J. \& Brown, S. F. (1993). Experimental methods in determining cyclic response of soils with particular reference to triaxial tests on Hostun sand, Proc. Conf. Experimental Methods in Earthquake Eng. and Struct. Dynamics, St.-Remy-lès-Chevreuse, France, 156-168.

Ridley, A. M. (1995). Strength-suction-moisture content relationships for kaolin under normal atmospheric conditions, Proc. 1st Int. Conf. on Unsaturated Soils, Paris, 645-651.

Roblee, C. J., Xiang-Song, L., Chan, C. K., Idriss, I. M., Wang, G., Herrmann, L. R. \& Jackura, K. A. (1994). Feasibility of a tool for in situ measurement of material properties of clays over a wide strain range, Dynamic Geot. Testing II, American Society for
Testing and Materials, STP 1213, 134-161.

Robnett, Q. L., Thompson, M. R., Knutson, R. M. \& Tayabji, S. D. (1975). Development of a structural model and materials evaluation procedures, University of Illinois, Report No. DoT-Fl-30038.

Rowe, G. M., Brown, S. F., Sharrock, M. J. \& Bouldin, M. G. (1995). Visco-elastic analysis of hot mix asphalt pavement structures, Transp. Res. Record No. 1482, Transportation Research Board, Washington, DC, 44-51.

Schofield, R. K. (1935). The $\mathrm{pF}$ of the water in soil, Trans. 3rd Int. Congress on Soil Science, 2, Oxford, $37-48$.

Schofield, A. N. \& Wroth, C. P. (1968). Critical state soil mechanics, McGraw-Hill, London.

Seed, H. B., Chan, C. K. \& Lee, C. E. (1962). Resilience characteristics of subgrade soils and their relation to fatigue failures, Proc. Int. Conf. Structural Design of Asphalt Pavements, Ann Arbor, Michigan, 611-636.

Seed, H. B., Chan, C. K. \& Monismith, C. L. (1955). Effects of repeated loading on the strength and deformation of compacted clay, Proc. High. Res. Board, 34, Washington, DC, 541-558.

Selig, E. T. \& Waters, J. M. (1994). Track geotechnology and substructure management, Thomas Telford, London.

Semmelink, C. J. \& de Beer, M. (1993). Development of a dynamic DRTT K-mould system, Res. Report DPVT 216, Roads and Transp. Tech., CSIR, Pretoria.

Semmelink, C. J. \& de Beer, M. (1995). Rapid determination of elastic and shear properties of road building materials with the K-mould, in Unbound aggregates in roads, University of Nottingham, 151-162.

Shaw, P. \& Brown, S. F. (1986). Cyclic simple shear testing of granular materials, Geotech. Testing J. American Society for Testing and Materials 9, No. 4, 213-220.

Shaw, P. \& Brown, S. F. (1988). The behaviour of dry granular materials under repeated load biaxial and triaxial stress conditions, Géotechnique 38, No. 4, 627-634.

Sorenson, A. \& Hayven, M. (1982). The Dynatest 8000 Falling Weight Deflectometer test system, Proc. Int. Symp. Bearing Capacity of Roads and Airfields, Trondheim, 1, 464-470.

Sousa, J. B. \& Chan, C. K. (1991). Computer applications in the geotechnical laboratories of the University of California at Berkeley, Proc. Geotech. Eng. Conf., Boulder, Colorado, American Society of Civil Engineers.

Stewart, H. E., Selig, E. T. \& Norman-Gregory, G. M. (1985). Failure criteria and lateral stresses in track foundations, Transp. Res. Record No. 1027, Transportation Research Board, Washington, DC, 59-64.

Sun, J. I., Golesorkhi, R. \& Seed, H. B. (1988). Dynamic Moduli and Damping Ratios for Cohesive Soils. Report No. UBC/EERC-88/15, Earthquake Engineering Research Center, 42.

Sweere, G. T. H. (1990). Unbound granular bases for roads, Doctoral thesis, Delft University of Technology.

Thom, N. H. \& Brown, S. F. (1988). The effect of grading and density on the mechanical properties of a crushed dolomitic limestone, Proc. Aust. Road Res. Board, 14, Pt. 7, 94-100.

Thom, N. H., Dawson, A. R. \& Brown, S. F. (1993). 
Improvements to road foundation design: development of pavement foundation design, Report PRG 93012, University of Nottingham.

Topp, G. C., Davis, J. L., Bailey, W. G. \& Zebchuk, W. D. (1984). The measurement of soil water content using a portable TDR hand probe, Canad. J. Soil Sci. 64, 313-321.

Transportation Research Board (1975). Test procedures for characterizing dynamic stress-strain properties of pavement materials, Special Report 162, Washington, D.C.

Turnbull, W. J. (1950). Appraisal of the CBR method, Development of CBR flexible pavement design method for airfields - a symposium, Trans. Am. Soc. Civ. Engrs, 547-554.

Tutumluer, E. \& Barksdale, R. D. (1995). Behaviour of pavements with granular bases - prediction and performance, in Unbound aggregates in roads, University of Nottingham, 173-183.

Vallerga, B. (1996). Private communication.

Van der Poel, C. (1954). A general system describing the visco-elastic properties of bitumens and its relation to test data, J. Appl. Chem. 4, 221-236.

van Dijk, W. \& Visser, W. (1977). The energy approach to fatigue for pavement design, Proc. Assoc. Asphalt Paving Technologists, 46, 1-40.

Viggiani, G. \& Atkinson, J. H. (1995). Stiffness of finegrained soil at very small strains, Géotechnique 45, No. 2, 249-265.

Vucetic, M., \& Dobry, R. (1991). Effect of Soil Plasticity on Cyclic Response, J. Geotech. Engrg, ASCE, 117, No. 1, 89-107.

Walker, R. N. (1985). The South African Heavy Vehicle Simulator, Accelerated Testing of Pavements, CSIR, Pretoria.

Warren, H. \& Dieckmann, W. L. (1963). Numerical computation of stresses and strains in a multiple-layer asphalt pavement system, Internal Report, Chevron Res. Corp, California.

Weiler, W. A. (1988). Small strain shear modulus of clay, Earthquake Eng. and Soil Dynamics II - Recent Advances in Ground Motion Evaluation, Geot. Special Report No. 20, Am. Soc. Civ. Engrs, 331-345.

Wheeler, S. J. \& Karube, D. (1995). State of the art report - constitutive modelling, Proc. 1st Int. Conf. Unsaturated Soils, Paris.

\section{VOTE OF THANKS}

DR R. H. JONES, Senior lecturer in Civil Engineering, University of Nottingham.

It is an honour and a great pleasure to propose the vote of thanks to the thirty-sixth Rankine Lecturer. All Rankine Lectures and lecturers can lay claim to being unique; this one was the first from the East Midlands and the first by a pavement engineer. The linking is highly appropriate. The region provides raw materials needed by pavement engineers, including beer and crushed rock granular sub-base. More significantly, it is the place where flexible pavements originated. In 1901, E. Purnell Hooley, the County Surveyor of Nottinghamshire, observed the binding effect of tar which had been accidentally spilt on an unbound road. Thus Tarmacadam (Tarmac) was born - a new material, a new company and a new word added to the English language. It was a happy coincidence that, some time later, the University of Nottingham should become involved in research on flexible pavements. Stephen Brown joined the team very early and has made a major contribution to the development of what has become an internationally recognised research group.

To date, pavement engineering has been a somewhat neglected part of geotechnics. Tonight, however, we have been treated to a worldwide review of pavement engineering in a lucid, well illustrated, and nicely paced lecture.

Essentially, we have heard of a soil-structure interaction problem, although the elements may be a little unfamiliar to the foundation engineer. The structure is the rails and sleepers of a railway or the bound layers of a road or airfield pavement, together with the underlying unbound layer(s) of granular materials. The soil considered was a clay subgrade, since granular materials behave as engineering soils whether within, or below the structure.

Professor Brown reviewed the relevant theory and practical tools (pavement experiments and laboratory and field testing, often with ingenious apparatus) and has examined the system requirements which are essentially dominated by serviceability.

In particular, features of the soil mechanics of pavements are transient, repeated loads applied to soils above the water table. The emphasis is on strength and stiffness characterized by permanent deformation and resilient modulus. We have heard about models of behaviour involving viscous response and demonstrating the importance of threshold stress ratio values. The history of the subject and particularly of the contributions of California and T/RRL were also covered.

Whilst pavement engineering may have been a neglected part of geotechnics the reverse is not true. Developments such as the finite element method, the critical state framework and in the understanding of earthquake engineering and of partially saturated soils have all been applied to the subject. Like Hooley, our Lecturer is a keen observer and sees the technical, engineering and commercial applications of his observations. Over the years, he has instilled these qualities into his team so that they have amassed a wealth of high quality data. The Rankine Lecture has given Stephen Brown the opportunity to present a thoughtful revisit of earlier work and to re-analyse the data in the light of the current theoretical concepts.

The Lecture has given a fascinating insight into the behaviour of materials and the application of design methods. It concluded with proposals for 
practical designs which could lead to a more theoretical approach than is currently used in the UK. Some empiricism would remain, but at a lower level in the hierarchy.

We have been privileged to hear an acknowledged master of his subject demonstrate clearly the role of soil mechanics in pavement engineer- ing. It was an ambitious lecture presented with a light, deft, touch. When he started, pavement engineering may have been a Cinderella but our eighteenth home Lecturer has ensured that it has come of age.

I ask you to join with me in showing your appreciation and thanks by acclamation. 